\title{
Day/Night Band Imager for a CubeSat
}

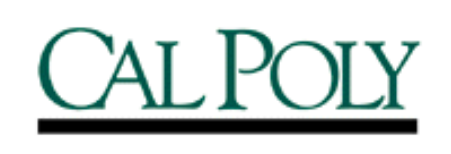

Eric Stanton

ELECTRICAL ENGINEERING DEPARTMENT

California Polytechnic State University

San Luis Obispo

A senior project report submitted in partial fulfillment for the degree of Bachelor of Science, Electrical Engineering

June 2012 


\begin{abstract}
Day/Night Band (DNB) earth sensing and meteorological systems like the Defense Meteorological Satellite Program (DMSP) Operational Linescan System (OLS) provide visible wavelength imagery 24 hours a day that is used primarily for cloud imaging in support of weather forecasting. This paper describes a compact push-broom imager that meets low light imaging requirements for DMSP OLS and the NOAA/NASA Joint Polar Satellite System (JPSS) as documented in the Integrated Operational Requirements Document 1] (IORD) including the imager design, system level concepts of operation for data collection, radiometric and spatial calibration, and data transmission to Earth. This small, lightweight imager complies with the low mass, low power CubeSat standard, and could be built into a variety of different satellites, for example, as a payload on Iridium NEXT, DMSP, or the International Space Station (ISS), Depending on power generation capabilities, the imager could be implemented as a free flyer in formation with other CubeSats or as a free flyer operating on its own. Desired performance specifications for this instrument can be divided into categories for each subsystem. The optic assembly will acquire scenes within a $112^{\circ}$ field of view onto a Charge-Coupled Device (CCD) focal plane sensor with resolution of $742 \mathrm{~m}$ or better across the entire swath. Thermal stabilization of the CCD focal plane array is necessary to increase the Signal to Noise Ratio (SNR), Also, the instrument contains an image processor for handling image acquisition and storage to onboard flash memory. Altogether, the CubeSat DNB imager described here is expected to be capable of collecting imagery suitable for detecting clouds, monitoring energy usage in major cities, and detecting human activity at night, while simultaneously meeting specifications for the CubeSat platform. In addition to the example missions described above, launch opportunities for CubeSat missions are available for universities through the Educational Launch of Nanosatellites (ELaNa), Therefore, a cost effective mission for demonstrating this DNB imager under the CubeSat specification appears feasible and provides a quick, low cost solution for implementing this system.
\end{abstract}


To my loving parents who always supported my dreams and aspirations. 


\section{Acknowledgements}

Dr. Jordi Puig-Suari, The PolySat Team, and The CubeSat Team

For invaluable lessons learned about satellite design, systems engineering, and project management

Dr. Dennis Derickson

For advising this project and connecting me with Dr. Puschell.

Dr. Jeffery Puschell

For incredible amounts of guidance and technical support with this project and my education during my senior year at Cal Poly. 


\section{Contents}

List of Tables viii

List of Figures

Glossary xiv

1 Introduction 1

1.1 Background ......................... 1

1.2 CubeSats at Cal Poly . . . . . . . . . . . . . . 1

1.3 Current Day/Night Band Imaging Technology . . . . . . . . . . . . 2

1.4 Goals and Scope of the Day/Night Band Imager for a CubeSat Project . 2

2 Requirements and Specifications 4

2.1 List of Requirements and Specifications . . . . . . . . . . . . 4

3 Conceptual Design

3.1 Level 0 Functional Decomposition _... . . . . . . . . . . . 7

3.2 Level 1 Functional Decomposition . . . . . . . . . . . . 8

3.3 Conceptual Design Calculations . . . . . . . . . . . . . . . . . 10

3.3 .1 Included Angle . . . . . . . . . . . . . . . . . . . . . . 10

3.3 .2 Swath Width . . . . . . . . . . . . . . . . 11

3.3.3 Horizontal Sampling Interval . . . . . . . . . . . . . . 11

3.3 .4 Detector Array . . . . . . . . . . . . . . . . . . . . 12

3.3.5 Lens Specifications . . . . . . . . . . . . . . . . 12

3.3 .6 Airy Disk Diameter . . . . . . . . . . . . . . . . 13

3.3 .7 Maximum Integration Time . . . . . . . . . . . . . 13

3.3 .8 Signal to Noise Ratio . . . . . . . . . . . . . . . . . . . 13 
4 Custom Lens Design and Focal Plane Array Specifications 16

4.1 Design Approach . . . . . . . . . . . . . . . . . . 16

4.2 Lens Design . . . . . . . . . . . . . . . . . . . . . . 17

4.2.1 Variables and Constraints . . . . . . . . . . . . . 17

4.2.2 Option \#1 Simulated Performance Characteristics . . . . . . . . 19

4.2.3 Option \#2 Simulated Performance Characteristics . . . . . . . . 21

4.3 Focal Plane Array Specifications . . . . . . . . . . . . . . . . 23

$4.3 .1 \quad$ Option $\# 1 \ldots \ldots \ldots \ldots$

4.3 .2 Option $\# 2 \ldots \ldots \ldots \ldots$

5 Imaging Demonstration $\quad[27$

5.1 Trade Study of Commercially Available Components . . . . . . . . . . . 27

$5.1 .1 \quad$ Lens . . . . . . . . . . . . . . . . . . . . . . . 27

$5.1 .2 \quad$ Focal Plane Array . . . . . . . . . . . . . . . . . . . . 27

5.2 Imaging System Demonstration and Testing . . . . . . . . . . . . . 27

5.2 .1 Testing Procedure and Setup . . . . . . . . . . . 28

5.2 .2 Testing Results . . . . . . . . . . . . . . . . . . . . 29

5.3 Discussion of Results . . . . . . . . . . . . . . . . . . . 32

6 Conclusions

6.1 Recommended Future Development . . . . . . . . . . . . . . . . . 33

A Senior Project Analysis

B Lens Design 42

B.1 Lens Option $\# 1 \ldots \ldots \ldots \ldots$. . . . . . . . . . . . . . . . . 42

B.2 Lens Option \#2 . . . . . . . . . . . . . . . . . . . . . . 55

$\begin{array}{lr}\text { C Parts List and Costs } & 67\end{array}$

D Datasheets

D.1 Theia SY110 . . . . . . . . . . . . . . . . . . . . . . . . 68 68

D.2 Sony ILX554B . . . . . . . . . . . . . . . . . . . . 71

E Code Listing $\quad 85$

E.1 Experimental MTF Generation . . . . . . . . . . . . . . . . . 85 
CONTENTS

Bibliography 


\section{List of Tables}

2- I Requirements and Specifications ............. 5

2- II Key DNB Performance Requirements . . . . . . . . . . . . 6

3- I Level 0 Functional Decomposition . . . . . . . . . . . . . 8

3- II Level 1 Functional Decomposition . . . . . . . . . . . . . . . . . . 10

4- I Variables and constraints for lens option $\# 1 \ldots \ldots . . \ldots$

4- II Variables and constraints for lens option $\# 2 \quad \ldots \ldots$

4- III Performance parameters of option \#1 . . . . . . . . . . . . . 20

4- IV Performance parameters of option \#2 . . . . . . . . . . . . . 22

4- V Focal Plane array specifications for option \#1 . . . . . . . . . . . . . 24

4- VI $n_{p e, \min }$ calculations and $n_{p e, \max }$ specifications for option \#1 . . . 25

4- VII Focal Plane array specifications for option \#2 . . . . . . . . . . . 25

4- VIII $n_{p e, \min }$ calculations and $n_{p e, \max }$ specifications for option \#2 . . . 25

A- I Original Project Cost Estimate . . . . . . . . . . . . 36

B- I Surface and aperture data for lens option \#1 . . . . . . . . . . 5 54

B- II Surface and aperture data for lens option \#2 . . . . . . . . . . . . 66

C- I List of parts acquired for this project and associated costs . . . . . . 67 


\section{List of Figures}

3.1 Level 0 Functional Decomposition Flow Diagram . . . . . . . . . 8

3.2 Level 1 Functional Decomposition Flow Diagram . . . . . . . . . . . 9

4.1 Option \#1 2D plot of lens elements . . . . . . . . . 20

$4.2 \quad$ Option \#1 MTF . . . . . . . . . . . . . . . . . . . . . . . . . . . 21

4.3 Option \#2 2D plot of lens elements . . . . . . . . . . . 22

$4.4 \quad$ Option \#2 MTF . . . . . . . . . . . . . . . . . . 23

5.1 Experimental setup for acquiring an MTF of the optical system . . 29

$5.2 \quad$ PSF for $0^{\circ}$ incidence from HeNe laser . . . . . . . . . . . . . . . . 30

5.3 MTF for $00^{\circ}$ incidence from HeNe laser . . . . . . . . . . . . . 30

$5.4 \quad$ PSF at edge of scan from HeNe laser . . . . . . . . . . . . . 31

$5.5 \quad$ MTF at edge of scan from HeNe laser . . . . . . . . . . . . . 31

A.1 Original Gantt Chart . . . . . . . . . . . . . . 37

B.1 Option \#1 3D Plot Side View . . . . . . . . . . . . . . 42

B.2 Option \#1 3D Plot Angled View . . . . . . . . . . . . . . 43

B.3 Option \#1 Spot Diagram . . . . . . . . . . . . . . . . . . . . . . . 44

B.4 Option \#1 Ray Aberration Trace . . . . . . . . . . . . . . . 45

B.5 Option \#1 Line Spread Function at $0^{\circ} \ldots \ldots \ldots$

B.6 Option \#1 Line Spread Function at $28^{\circ} \ldots \ldots \ldots$

B.7 Option \#1 Line Spread Function at $42^{\circ} \ldots \ldots$. . . . . . . . . . . 47

B.8 Option \#1 Line Spread Function at $55^{\circ} \ldots \ldots \ldots$. . . . . . . . 47

B.9 Option \#1 Point Spread Function at $0^{\circ} \ldots \ldots \ldots$

B.10 Option \#1 Point Spread Function at $28^{\circ} \ldots \ldots$. . . . . . . . . 48 
B.11 Option \#1 Point Spread Function at $42^{\circ} \ldots \ldots \ldots$

B.12 Option \#1 Point Spread Function at $55^{\circ} \ldots \ldots$. . . . . . . . . . 49

B.13 Option \#1 Element \#1 Drawing . . . . . . . . . . . . . . . 5 50

B.14 Option \#1 Element \#2 Drawing . . . . . . . . . . . . . 50

B.15 Option \#1 Element \#3 Drawing . . . . . . . . . . . . . . 51

B.16 Option \#1 Element \#4 Drawing . . . . . . . . . . . . . . . . . . 51

B.17 Option \#1 Element \#5 Drawing . . . . . . . . . . . . . . . . 52

B.18 Option \#1 Element \#6 Drawing . . . . . . . . . . . . . . . . . . 52

B.19 Option \#1 Element \#7 Drawing . . . . . . . . . . . . . . . . 55

B.20 Option \#1 Element \#8 Drawing . . . . . . . . . . . . . . . . 5 53

B.21 Option \#2 3D Plot Side View . . . . . . . . . . . . . . 55

B.22 Option \#2 3D Plot Angled View . . . . . . . . . . . 55

B.23 Option \#2 Spot Diagram . . . . . . . . . . . . . . . 55

B.24 Option \#2 Ray Aberration Trace . . . . . . . . . . . . . . . 57

B.25 Option \#2 Line Spread Function at $0^{\circ} \ldots \ldots \ldots \ldots$

B.26 Option \#2 Line Spread Function at $28^{\circ} \ldots \ldots \ldots$

B.27 Option \#2 Line Spread Function at $42^{\circ} \ldots \ldots \ldots$

B.28 Option \#2 Line Spread Function at $55^{\circ} \ldots \ldots \ldots$. . . . . . . . 59

B.29 Option \#2 Point Spread Function at $0^{\circ} \ldots \ldots \ldots$

B.30 Option \#2 Point Spread Function at $28^{\circ} \ldots \ldots$. . . . . . . . . 60

B.31 Option \#2 Point Spread Function at $42^{\circ} \ldots \ldots \ldots$

B.32 Option \#2 Point Spread Function at $55^{\circ} \ldots \ldots \ldots$

B.33 Option \#2 Element \#1 Drawing . . . . . . . . . . . . . . . . 62

B.34 Option \#2 Element \#2 Drawing . . . . . . . . . . . . . . . . 62

B.35 Option \#2 Element \#3 Drawing . . . . . . . . . . . . . . . . . 63

B.36 Option \#2 Element \#4 Drawing . . . . . . . . . . . . . . . . 63 63

B.37 Option \#2 Element \#5 Drawing . . . . . . . . . . . . . . . . . . 64

B.38 Option \#2 Element \#6 Drawing . . . . . . . . . . . . . . . . . . 64

B.39 Option \#2 Element \#7 Drawing . . . . . . . . . . . . . . . . . . 6 65

B.40 Option \#2 Element \#8 Drawing . . . . . . . . . . . . . 65 


\section{Glossary}

CubeSat Standardized pico-satellite form factor of about $10 \mathrm{~cm}^{3}$ volume and $1 \mathrm{~kg}$ mass for a $1 \mathrm{U}$, which can be scaled up to $2 \mathrm{U}$ and $3 \mathrm{U}$ sizes 2 . ii, $\mathrm{xi}, 1,2,4,5$, $7,8,16,33,35,38,40$

Day/Night Band A visual and near-infrared (500 nm to $700 \mathrm{~nm}$ ) low-light level (quarter moon) to full sunlight radiance sensor based on the Suomi NPP VisibleInfrared Imager-Radiometer Suite DNB, ii, xiii, 1, 34

Defense Meteorological Satellite Program United States Department of Defense program to monitor meteorological, oceanographic, and solar-terrestrial physics now run by the National Oceanic and Atmospheric Administration (NOAA), ii, xiii

Joint Polar Satellite System The NOAA's satellite system that will launch JPSS-1 in 2016, carrying a Visible-Infrared Imager-Radiometer Suite (VIIRS) instrument based on the Suomi NPP VIIRS instrument. ii, xiii

Modulation Transfer Function The magnitude component of the Optical Transfer Function that plots the transfer function of an imaging optical system against the spatial resolution at the focal plane of the system. xiii, 27

Operational Linescan System Visible and infrared imagery instruments from DMSP recording a $300 \mathrm{~km}$ swath. ii, xiv

PolySat The CubeSat development team at Cal Poly San Luis Obispo who previously developed $\mathrm{CP} 1, \mathrm{CP} 2, \mathrm{CP} 3, \mathrm{CP} 4, \mathrm{CP} 5$, and $\mathrm{CP} 6$ and are currently developing Ligthsail-I, CP7, IPEX, CP9, and EXOCUBE. 1, 2, 38, 40 
Suomi NPP Suomi National Polar-orbiting Partnership is an earth observing satellite from NASA launched in October 2011 carrying the VIIRS instrument. xi, xii, 2

Time Delay Integration The use of multiple pixel rows in a line scan $\mathrm{CCD}$ in order to sample a scene multiple times, increasing sensitivity, increasing dynamic range, and decreasing the number of Analog to Digital Converter (A/D) bits in the readout circuit. xiv, 14

Visible-Infrared Imager-Radiometer Suite A radiometer suite aboard Suomi NPP with multi-band imaging capabilites, providing atmospheric imagery for weather forecasting among a variety of other applications [3. xi, xiv, 34 


\section{Acronyms}

A/D Analog to Digital Converter. xii, 14

CCD Charge-Coupled Device. ii, xii, 10, 14, 24, 25, 28, 32, 35, 38, 41

DFT Discrete Fourier Transform. 28

DMSP Defense Meteorological Satellite Program. ii, xi

DNB Day/Night Band. ii, xi, 1, 2, 4, 8, 10, 11, 13, 14, 16, 27, 33, 35, 39, 40

EEZ Extended Economic Zone. 40

ELaNa Educational Launch of Nanosatellites. ii, 1, 5

GSI Ground Sample Interval. 11

IFOV Instantaneous Field of View. 11, 12

IORD Integrated Operational Requirements Document [1]. ii

ISS International Space Station. ii

JPSS Joint Polar Satellite System, ii, 2

LSF line spread function. 28

MTF Modulation Transfer Function, 27-29, 32

ND neutral density. 25, 26 
NOAA National Oceanic and Atmospheric Administration. xi

OLS Operational Linescan System. ii

PPOD Poly-Picosatellite Orbital Deployer. 1

PSF point spread function. $28,29,32$

SNR Signal to Noise Ratio. ii, 10, 13, 14, 17, 23, 32

TDI Time Delay Integration. 14, 15, 23, 32

VIIRS Visible-Infrared Imager-Radiometer Suite, xi, xii, 2, 4, 5, 10, 11, 13, 14, 33, 34 


\section{1}

\section{Introduction}

\section{$1.1 \quad$ Background}

The Day/Night Band Imager for a CubeSat was initially realized by Dr. Jeffery Puschell, a professor of practice at California Polytechnic State University San Luis Obispo, as a low light level sensor for either a small satellite or an unmanned aerial vehicle (UAV). Due to my experience with the Cal Poly CubeSat development team, PolySat, I presented the CubeSat platform as a means of implementing the sensor since a CubeSat supports many of the design specifications and adds benefits such as availability of launch opportunities. This paper describes the requirements and specifications, design, implementation, testing, and resulting performance characteristics of the DNB Imager for a CubeSat during the first phase of the design. The second phase of the design will improve upon the implementation and performance from the first phase such that a product is designed ready to fly as a satellite payload.

\subsection{CubeSats at Cal Poly}

The CubeSat specification was developed by a California Polytechnic State University San Luis Obispo (Cal Poly) and Stanford Universitys Space Systems Development Lab in 1999 as an educational platform for students to learn the end-to-end process of satellite development. The CubeSat community has now spread to universities, corporations, and governments around the world. Cal Poly provides the Poly-Picosatellite Orbital Deployer (PPOD) for the ELaNa program, supported by NASA and the Launch Services Program, which is a CubeSat deployment mechanism designed by Cal Poly 
engineering students for implementation as a secondary payload on Department of Defense, NASA, and commercial launch vehicles. PolySat has produced and launched five CubeSats, of which three have successfully reached orbit and carried out its respective mission. Now, PolySat currently manages six CubeSat projects.

\subsection{Current Day/Night Band Imaging Technology}

The VIIRS instrument on Suomi NPP as part of the JPSS uses a DNB imager as one of its many imaging capabilities. The performance characteristics [4 of the VIIRS DNB imager provide the projected performance characteristics of the DNB Imager for a CubeSat. By creating this specification, the DNB Imager for a CubeSat project does not require additional research of the minimum performance parameters that would enable a useful imager for the stated applications since the project benefits from prior research and testing publications on VIIRS 4, [5].

\subsection{Goals and Scope of the Day/Night Band Imager for a CubeSat Project}

The DNB Imager for a CubeSat project presented in this report is the first phase of the project's lifetime, from the September 2011 until June 2012. This first phase covers all necessary research foundation and initial hardware demonstration to support future development of a successful space-grade product. First, the conceptual design of the system presents the possible solutions for meeting the design requirements listed in Table 2- I. Due to the volume and aperture constraints of CubeSat form factor, the lens design will dictate the focal plane array in this project. Accordingly, a custom designed lens maximizes the imaging performance of the CubeSat form factor and shows the feasible capabilities of a refractive imaging system in a CubeSat for the DNB imager application. From this lens design requirements are set for the specification of a focal plane array that would adequately acquire images with this lens. Given these results, a trade study is performed in order to find the most cost efficient commercially available options for a lens and focal plane array that have comparable specifications. This lens and focal plane array system is then tested to determine the system level performance characteristics, and compared to the custom lens and focal plane array 
1.4 Goals and Scope of the Day/Night Band Imager for a CubeSat Project

design. The results of this first phase conclude if commercial parts would sufficiently meet the design requirements, or if a custom design should be further pursued and endorsed. 


\section{2}

\section{Requirements and Specifications}

\subsection{List of Requirements and Specifications}

The DNB Imager for a CubeSat fulfills the following specifications in order to serve as an effective $\mathrm{DNB}$ imager for the stated applications of earth sensing and meteorological missions. Primarily, the goal is to meet comparable imaging performance characteristics to the VIIRS DNB imager as well as adding features for improvement, while complying with the CubeSat Specification [2]. Final prototype testing for the first phase of the project is completed in June 2012 with the second phase following immediately in the summer of 2012. 
Table 2- I: Requirements and Specifications

\begin{tabular}{|c|c|c|}
\hline $\begin{array}{c}\text { Marketing } \\
\text { Requirements }\end{array}$ & $\begin{array}{l}\text { Engineering } \\
\text { Specifications }\end{array}$ & Justifications \\
\hline $2,4,5,6$ & $\begin{array}{l}\text { 1. Complies with the } \\
\text { CubeSat Specification } 2 \text {. }\end{array}$ & $\begin{array}{l}\text { The CubeSat platform can fly low cost, } \\
\text { small size, and low power payloads. Cube- } \\
\text { Sats have many launch opportunities in- } \\
\text { cluding the ELaNa service provided by } \\
\text { NASA. }\end{array}$ \\
\hline 1,3 & $\begin{array}{l}\text { 2. Meets the Key DNB } \\
\text { Performance Requirements } \\
\text { [6], shown in Table 2- II. }\end{array}$ & $\begin{array}{l}\text { These requirements correspond to the VI- } \\
\text { IRS DNB performance characteristics }\end{array}$ \\
\hline 2,6 & $\begin{array}{l}\text { Power consumption } \\
\text { does not exceed an average } \\
\text { of } 2 \mathrm{~W} \text { and a peak of } 20 \mathrm{~W} \text {. }\end{array}$ & $\begin{array}{l}\text { Feasible power limits for sustainable imag- } \\
\text { ing on a } 3 \mathrm{U} \text { CubeSat. }\end{array}$ \\
\hline \multicolumn{3}{|c|}{$\begin{array}{l}\text { 1. Acquire images of the earth in full sunlight and in quarter moonlight. } \\
\text { 2. Able to be used on a CubeSat satellite. } \\
\text { 3. Detect clouds, light from cities, and fishing vessels at night from low earth orbit. } \\
\text { 4. Low cost. } \\
\text { 5. Small size. } \\
\text { 6. Low power consumption. }\end{array}$} \\
\hline
\end{tabular}


Table 2- II: Key DNB Performance Requirements [6

\begin{tabular}{|c|c|}
\hline Description & Value \\
\hline Band Center & $700 \pm 14 \mathrm{~nm}$ \\
\hline Bandwidth & $400 \pm 20 \mathrm{~nm}$ \\
\hline $\begin{array}{c}\text { Horizontal Sample Interval, track and scan } \\
\text { (applies across the full swath) }\end{array}$ & $742 \mathrm{~m} \pm 5 \%$ \\
\hline $\begin{array}{c}\text { Horizontal Spatial Resolution (half-cycle } \\
\text { spatial freq. where MTF=0.5) }\end{array}$ & $<800 \mathrm{~m}$ \\
\hline Lmin, High Gain Stages (HGS) & $3.0 \mathrm{E}-5 \mathrm{~W} \mathrm{~m}^{-2} \mathrm{sr}^{-1}$ \\
\hline Lmax, Low Gain Stage & $200 \mathrm{~W} \mathrm{~m} \mathrm{sr}^{-1}$ \\
\hline SNR @ HGS Lmin \& scan angle $<53^{\circ}$ & 6 \\
\hline SNR @ HGS Lmin \& scan angle $\geq 53^{\circ}$ & 5 \\
\hline
\end{tabular}




\section{3}

\section{Conceptual Design}

The conceptual design of the DNB Imager for a CubeSat starts with functional decompositions detailing the inputs and output of the system and subsystem. Once these details are understood, some preliminary calculations show feasibility of the proposed design approach and architecture.

\subsection{Level 0 Functional Decomposition}

The functional decomposition process is a top down description of the DNB Imager for a CubeSat including all inputs, outputs, and functionality descriptions. The highest level functionality and I/O analysis is shown in the Level 0 functional decomposition (Figure 3.1, Table 3- I). The goal of this imager as a satellite payload is to image a scene (the earth) and output the image data so it can be transmitted to the earth ground station. The system needs power in order to run and some kind of controller to enable/disable the system as well as change the settings of the imager. 


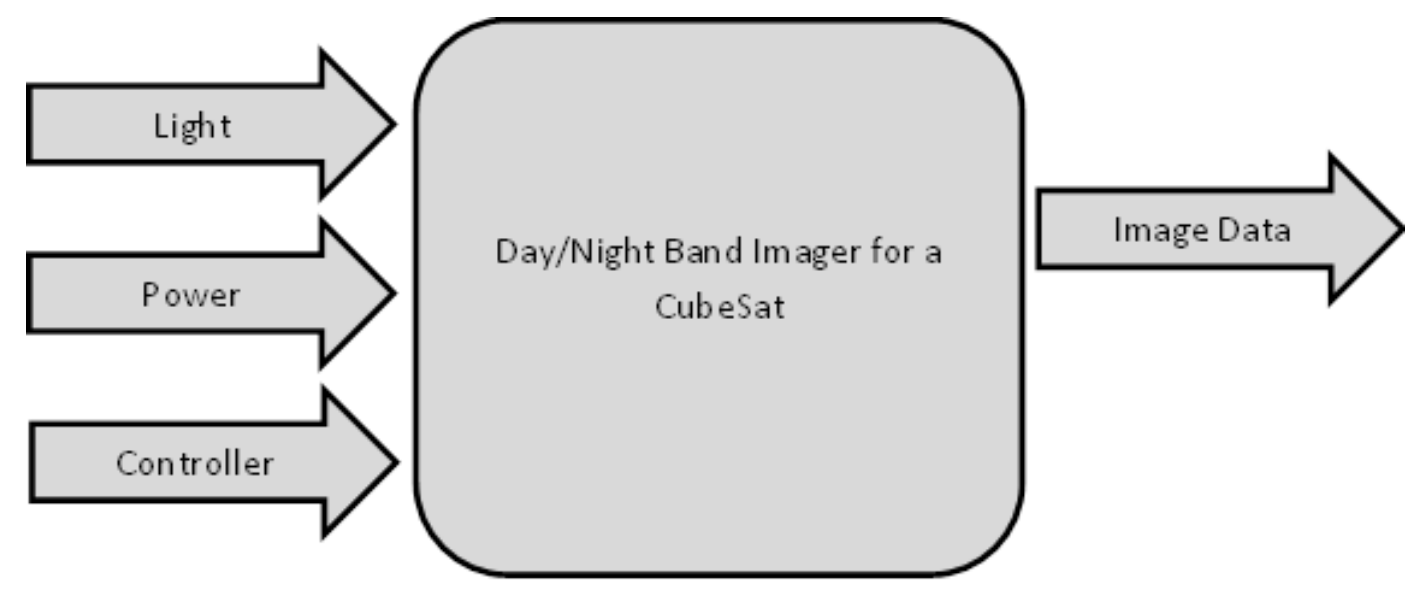

Figure 3.1: Level 0 Functional Decomposition Flow Diagram

Table 3- I: Level 0 Functional Decomposition Descriptions

\begin{tabular}{|c|c|l|}
\hline Parameter & Item & \multicolumn{1}{c|}{ Description } \\
\hline \multirow{3}{*}{ Inputs } & Light & $\begin{array}{l}\text { Light enters through an aperture controlled by } \\
\text { the primary lens. }\end{array}$ \\
\cline { 2 - 3 } & Power & $\begin{array}{l}\text { Power is provided to the sensor and image acqui- } \\
\text { sition circuitry from batteries and solar panels. }\end{array}$ \\
\cline { 2 - 3 } & Controller & $\begin{array}{l}\text { Input from avionics system for sending com- } \\
\text { mands to power on, capture an image, and } \\
\text { transmit image to avionics processor. }\end{array}$ \\
\hline Output & Image Data & $\begin{array}{l}\text { The image data transmitted to the onboard pro- } \\
\text { cessor which imports and transmits the data. }\end{array}$ \\
\hline System & $\begin{array}{c}\text { Day/Night Band } \\
\text { Imager for a CubeSat }\end{array}$ & $\begin{array}{l}\text { Acquire images during a maximum of full sun- } \\
\text { light and minimum of a quarter moonlight illu- } \\
\text { mination. }\end{array}$ \\
\hline
\end{tabular}

\subsection{Level 1 Functional Decomposition}

The DNB Imager for a CubeSat subsystem functionality and I/O are described in the Level 1 functional decomposition shown in Figure 3.2 and shown in Table 3- II. Besides mechanical mounting, the four main subsystems introduced here (the lens, 
focal plane array, image processor, and image data storage block) provide the necessary functionality to take the three inputs and produce the image data output.

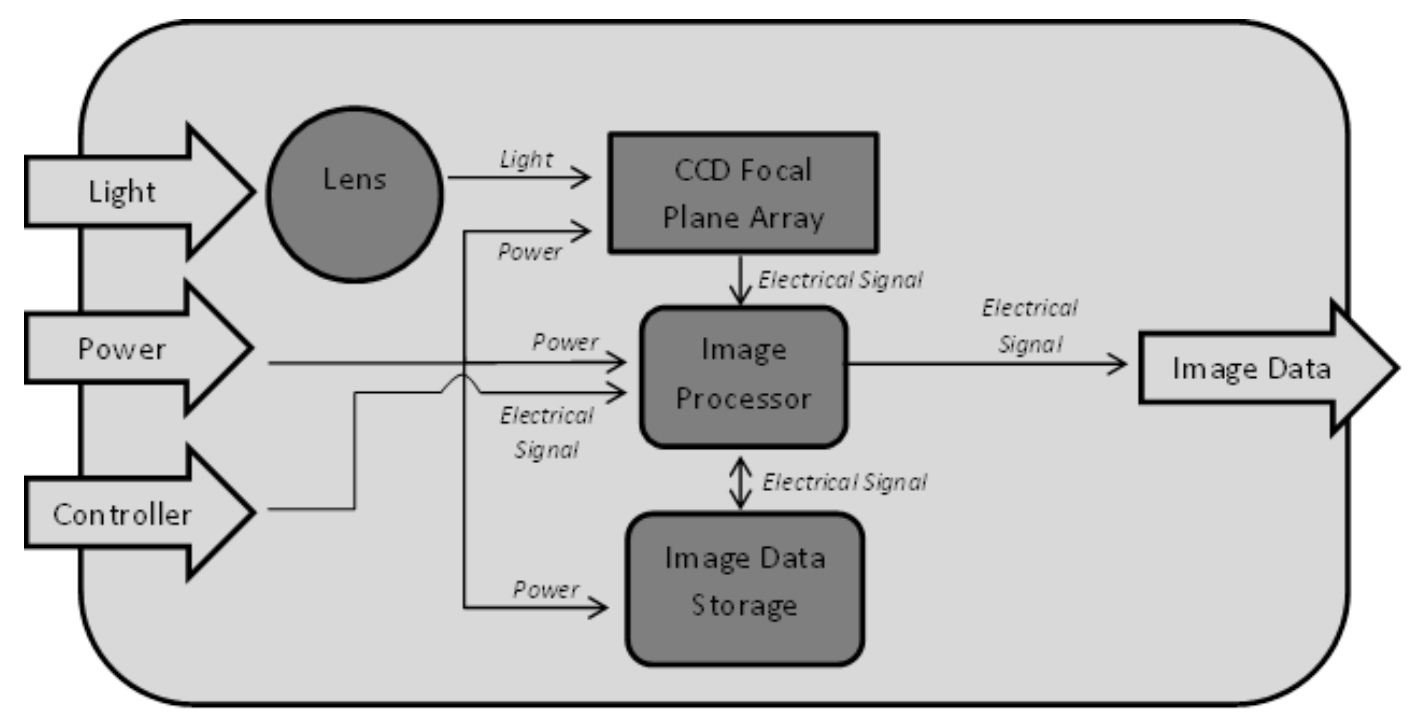

Figure 3.2: Level 1 Functional Decomposition Flow Diagram 
Table 3- II: Level 1 Functional Decomposition Descriptions

\begin{tabular}{|c|l|l|}
\hline Subsystem & \multicolumn{1}{|c|}{ Input } & \multicolumn{1}{|c|}{ Output } \\
\hline Lens & $\begin{array}{l}\text { Light is input to the system with } 112^{\circ} \text { field } \\
\text { of view. }\end{array}$ & $\begin{array}{l}\text { All input light is focused onto the } \\
\text { CCD focal plane array of about } 35 \\
\mathrm{~mm} \text { format. }\end{array}$ \\
\hline $\begin{array}{c}\text { CCD Focal } \\
\text { Plane }\end{array}$ & $\begin{array}{l}\text { Light is input to the CCD pixels, which } \\
\text { is then converted to the raw image data. } \\
\text { Electrical power must be regulated and } \\
\text { supplied to the CCD. }\end{array}$ & $\begin{array}{l}\text { The raw image data is output to } \\
\text { the image processor over a dedi- } \\
\text { cated image transfer bus. }\end{array}$ \\
\hline $\begin{array}{c}\text { Image } \\
\text { Processor }\end{array}$ & $\begin{array}{l}\text { Receives commands from the controller, } \\
\text { raw data from the CCD, and compressed } \\
\text { data from flash memory storage. Electri- } \\
\text { cal power must be regulated and supplied } \\
\text { to the image processor. }\end{array}$ & $\begin{array}{l}\text { Compresses raw image data in- } \\
\text { put and outputs the data to flash } \\
\text { memory storage. } \\
\text { pressed image data from flash } \\
\text { memory storage to the avionics } \\
\text { processor. }\end{array}$ \\
\hline Storage & $\begin{array}{l}\text { Receives compressed image data from the } \\
\text { image processor and stores it to non- } \\
\text { volatile memory. Electrical power must be } \\
\text { regulated and supplied to the image data } \\
\text { storage unit. }\end{array}$ & $\begin{array}{l}\text { Outputs compressed image data } \\
\text { to the image processor when } \\
\text { prompted by the image processor. }\end{array}$ \\
\hline
\end{tabular}

\subsection{Conceptual Design Calculations}

In order to determine the feasibility of this system architecture, the following preliminary calculations provide a basis for the performance capabilities of the design. Specifically, the calculation of expected SNR, along with the specifications of a lens and sensor. Most parameters are based off of the VIIRS DNB sensor [3 as a baseline for the project.

\subsubsection{Included Angle}

The included angle, $\phi$, of the earth that the DNB imager samples is calculated as follows for a given scan angle, $\theta$, of $56^{\circ}$, which corresponds to a $112^{\circ}$ field of view. This value is used in the following calculations for the swath width, detector array length, 
and the Ground Sample Interval (GSI), Equations for the included angle and GSI are taken from Section 3.9 of Remote Sensing Models and Methods for Image Processing 8.

$$
\begin{gathered}
\phi=\arcsin \left(\frac{R_{\text {Earth }}+\text { Altitude }}{R_{\text {Earth }}} \times \sin (\theta)\right)-\theta \\
\phi=13.6^{\circ}=0.237 \text { radians }
\end{gathered}
$$

\subsubsection{Swath Width}

The swath width of the DNB imager is the length on the earth's surface that is captured each frame as defined by the included angle $\phi$.

$$
\begin{gathered}
\text { Swath Width }=2 \times \phi \times R_{\text {Earth }} \\
\text { SwathWidth }=3029 \mathrm{~km}
\end{gathered}
$$

\subsubsection{Horizontal Sampling Interval}

The horizontal sampling interval is driven by the cross track spatial resolution requirement at the end of scan, $G S I_{e}\left(56^{\circ}\right)$, which is translated to a corresponding cross track spatial resolution at nadir, GSI(0). Since the Instantaneous Field of View (IFOV) is constant for all pixels on the focal plane, the spatial resolution at nadir will be better than at the end of scan. The horizontal sampling rate is matched to the spatial resolution at the end of scan. The altitude used for the calculations is $833 \mathrm{~km}$, which is based on VIIRS, also operating at that altitude [3].

$$
\begin{gathered}
\frac{G S I_{e}(\theta)}{G S I(0)}=\frac{\left[H+R_{E a r t h}(1-\cos \phi)\right] \cos \theta}{H \cos \theta+\phi} \\
\text { for } G S I_{e}\left(56^{\circ}\right)=742 m \\
G S I(0)=381 m
\end{gathered}
$$


The IFOV can now be calculated using values at nadir, even though IFOV is constant for the optical system.

$$
\begin{gathered}
I F O V=\frac{\text { GSI }(0)}{\text { Altitude }} \\
I F O V=457.38 \times 10^{-6} \text { radians }
\end{gathered}
$$

\subsubsection{Detector Array}

Now the number of detector elements and the physical length of the detector can be calculated from the total field of view, FOV , and the IFOV.

$$
\begin{gathered}
N_{\text {Elements }}=\frac{F O V}{I F O V} \\
N_{\text {Elements }}=4274 \\
L_{\text {Array }}=N_{\text {Elements }} * \text { Pitch } \\
L_{\text {Array }}=34.2 \mathrm{~mm}
\end{gathered}
$$

\subsubsection{Lens Specifications}

Besides the entrance aperture of the lens, which was already assumed as $6 \mathrm{~mm}$, the basic lens specifications are the focal length $(f)$ and f-number $(f / \#)$.

$$
\begin{gathered}
f=\frac{\text { Altitude } \times \text { Pitch }}{\text { Horizontal Sampling Interval }} \\
f=9 \mathrm{~mm} \\
f / \#=\frac{f}{\text { Entrance Aperture }} \\
f / \#=1.5
\end{gathered}
$$




\subsubsection{Airy Disk Diameter}

The radius of the airy disk, $R_{\text {Airy Disk, }}$, shows the limiting resolution of the optics. It is calculated for the longest wavelength in the $\mathrm{DNB}$ of $900 \mathrm{~nm}$ to show the worst case. Since the $R_{\text {Airy Disk }}$ is less than the detector pitch, it is not limiting the system.

$$
\begin{gathered}
R_{\text {Airy Disk }}=2.44 \times \lambda \times f \# \\
R_{\text {Airy Disk }}=1.6 \mu \mathrm{m}
\end{gathered}
$$

\subsubsection{Maximum Integration Time}

The maximum integration time, $t_{i n t, \max }$, of the sensor can be calculated given a known altitude of the imager. The ground speed of an object in orbit at this altitude can be calculated with the standard gravitational constant of earth, $\mu=398600435600000 \mathrm{~m}^{2} \mathrm{~s}^{-2}$, and the radius of earth's equator, $R_{\text {earth }}=6378136 \mathrm{~m}$ by the following equation from Space Mission Engineering: The New SMAD, Table 9-4 9.

$$
\begin{gathered}
\text { Ground Speed }=\sqrt{\frac{\mu}{R_{\text {earth }}+833 \mathrm{~km}}} \times \frac{R_{\text {earth }}}{R_{\text {earth }}+833 \mathrm{~km}} \\
\text { Ground Speed }=6.6 \mathrm{~km} / \mathrm{s}
\end{gathered}
$$

The maximum integration time, $t_{i n t, \max }$, can then be calculated from the horizontal sampling interval and the ground speed.

$$
\begin{gathered}
t_{\text {int }, \text { max }}=\frac{\text { Horizontal Sampling Interval }}{\text { Ground Speed }} \\
t_{\text {int, } \max }=112 \mathrm{~ms}
\end{gathered}
$$

\subsubsection{Signal to Noise Ratio}

Next, the SNR is calculated to show comparable image quality to the VIIRS DNB 7 . The etendue, or $A \Omega$ product, must be calculated first for the later calculation of the number of signal power electrons, where $\mathrm{A}$ is the source area and $\Omega$ is the solid angle subtended at the source. An entrance aperture must be assumed, so $6 \mathrm{~mm}$ will be used. 


$$
\begin{gathered}
A=\pi \times\left(\frac{\text { Entrance Aperture }}{2}\right)^{2} \\
\Omega=\left(\tan ^{-1}\left(\frac{\text { Horizontal Sampling Interval }}{\text { Altitude }}\right)\right)^{2} \\
A \Omega=22.43 \times 10^{-12} \mathrm{~m}^{2} \mathrm{sr}
\end{gathered}
$$

The maximum number of signal generated photo-electrons at the minimum radiance level, $n_{p e, m i n}$, is calculated from the etendue, the specified minimum scene radiance $\left(L_{\min }\right)$, the spectral width, the maximum integration time, $t_{i n t, \text { max }}$, an assumed quantum efficiency (QE) of the sensor of 50\%, and the energy of the incident light (average wavelength).

$$
\begin{gathered}
n_{p e, \min }=\frac{L_{\min } \times A \Omega \times \Delta \lambda \times t_{i n t, \max } \times Q E}{h \nu} \\
n_{p e, \min }=53 e^{-}
\end{gathered}
$$

The full well capacity, $n_{\text {full well }}$, of each pixel in the CCD is assumed to be $1 \mathrm{Me}^{-}$, which is comparable with current technology. Also, the maximum number of A/D bits is assumed to be 16, in accordance with high performance CCD technology, for each gain stage. This drives the number of electrons generated by quantization noise, $n_{q}$. The number of electrons generated by readout noise and the dark current $\left(n_{\text {read noise } \& i_{\text {dark }}}\right)$ will be estimated to be $200 \mathrm{e}^{-}$rms. Similar to the VIIRS DNB, Time Delay Integration (TDI) will be used to increase the $\mathrm{SNR}$. Since the $\mathrm{SNR}$ at the minimum scene radiance (Table 2- I) is a known and desired performance parameter, the required number of TDI stages, $N_{T D I}$, will be solved with maximum number of signal generated photo-electrons at the minimum radiance level, $n_{p e, \min }$.

$$
\begin{gathered}
n_{q}=\frac{{ }^{n_{\text {full well } /{ }^{16}}}}{12} \\
n_{q}=19.40 e^{-} \\
S N R_{\text {min scene radiance }}=\frac{N_{T D I} \times n_{\text {pe }, \text { min }}}{\sqrt{N_{T D I} \times n_{\text {pe, min }}+n_{\text {read noise } i_{\text {dark }}+n_{q}}}}
\end{gathered}
$$




$$
N_{T D I} \geq 2
$$

In order to increase the dynamic range of the sensor, a separate row of pixels will be used to image the high radiance level input light and this separate row will use a different integration time than the TDI rows. An assumed typical minimum integration time, $t_{i n t, \min }$, of $1 \mathrm{~ms}$ is used here. The number of electrons, $n_{p e, \max }$, generated from the maximum input radiance, $L_{\max }$, must be within the full well capacity, $n_{\text {full well }}$. Also assumed is the quantum efficiency, $Q E$, of $50 \%$ and the average wavelength is used for the energy of the incident light.

$$
\begin{gathered}
n_{p e, \max }=\frac{L_{\max } \times A \Omega \times \Delta \lambda \times t_{\text {int }, \min } \times Q E}{h \nu} \\
n_{p e, \max }=948.0 \times 10^{3} e^{-}
\end{gathered}
$$

The maximum detectable radiance level before saturation, $L_{\text {saturation }}$, can be calculated using the full well capacity of each pixel.

$$
\begin{gathered}
n_{\text {full well }}=\frac{L_{\text {saturation }} \times A \Omega \times \Delta \lambda \times t_{\text {int }, \min } \times Q E}{h \nu} \\
L_{\text {saturation }}=211 \mathrm{Wm}^{-2} \mathrm{sr}^{-1}
\end{gathered}
$$


4

\section{Custom Lens Design and Focal Plane Array Specifications}

\subsection{Design Approach}

The design process was borrowed directly from Ch. 9 of Optical System Design [10. This is a 12 step design process specific to optical design, of which only the first 7 were used due to the scope of this project:

1. Review specifications

2. Select a starting point

3. Establish variables and constraints

4. Set performance error function

5. Optimize

6. Evaluate performance

7. Repeat steps 3,5 , and 6 until design goals are met

A student license of the CODE V [11] optical design software was obtained for implementing this lens design process for the DNB Imager for a CubeSat. 
Each step of the design process is covered in the following section, 4.2 , but each step is not indivudually detailed. Since this is an iterative design process, it would be too verbose to show every design step in this report.

\subsection{Lens Design}

To begin the design, a review of the specifications (previously determined in section 3.3 and Table 2- I) lead to the starting point of the lens design.

\section{Lens Specifications}

- Real image

- $110^{\circ} \mathrm{FOV}$

- $\mathrm{f} / \# \sim 1.5$

- Largest element diameter $<80 \mathrm{~mm}$

- Total length $<140 \mathrm{~mm}$

- Wavelengths of $500 \mathrm{~nm}$ to $900 \mathrm{~nm}$

Optical System Design 10 suggests to use a patented lens design to start. CODE V also provides a database of patented lens designs, organized and search-able by critical lens specifications. Given the specifications above, a wide angle imaging lens patented in Japan [12] was chosen as the starting point.

\subsubsection{Variables and Constraints}

After many iterations, two designs are presented in this report, using different parameters for the design constraints. The first lens (option \#1) has an entrance aperture of $6 \mathrm{~mm}$ and was optimized with the constraints shown in Table 4- I. Section 4.2 .2 details all of the performance parameters of this lens. While the option \#1 provides a good optical performance geometrically, a larger entrance aperture would help increase the SNR performance of the system, so option \#2 was developed with an entrance aperture of $8 \mathrm{~mm}$. The constraints for option \#2 are shown in Table 4- II. 
Table 4- I: Variables and constraints for lens option \#1

\begin{tabular}{|c|c|c|c|}
\hline Parameter & Variable/Fixed & Value & Unit \\
\hline Entrance Aperture & Fixed & 6.0 & $\mathrm{~mm}$ \\
\hline Effectice Focal Length & Variable & 8.0 to 10.0 & $\mathrm{~mm}$ \\
\hline Overall Length & Variable & $<150.0$ & $\mathrm{~mm}$ \\
\hline Element Center Thickness & Variable & 1.0 to 30.0 & $\mathrm{~mm}$ \\
\hline Element Edge Thickness & Variable & $>1.0$ & $\mathrm{~mm}$ \\
\hline Air Edge Separation & Variable & $>0.0025$ & $\mathrm{~mm}$ \\
\hline Axial Air Space & Variable & $>0.1$ & $\mathrm{~mm}$ \\
\hline Wavelengths & Fixed & $500 ; 700 ; 900$ & $\mathrm{~nm}$ \\
\hline Incident Fields (Object Angle) & Fixed & $0,28,42,55$ & Degrees \\
\hline Glass & Variable & $\begin{array}{r}\text { PSK53A; NBALF4; } \\
\text { SF5; SF57; FK54; } \\
\text { PBH71 }\end{array}$ & $\mathrm{N} / \mathrm{A}$ \\
\hline Temperature & Fixed & 20.0 & Degrees $\mathrm{C}$ \\
\hline Pressure & Fixed & 760.0 & $\mathrm{~mm} \mathrm{Hg}$ \\
\hline Error Function (Automatic Design) & Variable & $\begin{array}{r}\text { MTF/Transverse Ray } \\
\text { Abberation/Wavefront } \\
\text { Error Variance }\end{array}$ & $\mathrm{N} / \mathrm{A}$ \\
\hline Error Function (Global Synthesis) & Fixed & MTF & $\mathrm{N} / \mathrm{A}$ \\
\hline
\end{tabular}


Table 4- II: Variables and constraints for lens option \#2

\begin{tabular}{|c|c|c|c|}
\hline Parameter & Variable/Fixed & Value & Unit \\
\hline Entrance Aperture & Fixed & 8.0 & $\mathrm{~mm}$ \\
\hline Effectice Focal Length & Variable & 8.0 to 12.0 & $\mathrm{~mm}$ \\
\hline Overall Length & Variable & $<150.0$ & $\mathrm{~mm}$ \\
\hline Element Center Thickness & Variable & 1.0 to 30.0 & $\mathrm{~mm}$ \\
\hline Element Edge Thickness & Variable & $>1.0$ & $\mathrm{~mm}$ \\
\hline Air Edge Separation & Variable & $>0.0025$ & $\mathrm{~mm}$ \\
\hline Axial Air Space & Variable & $>0.1$ & $\mathrm{~mm}$ \\
\hline Wavelengths & Fixed & $500 ; 700 ; 900$ & $\mathrm{~nm}$ \\
\hline Incident Fields (Object Angle) & Fixed & $0,28,42,55$ & Degrees \\
\hline Glass & Variable & $\begin{array}{r}\text { PSK53A; NBALF4; } \\
\text { SF5; SF57; FK54; } \\
\text { PBH71 }\end{array}$ & $\mathrm{N} / \mathrm{A}$ \\
\hline Temperature & Fixed & 20.0 & Degrees C \\
\hline Pressure & Fixed & 760.0 & $\mathrm{~mm} \mathrm{Hg}$ \\
\hline Error Function (Automatic Design) & Variable & $\begin{array}{r}\text { MTF/Transverse Ray } \\
\text { Abberation/Wavefront } \\
\text { Error Variance }\end{array}$ & $\mathrm{N} / \mathrm{A}$ \\
\hline Error Function (Global Synthesis) & Fixed & MTF & $\mathrm{N} / \mathrm{A}$ \\
\hline
\end{tabular}

\subsubsection{Option \#1 Simulated Performance Characteristics}

This section describes the resulting performance and specifications for the lens design of option \#1 relevant to the performance analysis. Detailed analysis diagrams, lens data, and drawings are presented in Appendix B. Figure 4.2 Table $4-\mathrm{V}$ reports the specifications of the design. 
Table 4- III: Performance parameters of option \#1

\begin{tabular}{|l|c|l|}
\hline \multicolumn{1}{|c|}{ Parameter } & \multicolumn{1}{c|}{ Value } & \multicolumn{1}{c|}{ Unit } \\
\hline Effective Focal Length & 10.0 & $\mathrm{~mm}$ \\
\hline F/\# & 1.6667 & $\mathrm{~mm}$ \\
\hline Total Length & 149.6801 & $\mathrm{~mm}$ \\
\hline Paraxial Image Height & 14.2815 & $\mathrm{~mm}$ \\
\hline Exit Pupil Diameter & 13.8388 & $\mathrm{~mm}$ \\
\hline MTF 50\% Cut-off (Figure 4.2) & 112.0 & cycles $/ \mathrm{mm}$ \\
\hline
\end{tabular}

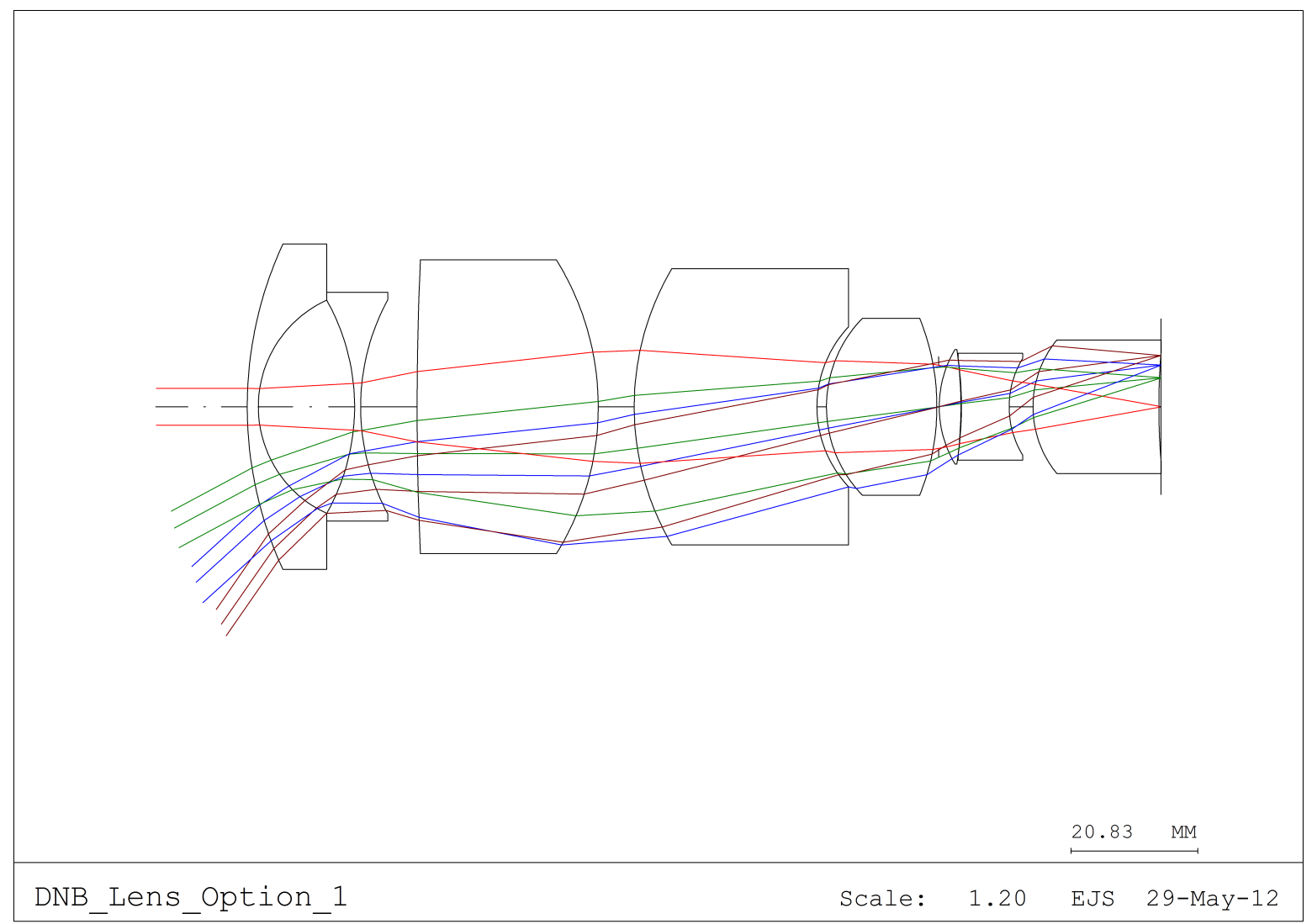

Figure 4.1: Option \#1 2D plot of lens elements 
4.2 Lens Design

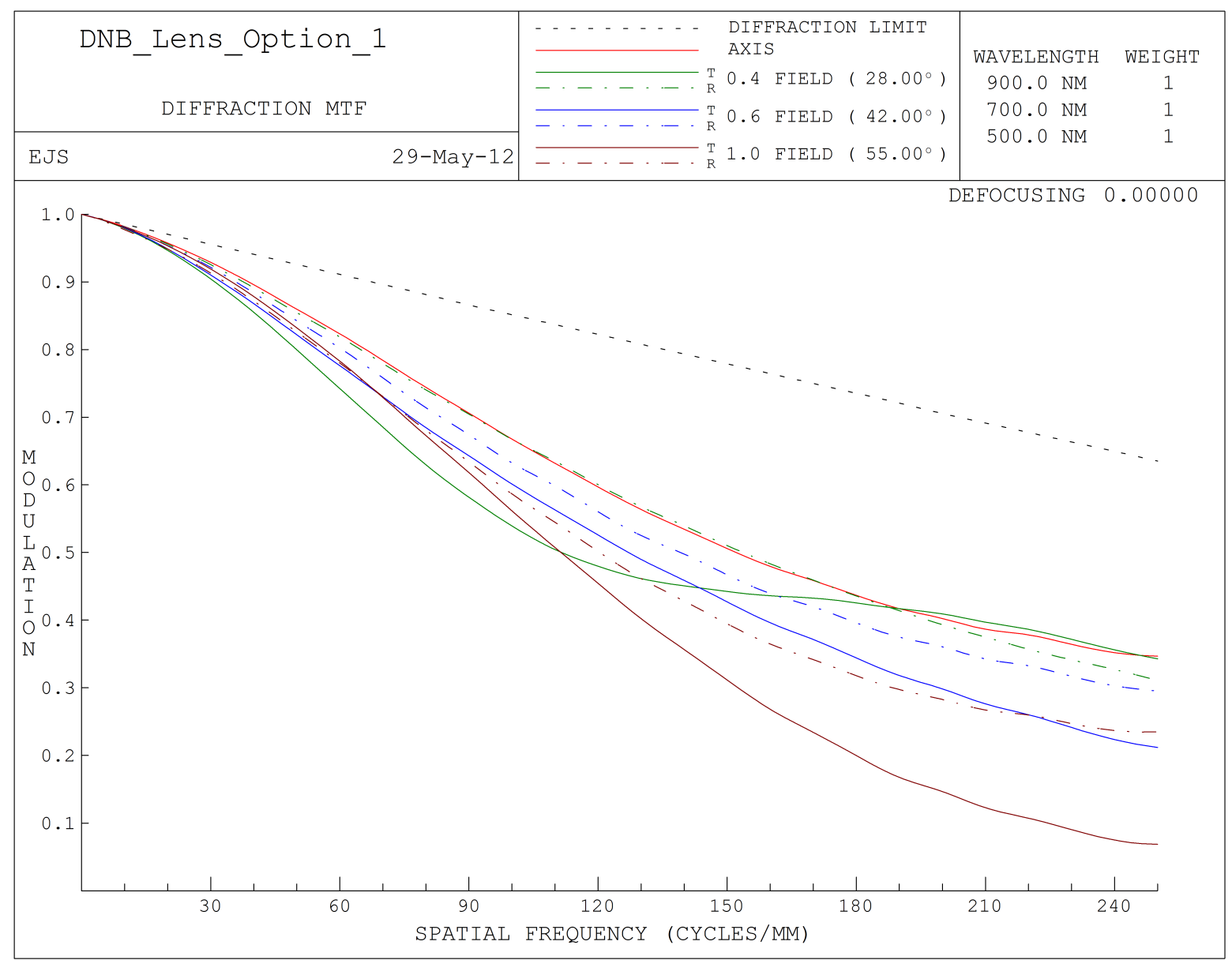

Figure 4.2: Option \#1 MTF

\subsubsection{Option \#2 Simulated Performance Characteristics}

This section describes the resulting performance and specifications for the lens design of option \#2 relevant to the performance analysis. Detailed analysis diagrams, lens data, and drawings are presented in Appendix B. Figure 4.4 Table 4- VII reports the specifications of the design. 
Table 4- IV: Performance parameters of option \#2

\begin{tabular}{|l|c|l|}
\hline \multicolumn{1}{|c|}{ Parameter } & \multicolumn{1}{c|}{ Value } & \multicolumn{1}{c|}{ Unit } \\
\hline Effective Focal Length & 12.0 & $\mathrm{~mm}$ \\
\hline F/\# & 1.50 & $\mathrm{~mm}$ \\
\hline Total Length & 149.3996 & $\mathrm{~mm}$ \\
\hline Paraxial Image Height & 17.1378 & $\mathrm{~mm}$ \\
\hline Exit Pupil Diameter & 15.6019 & $\mathrm{~mm}$ \\
\hline MTF 50\% Cut-off (Figure 4.4$)$ & 82.0 & $\mathrm{cycles} / \mathrm{mm}$ \\
\hline
\end{tabular}

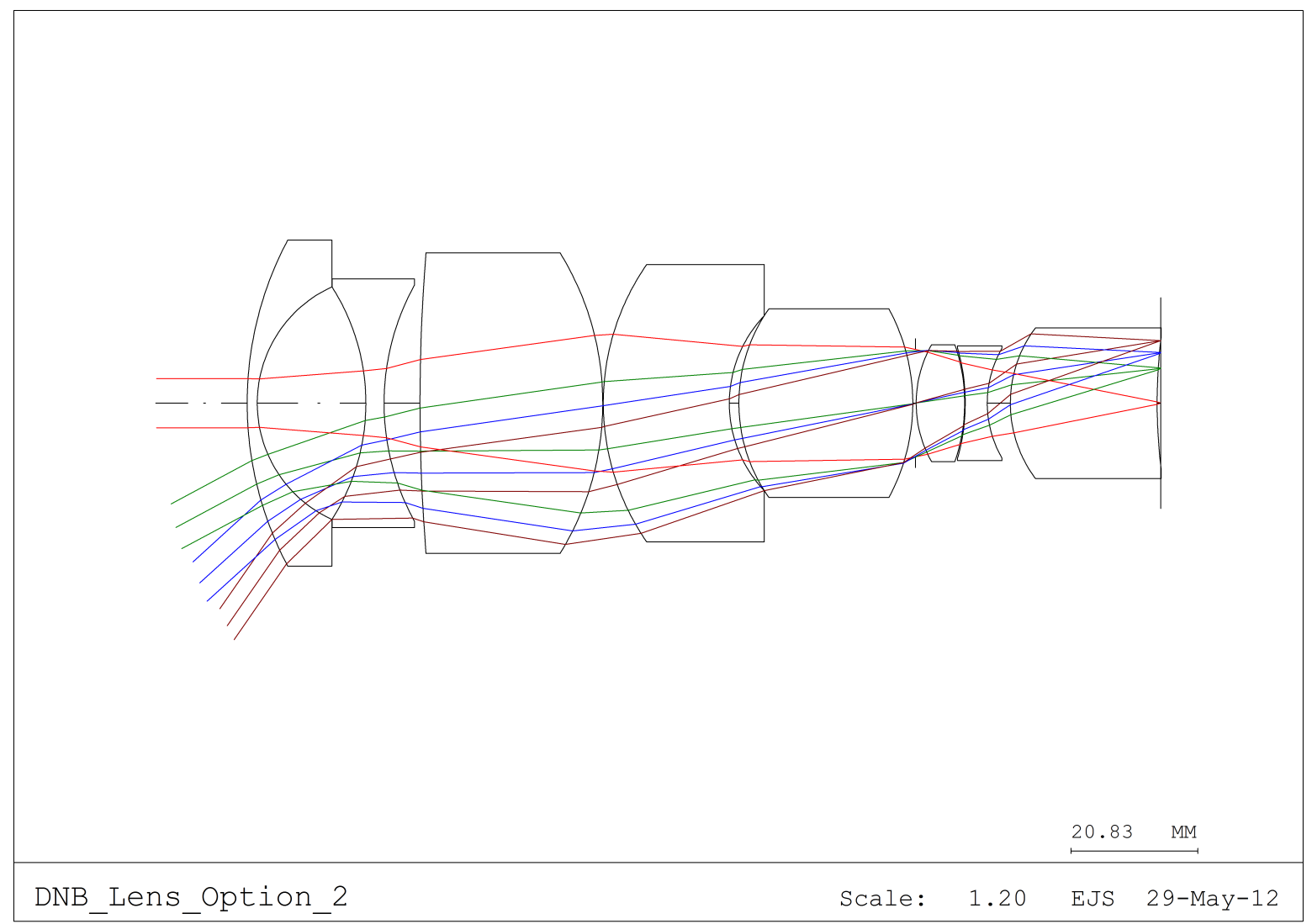

Figure 4.3: Option \#2 2D plot of lens elements 


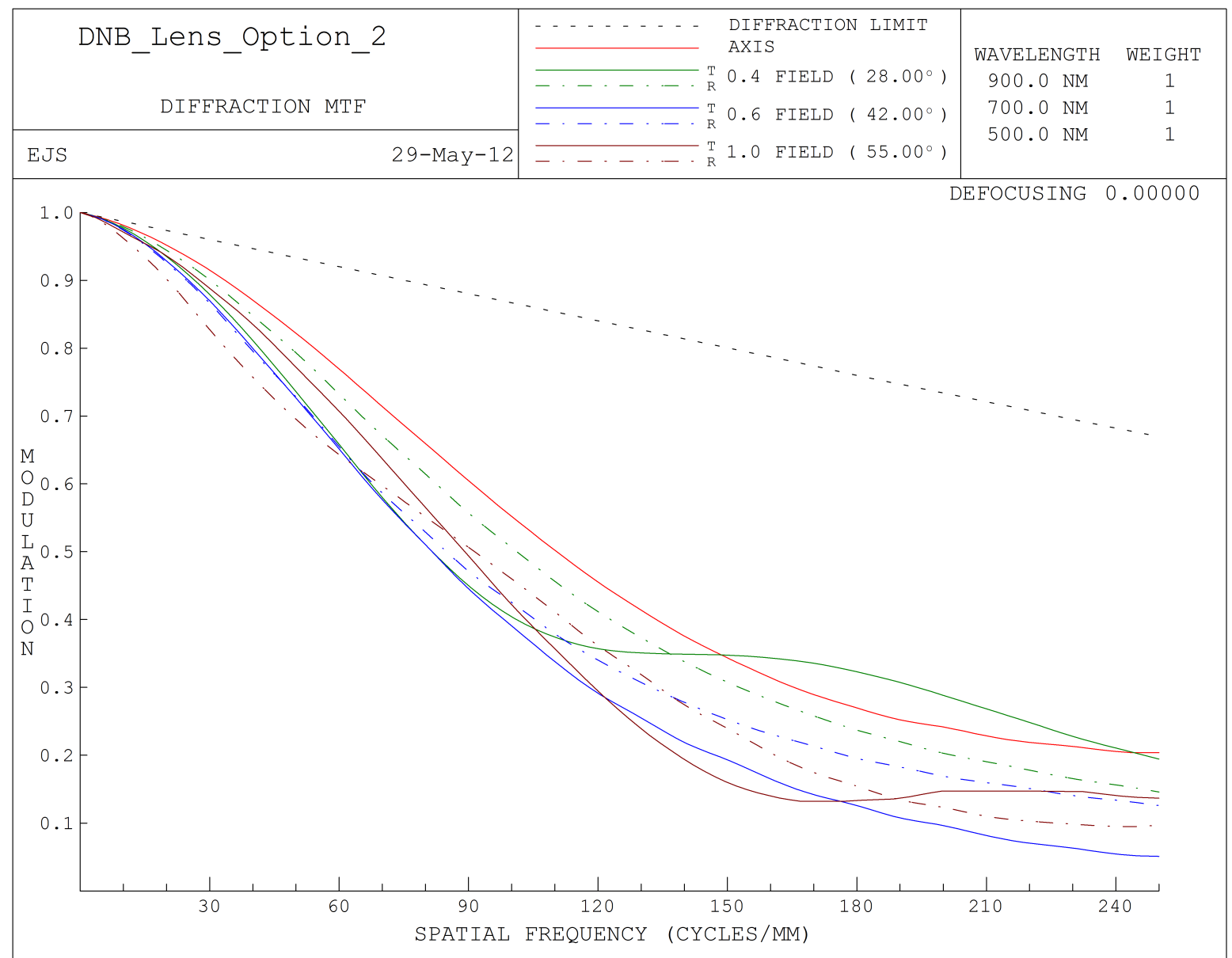

Figure 4.4: Option \#2 MTF

\subsection{Focal Plane Array Specifications}

By re-arranging the SNR equation from Section 3.3.8, the minimum number of signal generated photo-electrons is calculated, assuming 3 stages of TDI. The same values are used for the number noise electrons as in Section 3.3.8.

$$
\begin{gathered}
S N R_{\text {min scene radiance }}=\frac{N_{T D I} \times n_{\text {pe }, \text { min }}}{\sqrt{N_{T D I} \times n_{\text {pe, min }}+n_{\text {read noise \& } i_{\text {dark }}+n_{q}}}} \\
n_{\text {pe,min }} \geq 36.3 e^{-}
\end{gathered}
$$


Each lens design is compared to this minimum number of electrons generated for the minimum radiance level. Similarly, the number of electrons generated at the maximum radiance level is compared to the full well capacity, which is assumed to be $1 \mathrm{Me}^{-}$.

The maximum pixel size, $D_{\text {maximum pixel }}$, is taken to be the size at which the MTF of the sensor equals the MTF cut-off for each lens, which can be calculated as follows.

$$
D_{\text {maximum pixel }} \leq \frac{1}{f_{\text {spatial @ MTF 50\% cut-off }}}
$$

The total number of pixels, $N_{\text {total pixels }}$, can be calculated from this maximum pixel size and the paraxial image height, $h_{\text {paraxial }}$.

$$
N_{\text {total pixels }}=\frac{h_{\text {paraxial }}}{D_{\text {maximumpixel }}}
$$

Now the total sensor length, $L_{\text {Sensor }}$, can be specified.

$$
L_{\text {Sensor }}=N_{\text {total pixels }} \times D_{\text {maximumpixel }}
$$

\subsubsection{Option \#1}

Table $4-\mathrm{V}$ shows the specifications of the option \#1 CCD, except for the calculations of the $n_{p e, \min }$ and $n_{p e, \max }$, which are shown in Table C- I.

Table 4- V: Focal Plane array specifications for option \#1

\begin{tabular}{|l|r|l|}
\hline \multicolumn{1}{|c|}{ Specification } & Value & Unit \\
\hline Maximum Pixel Size & 8.9 & $\mu \mathrm{m}$ \\
\hline Minimum Number of Pixels & 3200.0 & pixels \\
\hline Total Length & 28.56 & $\mathrm{~mm}$ \\
\hline
\end{tabular}


Table 4- VI: $n_{p e, \min }$ calculations and $n_{p e, \max }$ specifications for option \#1

\begin{tabular}{|l|r|c|c|}
\hline Wavelength & $n_{p e, \min }$ & $n_{p e, \max }$ & \# of Bits Generated by $n_{p e, \min }$ \\
\hline $500 \mathrm{~nm}$ & 39 & $693 \times 10^{3}$ & 3 \\
\hline $600 \mathrm{~nm}$ & 47 & $831 \times 10^{3}$ & 3 \\
\hline $700 \mathrm{~nm}$ & 54 & $970 \times 10^{3}$ & 3 \\
\hline $800 \mathrm{~nm}$ & 62 & $1108 \times 10^{3}$ & 4 \\
\hline $900 \mathrm{~nm}$ & 70 & $1247 \times 10^{3}$ & 4 \\
\hline
\end{tabular}

Option \#1 meets the requirement for the minimum $n_{p e, m i n}$, but the full well capacity is exceeded for the $n_{p e, \max }$. Therefore, a neutral density (ND) filter can be added to the low gain stage row of pixels in order to reduce the $n_{p e, \max }$ to be within the full well capacity.

\subsubsection{Option \#2}

Table 4- VII shows the specifications of the option \#2 CCD, except for the calculations of the $n_{p e, \min }$ and $n_{p e, \max }$, which are shown in Table 4- VIII.

Table 4- VII: Focal Plane array specifications for option \#2

\begin{tabular}{|l|r|l|}
\hline \multicolumn{1}{|c|}{ Specification } & Value & Unit \\
\hline Maximum Pixel Size & 12.2 & $\mu \mathrm{m}$ \\
\hline Minimum Number of Pixels & 2811.0 & pixels \\
\hline Total Length & 34.28 & $\mathrm{~mm}$ \\
\hline
\end{tabular}

Table 4- VIII: $n_{p e, \min }$ calculations and $n_{p e, \max }$ specifications for option \#2

\begin{tabular}{|l|r|c|c|}
\hline Wavelength & $n_{p e, \min }$ & $n_{p e, \max }$ & \# of Bits Generated by $n_{p e, \min }$ \\
\hline $500 \mathrm{~nm}$ & 69 & $1108 \times 10^{3}$ & 4 \\
\hline $600 \mathrm{~nm}$ & 83 & $1330 \times 10^{3}$ & 4 \\
\hline $700 \mathrm{~nm}$ & 97 & $1551 \times 10^{3}$ & 4 \\
\hline $800 \mathrm{~nm}$ & 110 & $1773 \times 10^{3}$ & 4 \\
\hline $900 \mathrm{~nm}$ & 124 & $1994 \times 10^{3}$ & 5 \\
\hline
\end{tabular}


Option \#2 also meets the requirement for the minimum $n_{p e, m i n}$, but the full well capacity is exceeded for the $n_{p e, \max }$. Therefore, a ND filter can be added to the low gain stage row of pixels in order to reduce the $n_{p e, \max }$ to be within the full well capacity. 


\section{5 \\ Imaging Demonstration}

\subsection{Trade Study of Commercially Available Components}

Part of this study is to find the best options of commercially available and affordable parts for implementing this system. The following components were obtained and used for the demonstration and analysis during the first phase of the project and are intended on being upgraded in order to better meet the design requirements. Reasons for choosing the following parts were based first on availability and secondly on the performance specifications.

\subsubsection{Lens}

The Theia SY110 was chosen for this project because of its field of view, f/\#, and optimization for DNB applications. The cost for the lens is shown in Appendix $\mathrm{C}$ and the datasheet is shown in Appendix $\mathrm{D}$.

\subsubsection{Focal Plane Array}

The Thorlabs LC100 was chosen for this project because of the length of the sensor, the sensitivity, and the dynamic range.

\subsection{Imaging System Demonstration and Testing}

Characterization of the optical system is presented with the experimental Modulation Transfer Function (MTF) of the system. The MTF is a system level performance 
parameter that factors the $\mathrm{MTF}$ of all subsystems involved in the image acquisition: the lens, CCD array, CCD readout circuitry, and data quantization. From the experimental MTF, the system's optical performance can be evaluated and compared to the subsystem manufacturer's specifications.

\subsubsection{Testing Procedure and Setup}

To experimentally find the MTF of an optical system, a point spread function (PSF) or line spread function (LSF) must be imaged. The $\overline{P S F}$ is a unit impulse function of light intensity in two dimensions, while the LSF is in impulse function in one dimension. Either could have been used for this experiment since it is a linear array, so the PSF was chosen due to convenience.

In order to obtain valid image data of an actual $\mathrm{PSF}$, the camera must view a point of light that is made as small as possible while still attaining enough radiance to be sensed by the CCD. A red HeNe laser $(632.8 \mathrm{~nm})$ projected onto a screen, as shown in Figure 5.1, was used as the point source for the camera. In order to minimize the experimental error, it was setup in a dark room with no ambient light. Once the PSF was successfully imaged, the raw data was processed through a Discrete Fourier Transform (DFT) in Matlab (source code shown in Appendix E). 


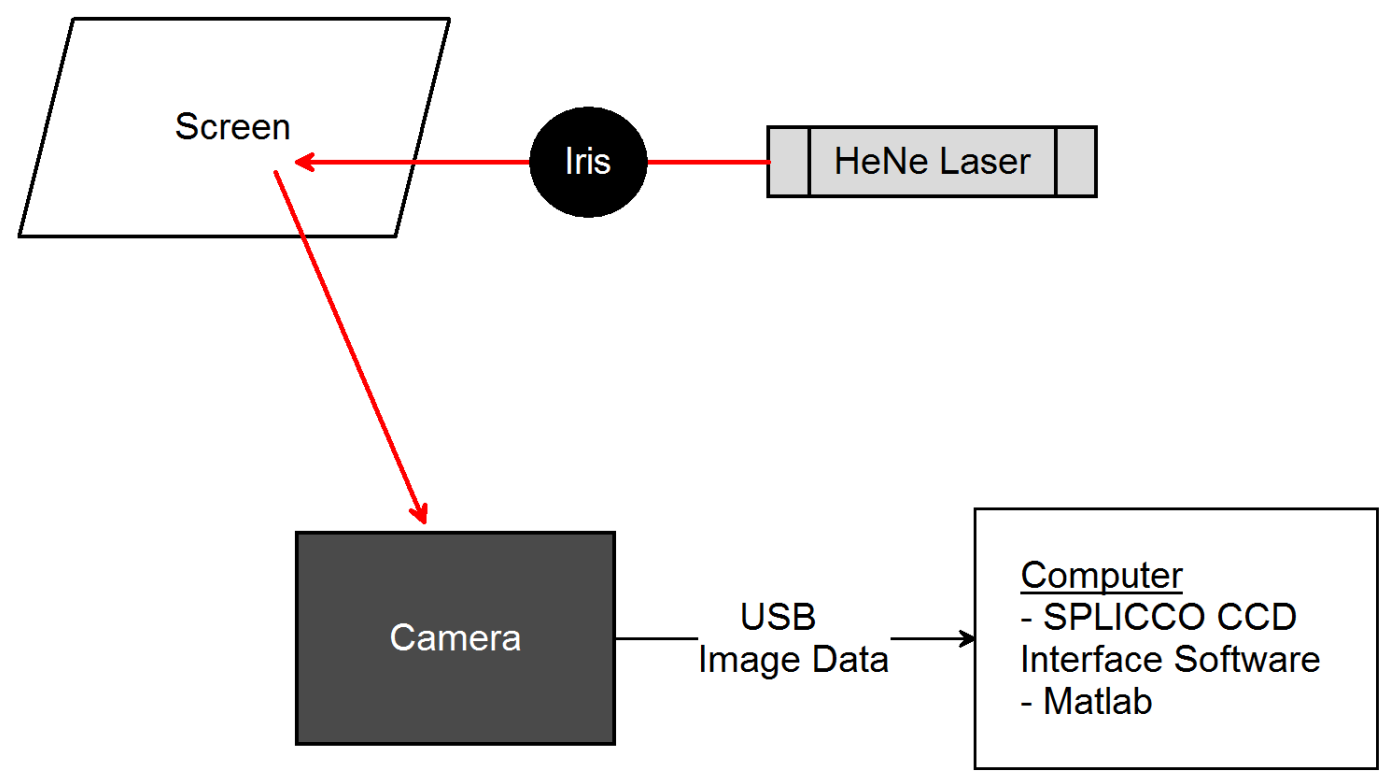

Figure 5.1: Experimental setup for acquiring an MTF of the optical system

\subsubsection{Testing Results}

The first MTF 5.3 shows the response to a $\mathrm{PSF}$ with $0^{\circ}$ incidence and the second $\mathrm{MTF}$ 5.5 shows the response to a $\mathrm{PSF}$ at the edge of the detector's active pixels. 


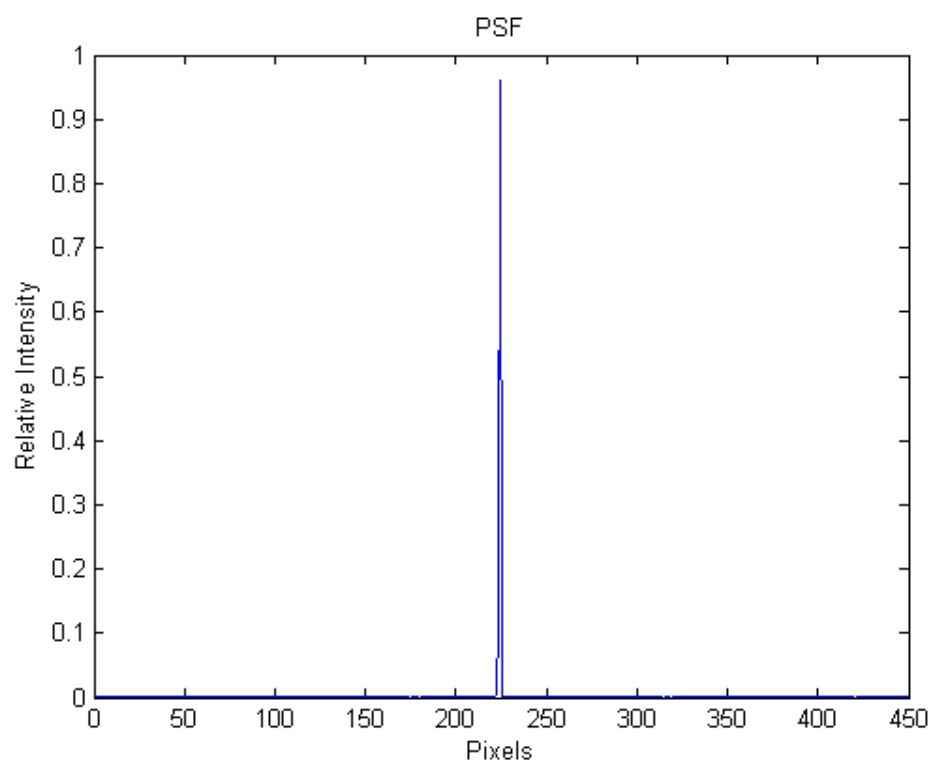

Figure 5.2: $\mathrm{PSF}$ for $0^{\circ}$ incidence from $\mathrm{HeNe}$ laser

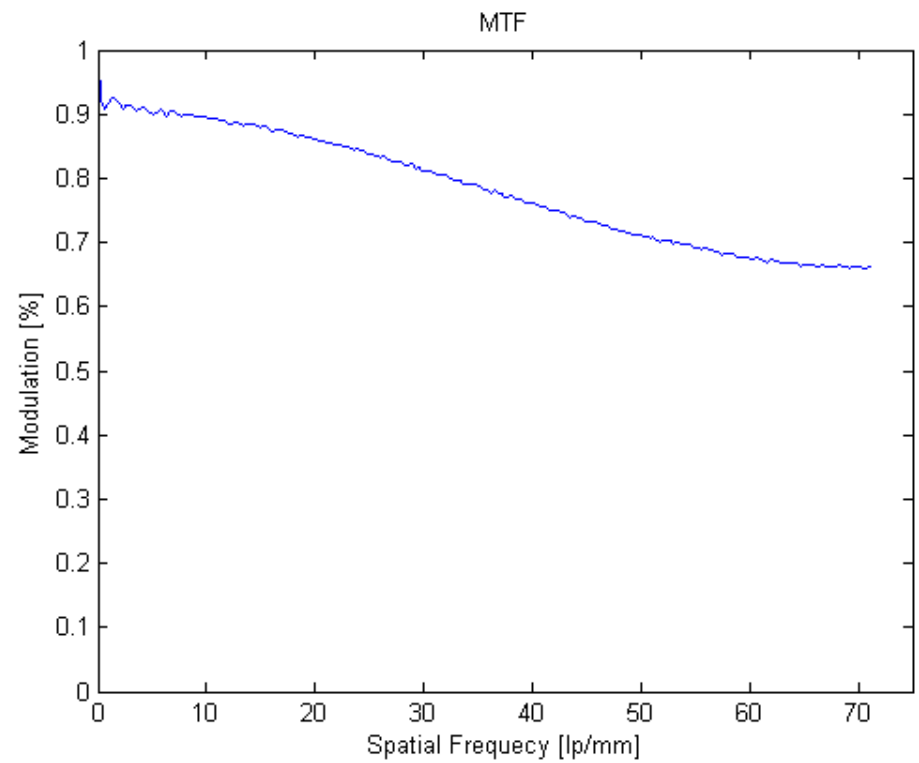

Figure 5.3: $\mathrm{MTF}$ for $0^{\circ}$ incidence from $\mathrm{HeNe}$ laser 


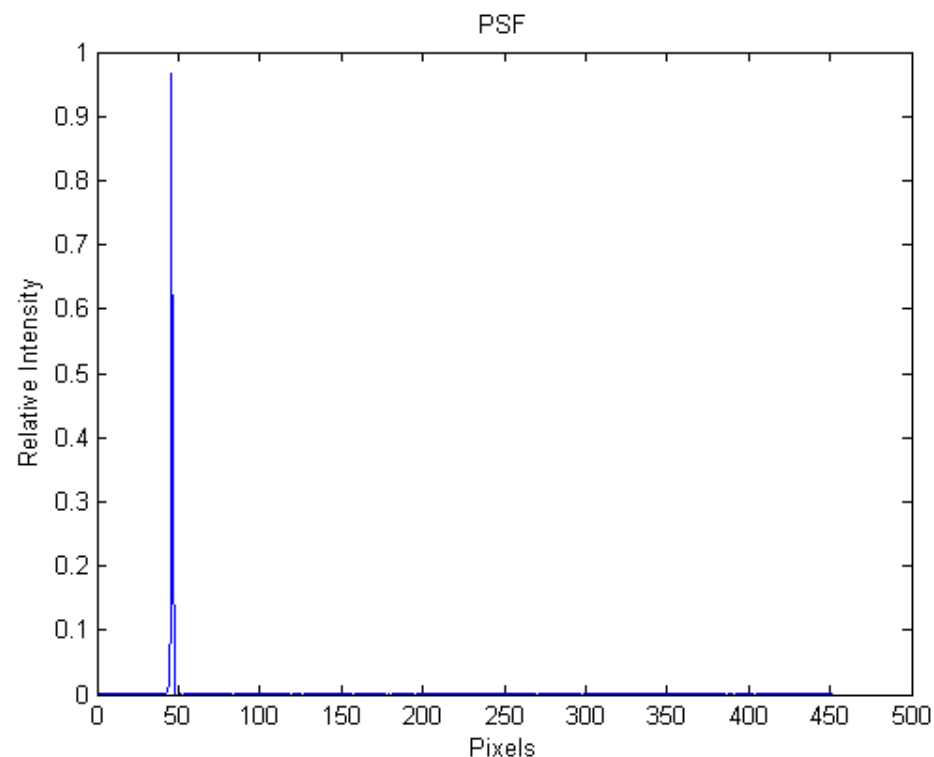

Figure 5.4: PSF at edge of scan from HeNe laser

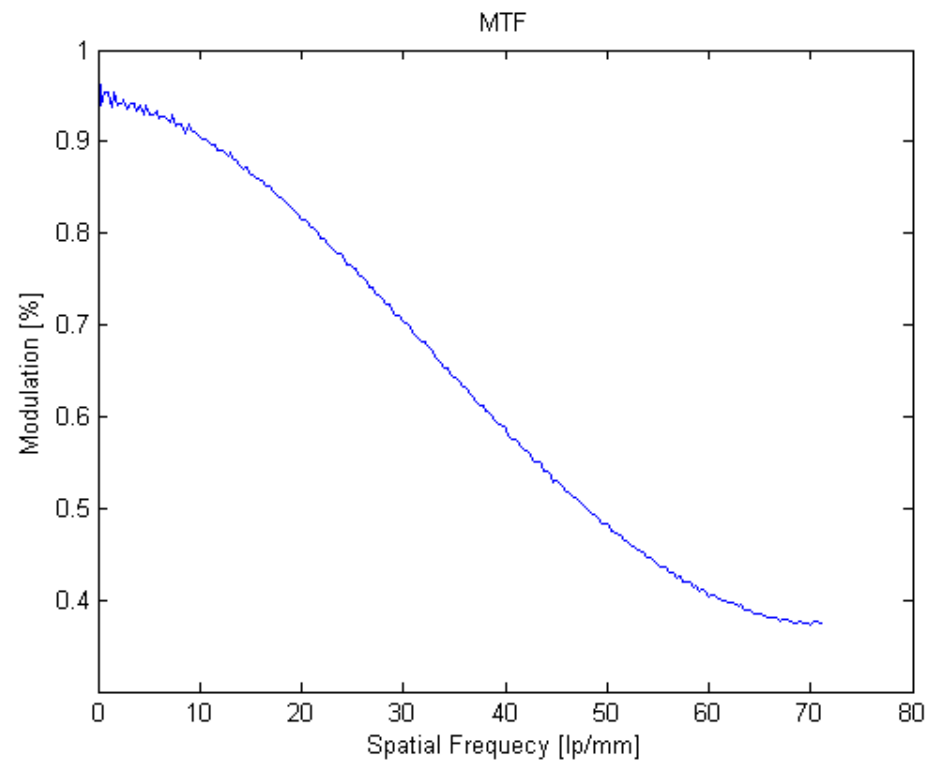

Figure 5.5: MTF at edge of scan from HeNe laser 


\subsection{Discussion of Results}

\subsection{Discussion of Results}

The results of the experimental $\mathrm{MTF}$ show good optical performance, but there are some clear issues that prevent the system from meeting the overall performance requirements.

First, the aperture of the lens is not large enough to utilize the entire length of the $\mathrm{CCD}$. This prevents the system from having an acceptable $\mathrm{SNR}$ and the detectors of the $\mathrm{CCD}$ would be required to be much smaller in order to meet the spatial resolution requirements. Even if the $\mathrm{CCD}$ did have small enough detector pitch, the $\mathrm{MTF}$ of the lens would limit the resolution of the system. The limited aperture of the lens limits the number of active pixels on the the CCD from 2048 to 450, as shown in the PSF images in Figure 5.2 and Figure 5.4 .

Second, the CCD detector pitch of $14 \mu \mathrm{m}$ is almost twice the width of the assumed $8 \mu \mathrm{m}$ and the total length of the sensor, $28.7 \mathrm{~mm}$, is not long enough to view the entire swath width of $3029 \mathrm{~km}$. Again, this limits the $\mathrm{MTF}$ response of the system and, consequently, the spatial resolution capability.

The experimental test did provide a good demonstration of the expected optical performance of the system. The next step of the project would be to find a new lens with similar $\mathrm{f} / \#$ and field of view, but also a larger aperture. The chosen CCD does have good sensitivity because of its rectangular $14 \mu \mathrm{m}$ by $56 \mu \mathrm{m}$ pixels. Further experimentation with a new lens could show if this $\mathrm{CCD}$ has enough sensitivity to meet the low radiance requirement of $3.0 \times 10^{-5} \mathrm{Wm}^{-2} \mathrm{sr}^{-1}$ using a similar integration time as the maximum integration time of $112 \mathrm{~ms}$. Essentially, this CCD is similar to a square pixel (14 $\mu \mathrm{m}$ by $14 \mu \mathrm{m})$ with 4 stages of TDI, so the saturation radiance level could be scaled up from the experimental saturation radiance level of this $\mathrm{CCD}$ by a factor of 4. The sensitivity performance of this system is expected to be about twice as high as a system with detector pitch of $8 \mu \mathrm{m}$, so this could be factored into the performance and compared to the ideal system architecture performance. 


\section{6}

\section{Conclusions}

The first phase of this project concludes that a DNB imager for a CubeSat can feasibliy be designed to meet and possibly exceed the performance specifications detailed for the VIIRS DNB instrument. From the initial calculations, custom lens design, and custom focal plane array specifications, a baseline design for the DNB imager for a CubeSat provides evidence that this project could exceed the performance capabilites required for the VIIRS instrument and serve as a much more cost effective solution for a future DNB instrument. The DNB imager for a CubeSat expands the capabilites of current remote sensing technology and would increase the efficiency of programs supporting earth sensing and meteorological missions by utilizing commercial technology developments and other cost effective solutions that are employed by CubeSat developers.

\subsection{Recommended Future Development}

The second phase of the project must first develop a test bench unit of the system in order to experimentally prove that the performance requirements are met. Once this is completed, further support of the project will allow for the development of a custom lens and $\mathrm{CCD}$ design and manufacturing. This flight unit must be designed together with a CubeSat development team since the CubeSat's bus must be customized in order to support this relatively large payload. 


\section{Appendix A}

\section{Senior Project Analysis}

Project Title: Day/Night Band Imager for a CubeSat

Student's Name: Eric Stanton

Student's Signature:

Advisor's Name: Dr. Dennis Derickson Advisor's Initials:

Date:

\section{- Summary of Functional Requirements}

The Day/Night Band (DNB) Imager for a CubeSat project designs a system that captures images of earth from a CubeSat satellite with as high as full sunlight or as low as quarter moonlight illumination and demonstrates image performance characteristics based on the Visible-Infrared Imager-Radiometer Suite (VIIRS) Day/Night Band sensor. The imager design is presented in this report along with a bread-board optical test bench demonstration of the hardware.

\section{- Primary Constraints}

It is projected that the primary constraints for this project involve meeting the specifications for the image resolution while also meeting the CubeSat volume and mass specifications. The spatial horizontal sampling interval of the imager must be $742 \mathrm{~km}$ or better in order to meet the performance characteristics of the VIIRS DNB. This specification will be exceeded in the center of the focal plane array because the lowest resolution resides on the edges of the focal plane array due to the curvature of the earth that is incident on the edge of the focal plane array. Depending on the final design, custom parts for the lens or the $\mathrm{CCD}$ array may need to be ordered, which will drive up costs from the proposed budget and 
increase lead time on parts. Power system analysis must show that the design can be implemented under 2 Watts of average power consumption and no more the 20 Watts of peak power dissipation.

\section{- Economic}

The economic impacts include human capital, financial capital, manufactured capitol, and natural capital. Dr. Jeffery Puschell and I worked on this project in the design and testing phase and I planned on working a total of 150 hours on the project. After the DNB Imager for a CubeSat is manifested on a CubeSat and launched into orbit, ground station operations will require an attendant to run satellite operations and downlink the images taken by the imager. The original projected cost estimate chart in Table A- I details the financial capital required by this project and shows the total projected cost under $\$ 20,000$. The parts to be manufactured include electronic circuit board components, glass lenses, a CCD array, and aluminum structural parts. All of the manufactured parts include natural capital from the raw materials used to create the parts. These include but are not limited to aluminum, silicon, fiberglass, and glass. About $75 \%$ of costs accrue during the hardware procurement stage during January and February of 2012 as well as during the testing phase during April of 2012 to run the thermal test.

Since the project is a research project, there is no economic beneficiary and the project does not create any monetary earnings. The first phase of this project will be completed by June 2012, but will not be put into operation until the entire CubeSat satellite is complete. This future design is projected to continue through the summer of 2012 and finish in June of 2014. Once the DNBd CubeSat is launched into low earth orbit, the projected mission lifetime is about 2 years depending on the orbit altitude and inclination. Operation costs will be minimal since the satellite will communicate with the Cal Poly ground station run by Cal Poly student volunteers. Figure A.1 shows the Gantt chart displaying the projected timeline of all project tasks. The fall 2011 academic quarter is dedicated to planning and preparation, including preparing documents and a structured design and test plan. The winter 2012 academic quarter is dedicated to the design and subsystem testing phase of the project. Two design and testing 
Table A- I: Original Projected Cost Estimate

\begin{tabular}{|c|c|c|c|c|c|}
\hline Category & Item & Hours/Quantity & $\frac{\text { Expected }}{\text { Cost per Item }}$ & $\begin{array}{c}\text { Maximum } \\
\text { Cost per Item }\end{array}$ & $\begin{array}{c}\text { Minimum } \\
\text { Cost per Item }\end{array}$ \\
\hline \multirow{3}{*}{ Labor } & $\begin{array}{l}\text { Eric Stanton - } \\
\text { Project Lead }\end{array}$ & 150 & $\$ 10$ & $\$ 15$ & $\$ 10$ \\
\hline & $\begin{array}{l}\text { Mechanical } \\
\text { Engineer }\end{array}$ & 15 & $\$ 10$ & $\$ 15$ & $\$ 10$ \\
\hline & $\begin{array}{l}\text { Computer } \\
\text { Engineer }\end{array}$ & 40 & $\$ 10$ & $\$ 15$ & $\$ 10$ \\
\hline \multirow{5}{*}{ Parts } & $\begin{array}{l}\text { Electronics - } \\
\text { Boards }\end{array}$ & 12 & $\$ 100$ & $\$ 120$ & $\$ 90$ \\
\hline & $\begin{array}{l}\text { Electronics - } \\
\text { Components }\end{array}$ & 2 & $\$ 1,000$ & $\$ 1,200$ & $\$ 700$ \\
\hline & $\begin{array}{l}\text { Electronics - } \\
\text { Assembly }\end{array}$ & 12 & $\$ 75$ & $\$ 85$ & $\$ 60$ \\
\hline & Focal Plane & 3 & $\$ 1,000$ & $\$ 1,500$ & $\$ 500$ \\
\hline & $\begin{array}{l}\text { Mechanical - } \\
\text { Structure }\end{array}$ & 3 & $\$ 1,000$ & $\$ 1,500$ & $\$ 800$ \\
\hline $\begin{array}{c}\text { Cumulative } \\
\text { Cost }\end{array}$ & & & $\$ 17,550$ & $\$ 22,935$ & $\$ 11,850$ \\
\hline $\begin{array}{l}\text { Projected } \\
\text { Cost }\end{array}$ & $\begin{array}{l}\text { Using Eq.6 } \\
\text { from } 13\end{array}$ & & & $\$ 17,498$ & \\
\hline
\end{tabular}

iterations are planned for the electronics design in this quarter. The mechanical and optical designs do not lie in the critical path since standard commercial parts can be purchased if the designs are not completed on schedule. The last academic quarter, spring 2012, is dedicated for doing system level testing. Throughout the entire preparation, design, test, and iteration processes, general documentation and the final report are prepared. 
Eric Stanton
EE 460-03 Fall 2011

EE 460-03 Fall 2011
Senior Project Gantt Chart

Day/Night Band Imager for a CubeSat \begin{tabular}{c|}
\hline Research and Preparation \\
\hline Design \\
\hline Review and Feedback \\
\hline Hardware Procurement \\
\hline
\end{tabular}

\begin{tabular}{c|c}
\hline Assemble Hardware & \\
\hline Testing \\
\hline Progress Report Due & \\
\hline Final Project Due & \\
\hline
\end{tabular}

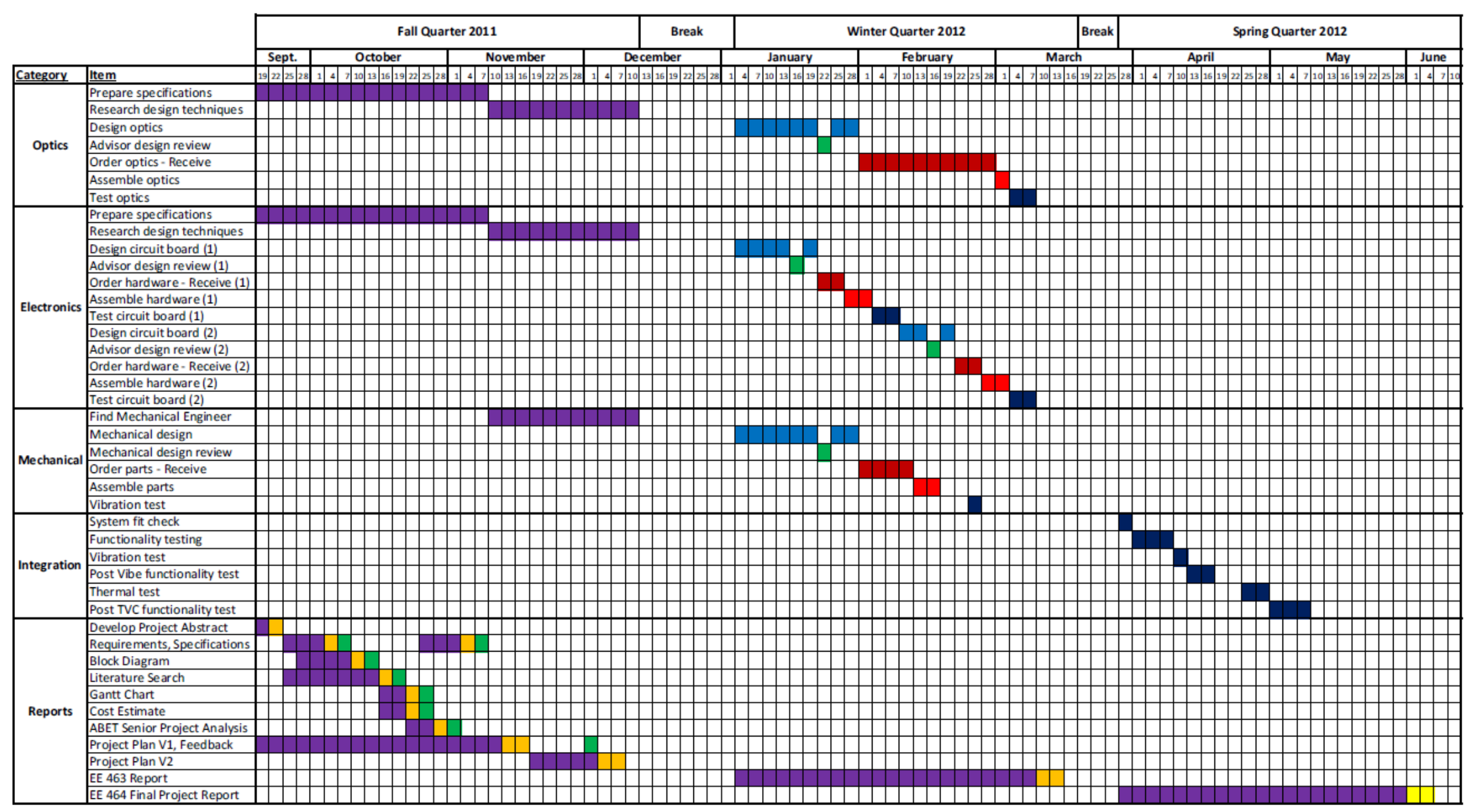

Figure A.1: Original Gantt Chart 


\section{- If manufactured on a commercial basis}

If this project were manufactured on a commercial basis there would be one unit produced per year at a cost of about $\$ 20,000$. The purchase price could be $\$ 100,000$ yielding a profit of $\$ 80,000$. This profit is necessary to cover the labor costs associated with building each unit. The operating cost of the unit for the user would include the labor of a ground station operator for about 2 years. If the ground station operator earns $\$ 20$ per hour and works 2 hours per day on this satellite 260 days per year, this would accrue to a total operation cost of $\$ 20,800$.

\section{- Environmental}

The environmental impacts of this project pertain to manufacturing of the purchased components and parts. Primarily, the adverse effects of semiconductor production are due to chemicals used in the manufacturing process. These chemicals pose health risks to the workers and to the community through ecosystem provisioning services such as drinking water and crops if improperly disposed. Other species that might consume water contaminated with these improperly disposed materials may also suffer health risks. Some of the dangerous chemicals include acetone, arsenic, arsine, benzene, cadmium, hydrochloric acid, lead, methyl chloroform, toluene, and trichloroethylene [14. All of the semiconductor parts for the project could be chosen to be RoHS (Restriction of Hazardous Substances Directive) compliant in order to reduce hazardous materials. During the projects development lifetime in the PolySat lab at Cal Poly, cleaning and testing by-products produce waste that requires disposal or recycling. For cleaning, isopropyl alcohol is absorbed by micro-fiber cloths and disposed. Nitrogen that cools the thermal-vacuum chamber evaporates into the air after it warms and vaporizes. Due to the low mass and volume of the CubeSat satellite, upon the end-of-life it will de-orbit and burn up completely during re-entry into the atmosphere leaving no space debris or environmental impact.

\section{- Manufacturability}

The project consists of four subsystems that must be manufactured: the lens, CCD array, image processor, and data storage. All of these subsystems will be manufactured through standard processes so special manufacturing considerations will not be considered when ordering the individual parts and subsystems. 


\section{- Sustainability}

While in the design and development phase, the DNB Imager for a CubeSat affects ecosystem services through the waste produced during testing phase. All of the non-recyclable waste generated, such as leaded solder and isopropyl alcohol, travels to a landfill and decomposes. Packaging materials from ordered parts become recycled. The imager does not need any maintenance after it is launched and it is not a sustainable product since it will burn up during its end of life de-orbit. If the project were upgraded in the future to support sustainability post-mission lifetime, the sensor could be incorporated in a satellite that re-enters the atmosphere without burning such that it could be recovered and re-used. The project may incorporate the production of an engineering unit that will stay in the PolySat lab and be reused in the future. This part of the project will never be disposed and after it no longer functions it will be put on display. Another option for creating a sustainable design would be to reuse the by-product chemicals from the manufacturing process on future electronic manufacturing. This would require major upgrades to the manufacturers facilities and recycling capabilities, which is out of the scope for this project. The manufacturers of the lens already reuse the extra material used for producing glass by melting down excess glass.

\section{- Ethical}

The ethical analysis presented here follows the ethical framework of The Golden Rule: to treat others only as you would consent to be treated. This project will be used as an earth imager for tracking energy usage in established cities, monitoring weather and cloud movement, and detecting human movement at night. If the DNB Imager for a CubeSat is used for the proposed applications, then no ethical issues will arise. Tracking energy usage in established cities generates data for monitoring economic development of the city. This is objective data that is merely informative for any interested persons. Monitoring clouds provides weather forecasting data that could potentially be used for an early warning system for hurricanes, tropical storms, or other dangerous cloud formation developments. If an early warning sign of a dangerous storm is acquired through this imager, it must be reported to the pertinent news stations in order to provide 
sufficient warning to the people who may be affected by the storm. This is consistent with the first point of the IEEE Code of Ethics [15. The last application of detecting human activity at night is directed towards tracking or finding fishing vessels in the Extended Economic Zone (EEZ) of a particular nation. Again, this could produce important information that could save the lives of the fishermen on board the vessel. Therefore, the acquired images must be relayed to the pertinent rescue stations that could interpret the images and take necessary actions. If the imager is not used for the proposed applications, unethical actions could ensue by acquiring images for spying on human activity or targeting a potential attack point.

\section{- Health and Safety}

Health and safety concerns for this project are primarily associated with the thermal testing of the DNB Imager for a CubeSat. The Cal Poly thermal-vacuum chamber uses liquid nitrogen to cool the chambers contents and could potentially leak nitrogen into the thermal-vacuum room, suffocating the occupants if there is insufficient ventilation. An oxygen meter located inside the test room warns the occupants if a leak in the liquid nitrogen tank causes a dangerous drop in the percentage of oxygen in the room. If such an incident were to occur, a sign in the thermal-vacuum chamber room prompts the operators to evacuate the building immediately.

\section{- Social and Political}

Dr. Puschell from Raytheon proposed this project and Raytheon supports the first phase of the design at Cal Poly. Therefore, the primary stake holders, Raytheon and Cal Poly, each have partial ownership over the intellectual property of the products design. Cal Polys CubeSat design team, PolySat, also benefits from the development of the imager because they are the primary consideration for the development of the CubeSat which will fly the DNB for a CubeSat. The research results published in this senior project report provide intellectual benefits to readers of this report. The shipping companies and manufacturing companies chosen to deliver and produce parts for the project receive economic benefit from the research grant provided by Raytheon. The manufacturers of the components used in the design also directly benefit from advertisement in this report. 


\section{- Development}

This project requires me to learn an optical lens design and simulation computer application, allowing me to purchase either a standard lens or custom lens after researching what lenses are currently on the market. I also had to research the current CCD focal plane array technology in order to find a suitable focal plane array for satellite imagery. 


\title{
Appendix B
}

\section{Lens Design}

\author{
B.1 Lens Option \#1
}
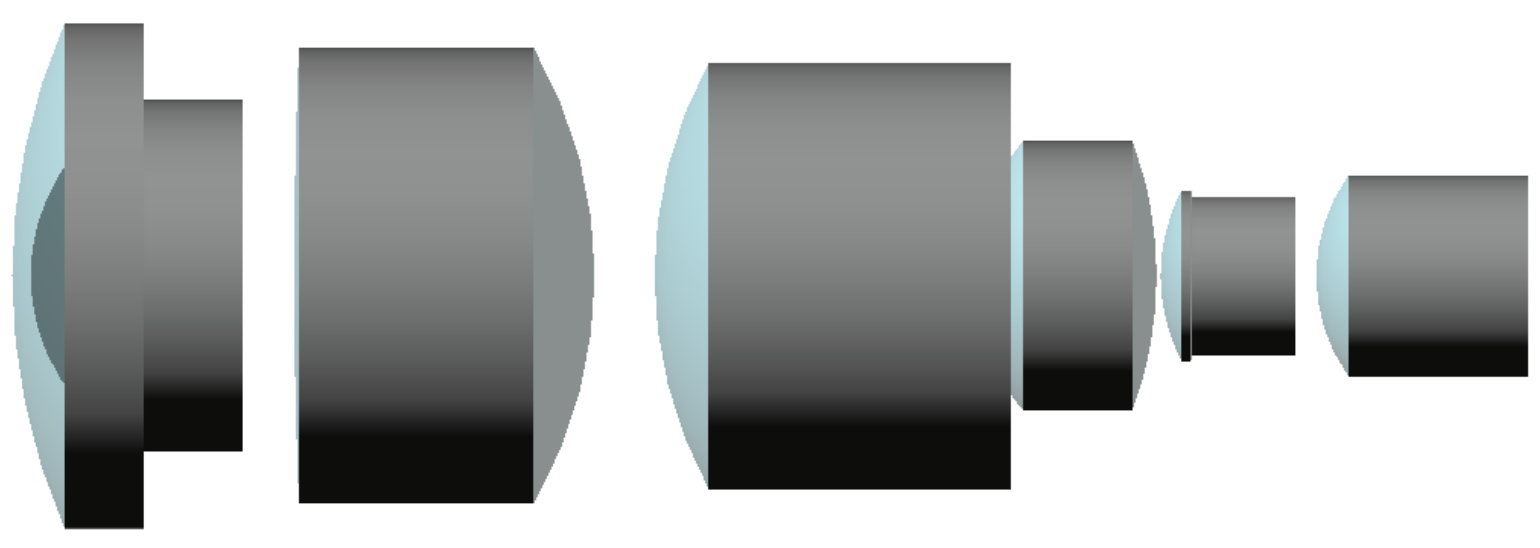

Figure B.1: Option \#1 3D Plot Side View 
B.1 Lens Option \#1

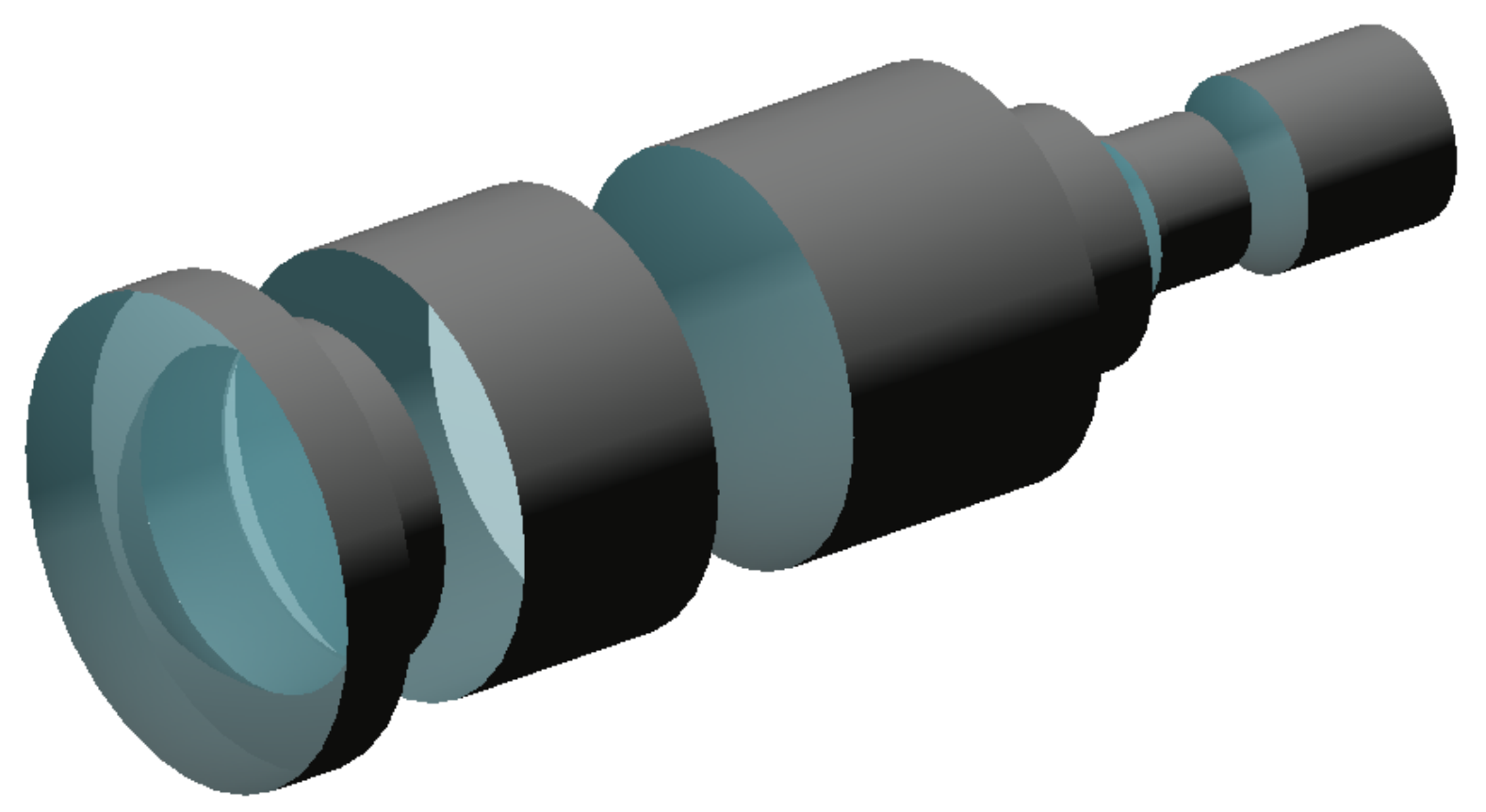

Figure B.2: Option \#1 3D Plot Angled View 


\section{B.1 Lens Option \#1}

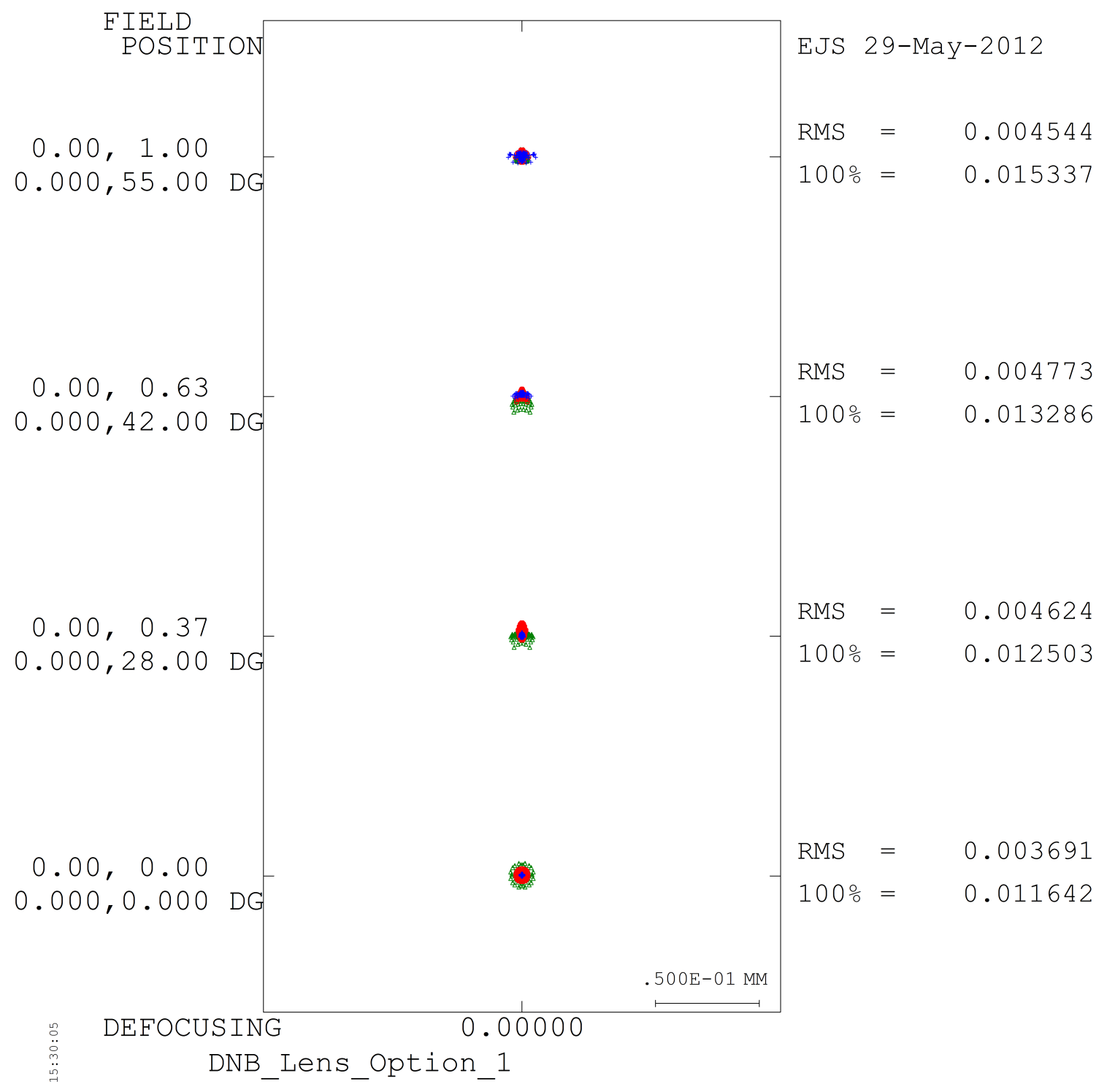

Figure B.3: Option \#1 Spot Diagram 
B.1 Lens Option \#1

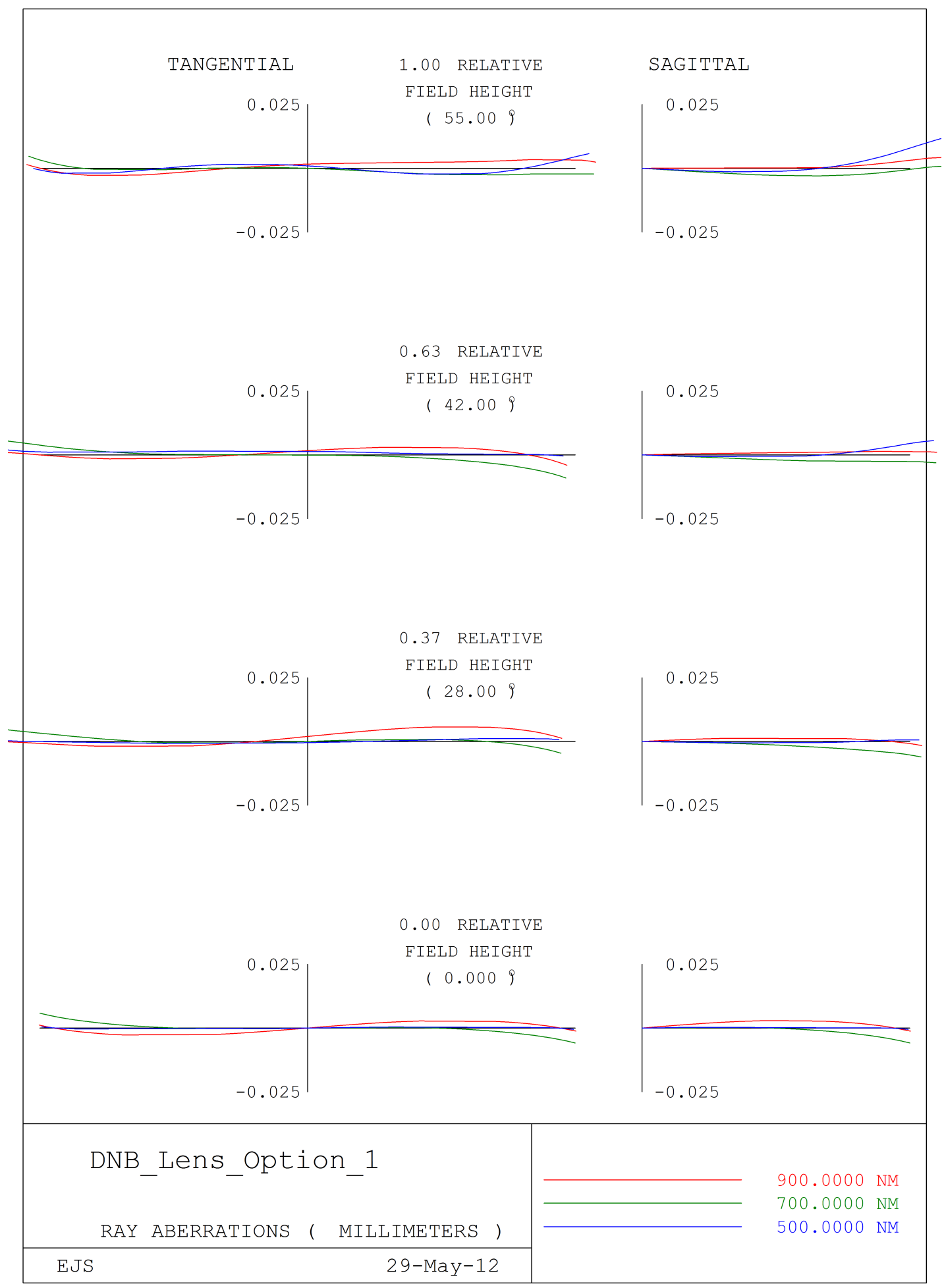

Figure B.4: Option \#1 Ray Aberration Trace 


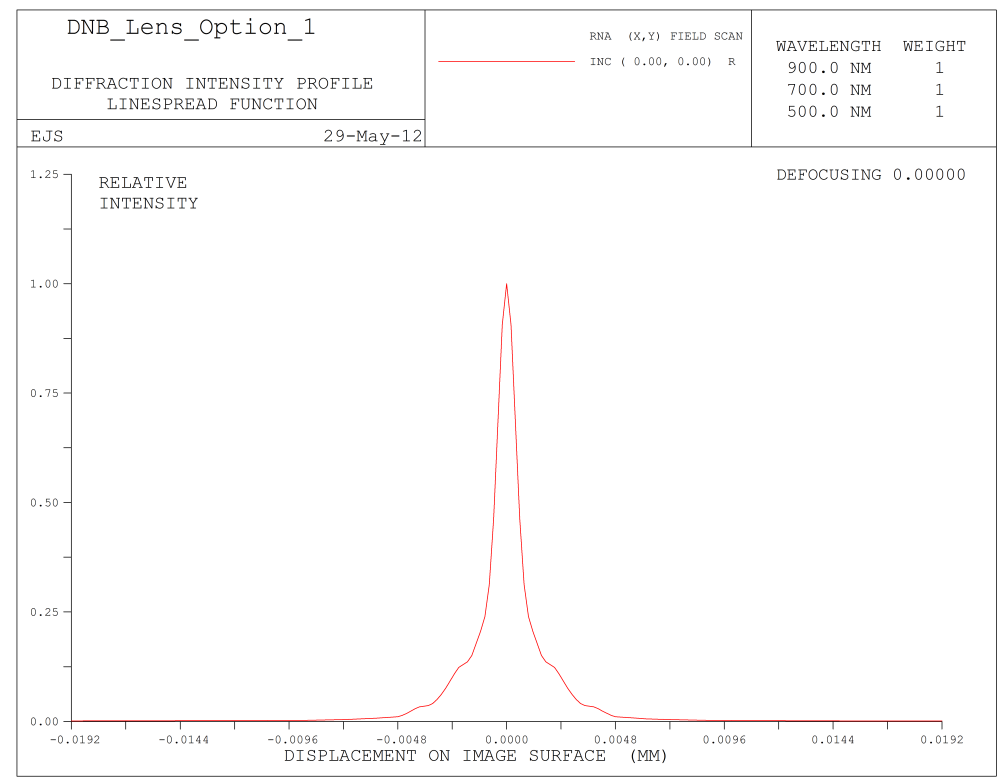

Figure B.5: Option \#1 Line Spread Function at $0^{\circ}$

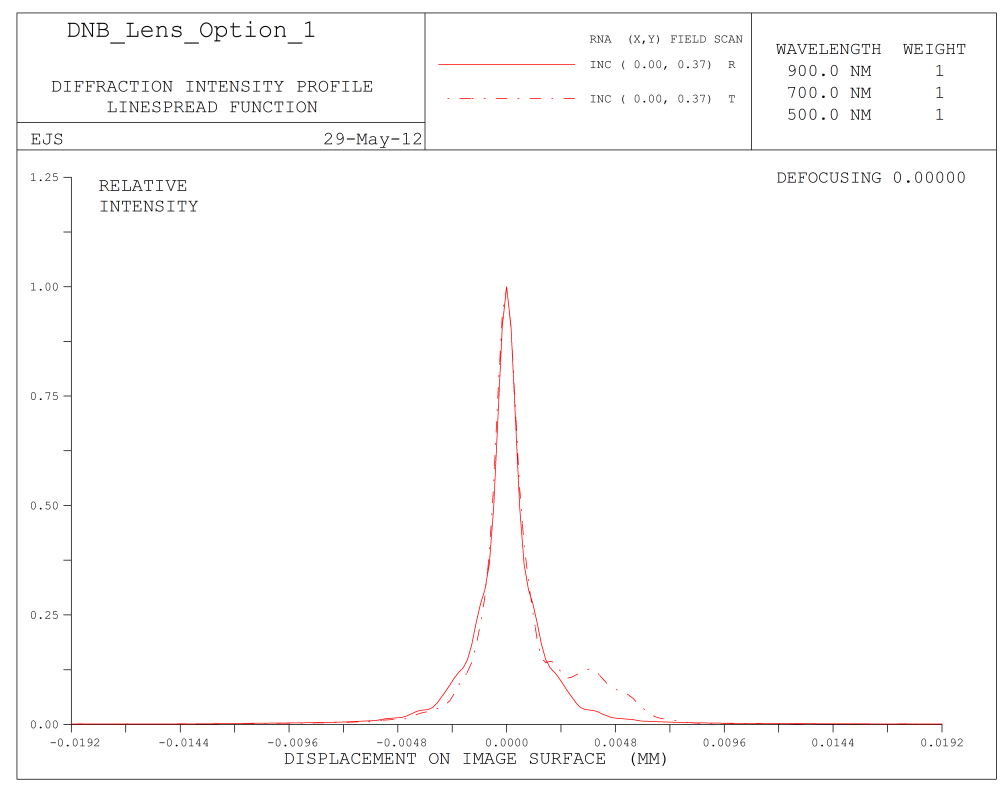

Figure B.6: Option $\# 1$ Line Spread Function at $28^{\circ}$ 


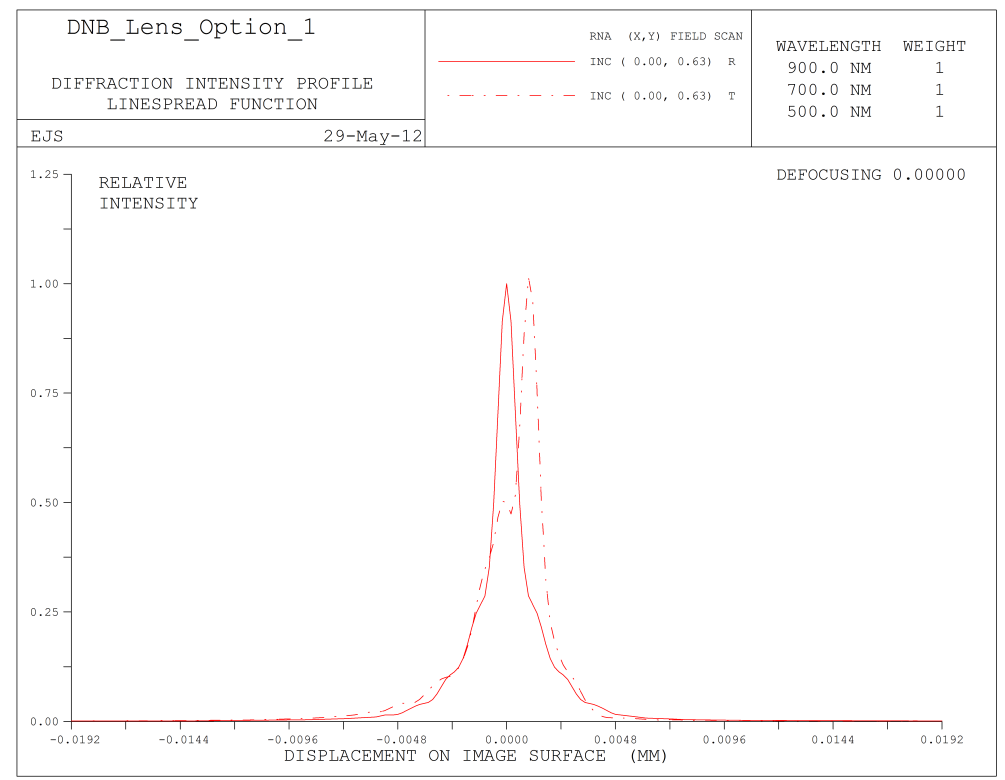

Figure B.7: Option \#1 Line Spread Function at $42^{\circ}$

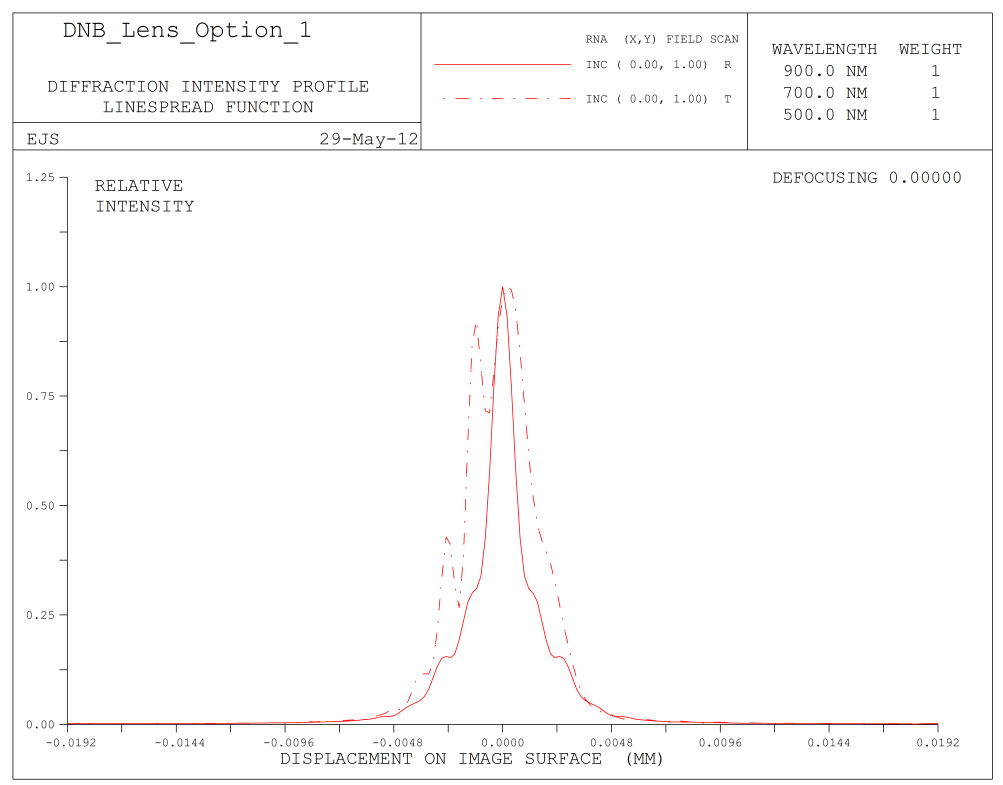

Figure B.8: Option \#1 Line Spread Function at $55^{\circ}$ 


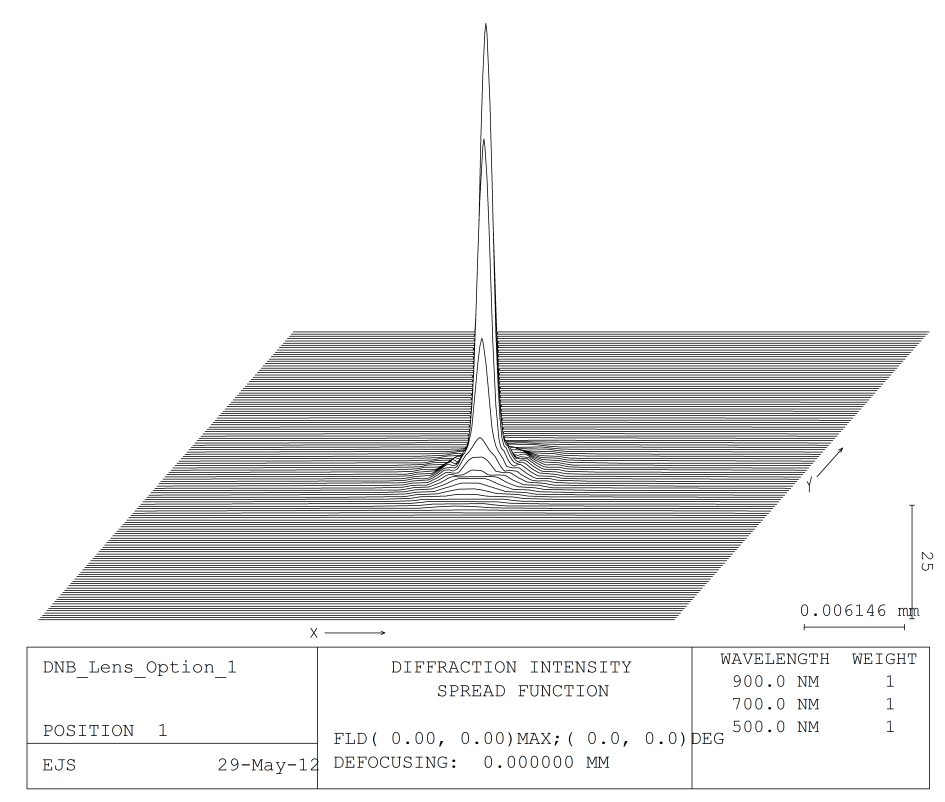

Figure B.9: Option \#1 Point Spread Function at $0^{\circ}$

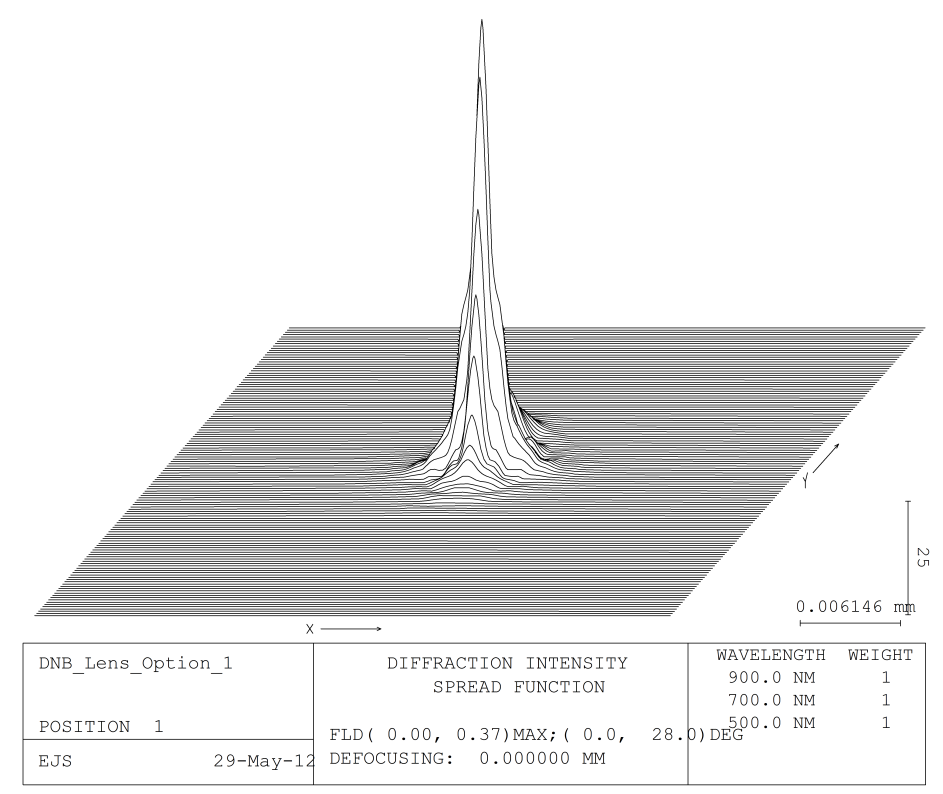

Figure B.10: Option \#1 Point Spread Function at $28^{\circ}$ 


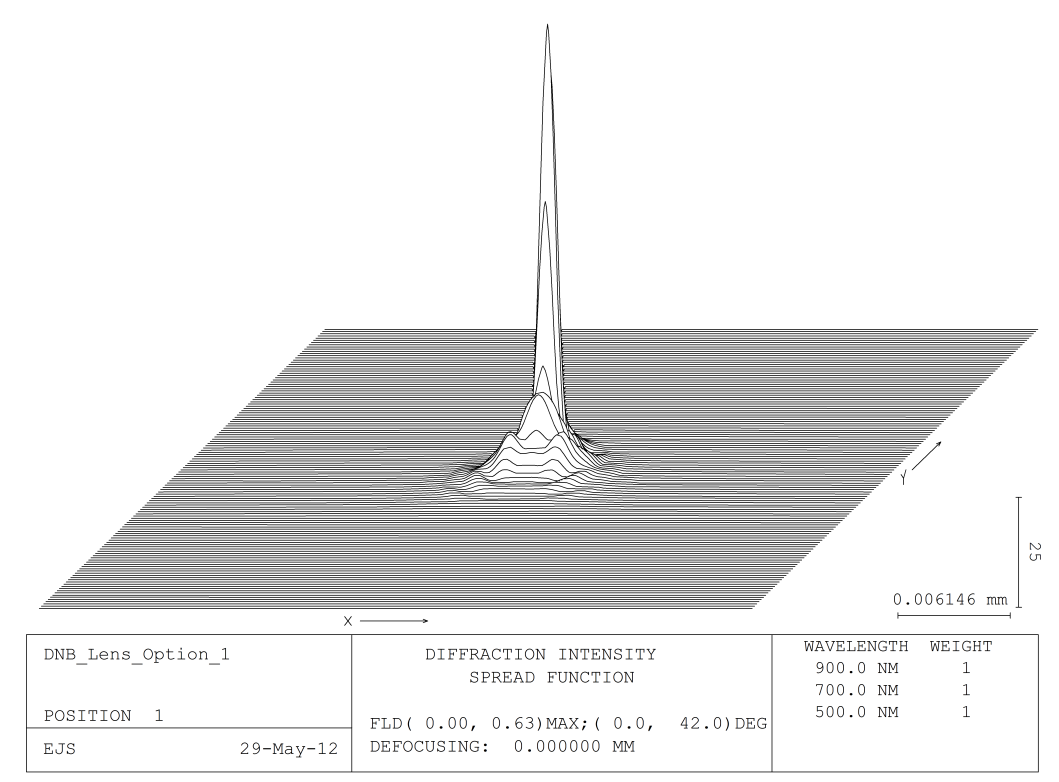

Figure B.11: Option \#1 Point Spread Function at $42^{\circ}$

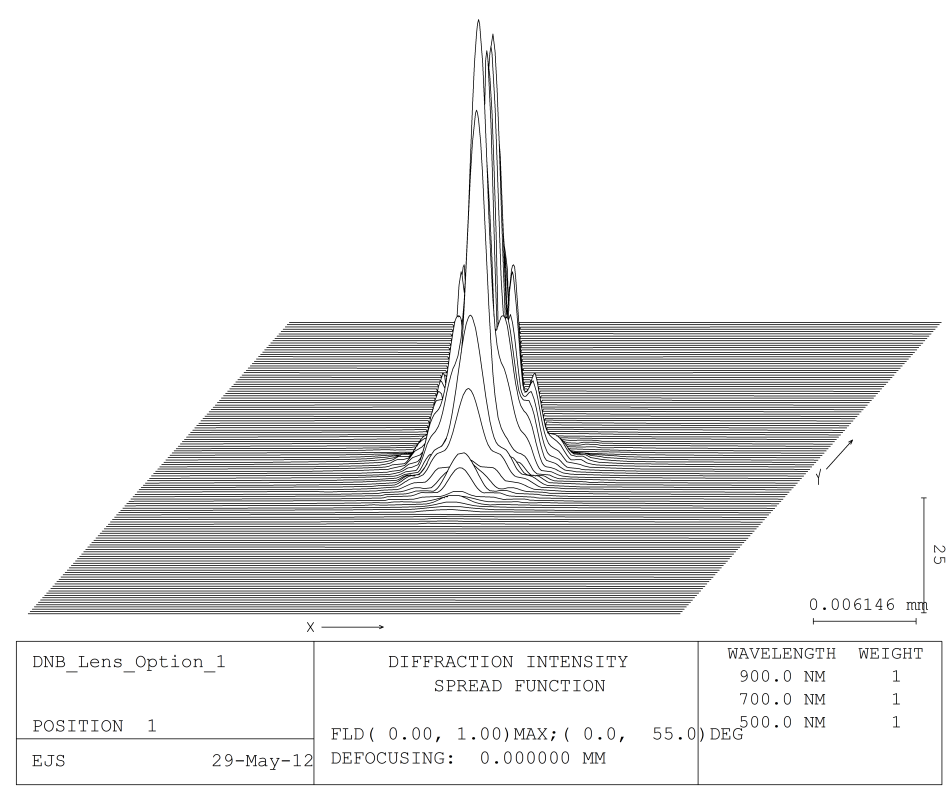

Figure B.12: Option \#1 Point Spread Function at $55^{\circ}$ 


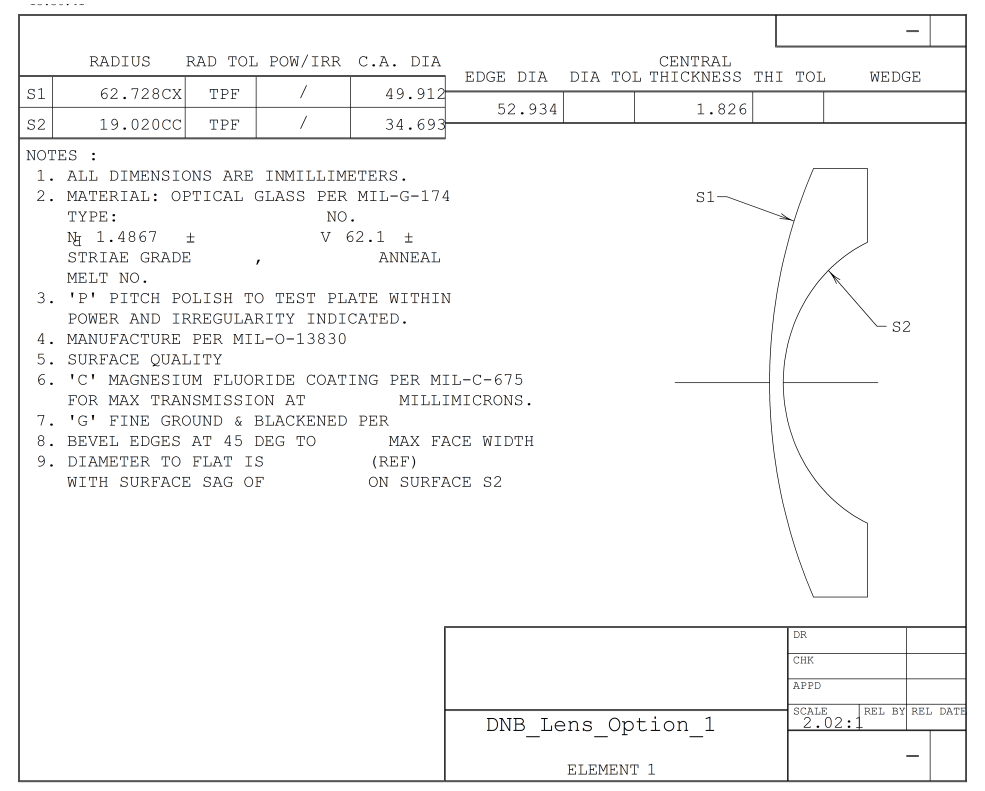

Figure B.13: Option \#1 Element \#1 Drawing

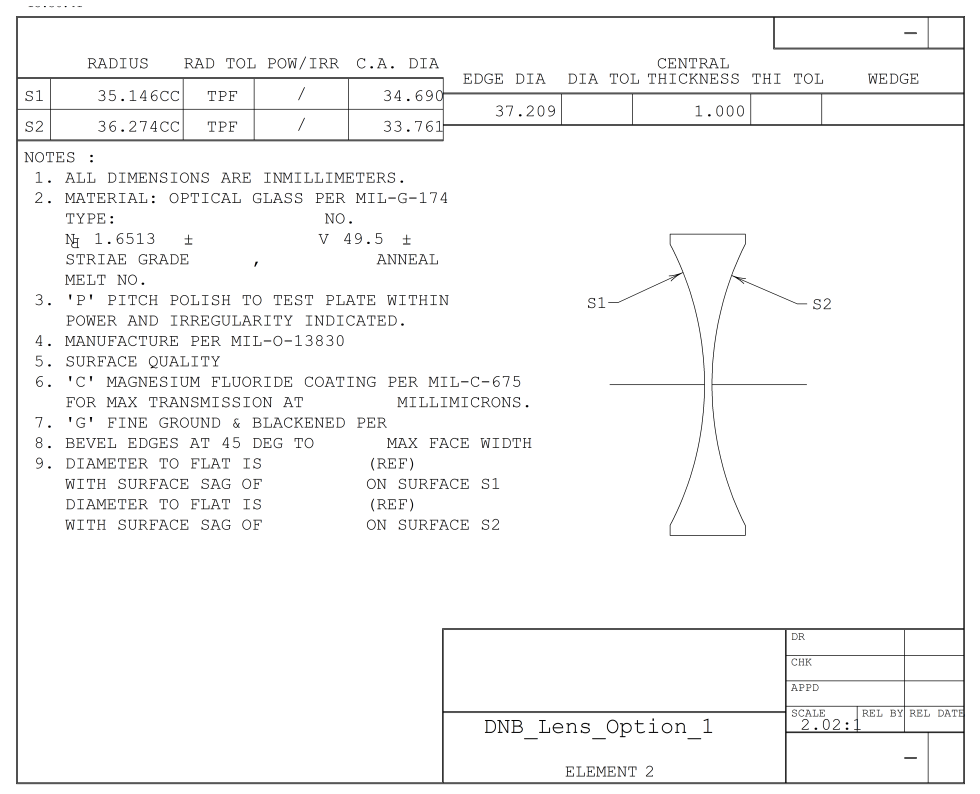

Figure B.14: Option \#1 Element \#2 Drawing 


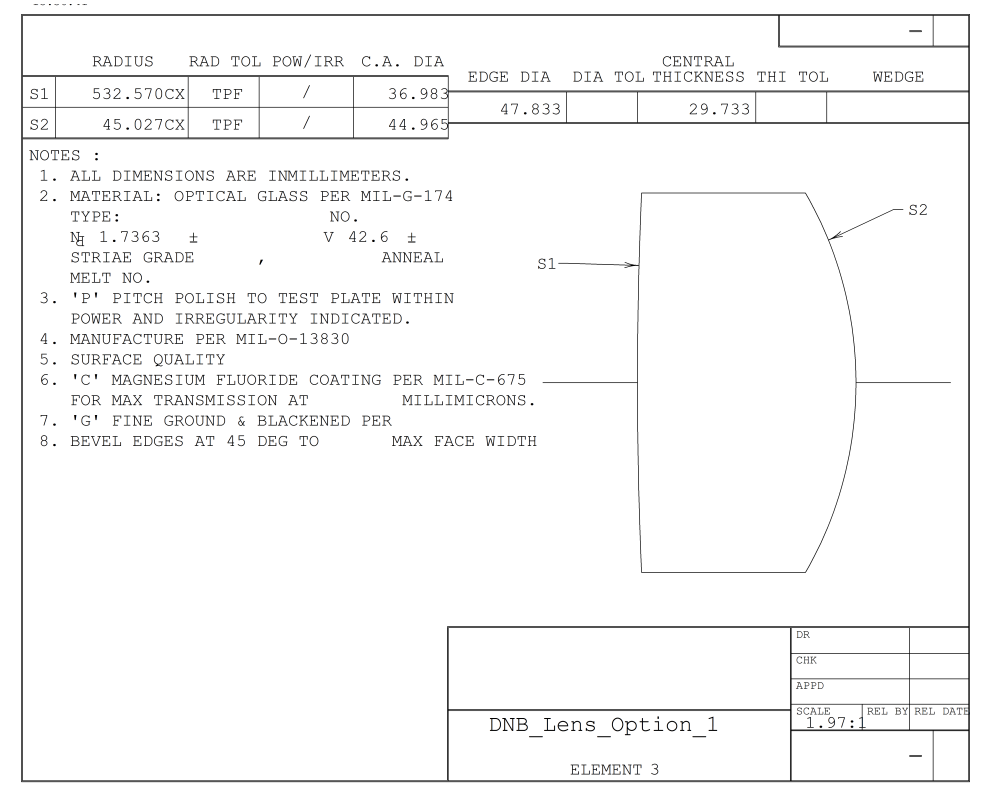

Figure B.15: Option \#1 Element \#3 Drawing

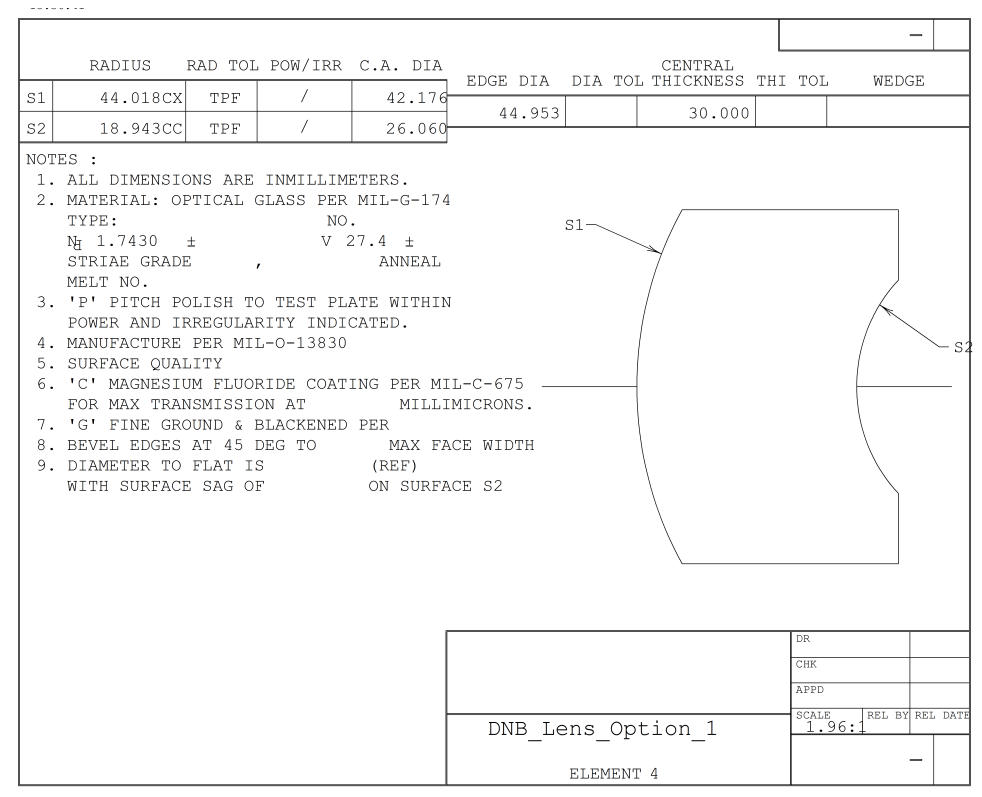

Figure B.16: Option \#1 Element \#4 Drawing 


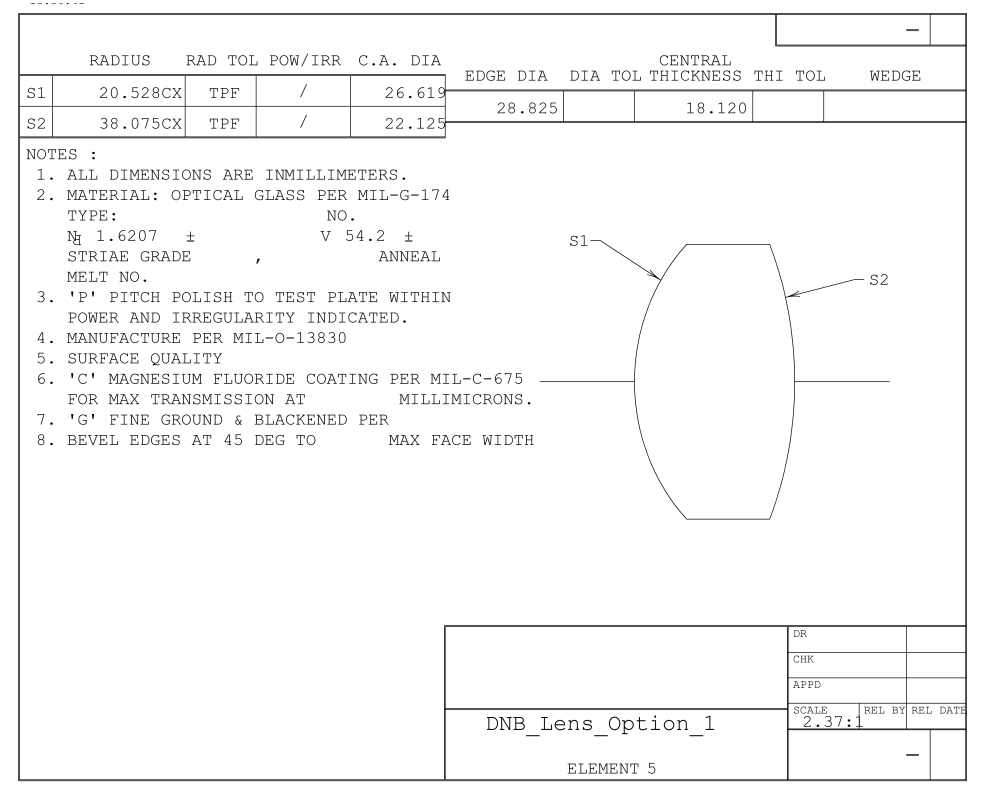

Figure B.17: Option \#1 Element \#5 Drawing

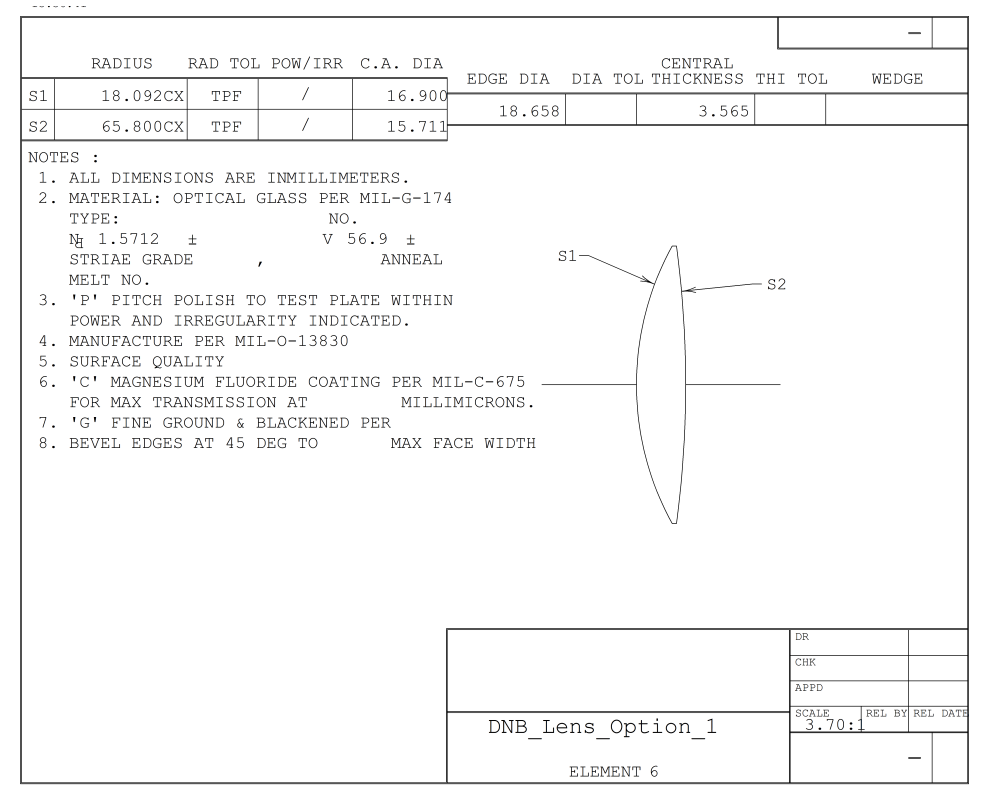

Figure B.18: Option \#1 Element \#6 Drawing 


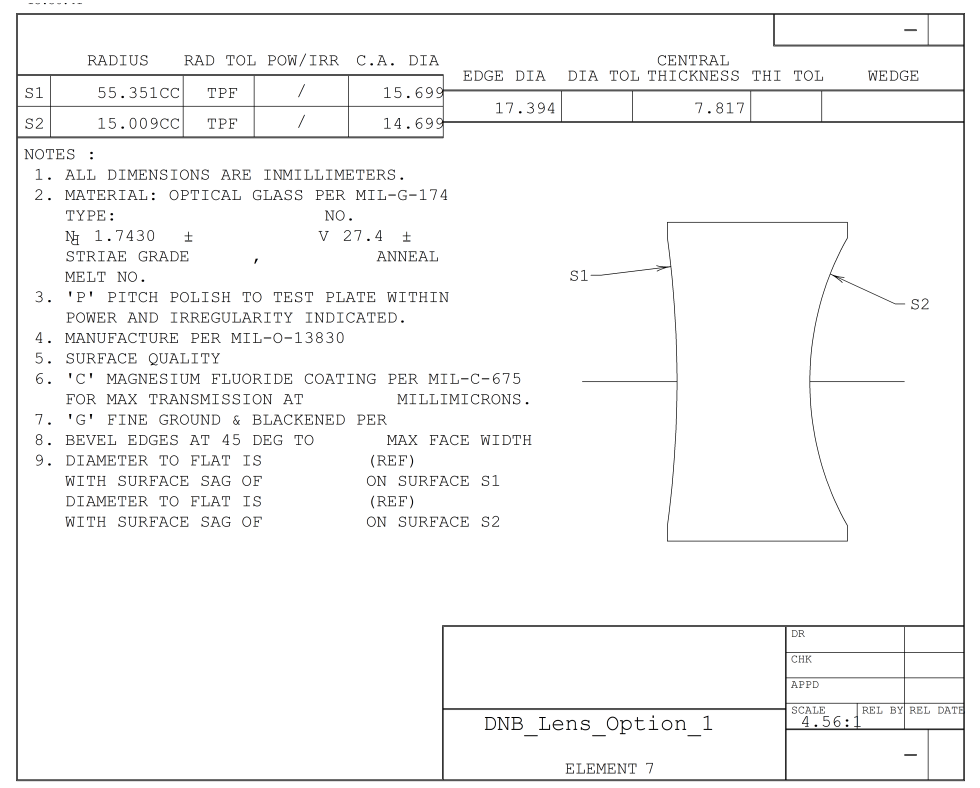

Figure B.19: Option \#1 Element \#7 Drawing

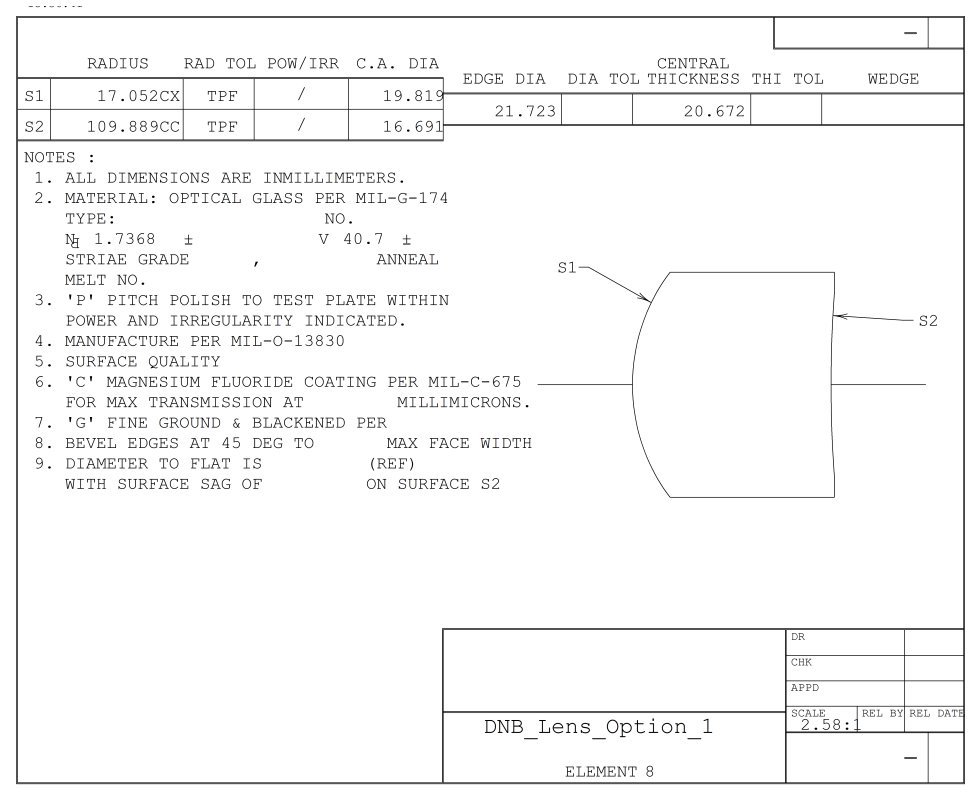

Figure B.20: Option \#1 Element \#8 Drawing 
Table B- I: Surface and aperture data for lens option \#1

\begin{tabular}{|l|r|r|r|r|}
\hline Surface & \multicolumn{1}{c|}{ Radius } & Thickness & Glass Type & Semi-Aperture \\
\hline $1:$ & 62.728 & 1.826 & 486743.620761 & 24.956 \\
\hline $2:$ & 19.020 & 15.799 & & 17.346 \\
\hline $3:$ & -35.146 & 1.000 & 651273.494922 & 17.345 \\
\hline $4:$ & 36.274 & 9.272 & & 16.880 \\
\hline $5:$ & 532.570 & 29.733 & 736270.426229 & 18.492 \\
\hline $6:$ & -45.027 & 5.910 & & 22.483 \\
\hline $7:$ & 44.018 & 30.000 & 742998.274141 & 21.088 \\
\hline $8:$ & 18.943 & 1.567 & & 13.030 \\
\hline $9:$ & 20.528 & 18.120 & 620671.542050 & 13.309 \\
\hline $10:$ & -38.075 & 0.282 & & 11.062 \\
\hline STOP: & INFINITY & 0.100 & & 6.766 \\
\hline $12:$ & 18.092 & 3.565 & 571179.569083 & 8.450 \\
\hline $13:$ & -65.800 & 0.091 & & 7.855 \\
\hline $14:$ & -55.351 & 7.816 & 742998.274141 & 7.850 \\
\hline $15:$ & 15.009 & 3.925 & & 7.350 \\
\hline $16:$ & 17.052 & 20.672 & 736844.406837 & 9.910 \\
\hline $17:$ & 109.889 & 0.915 & & 8.345 \\
\hline
\end{tabular}




\section{B.2 Lens Option \#2}

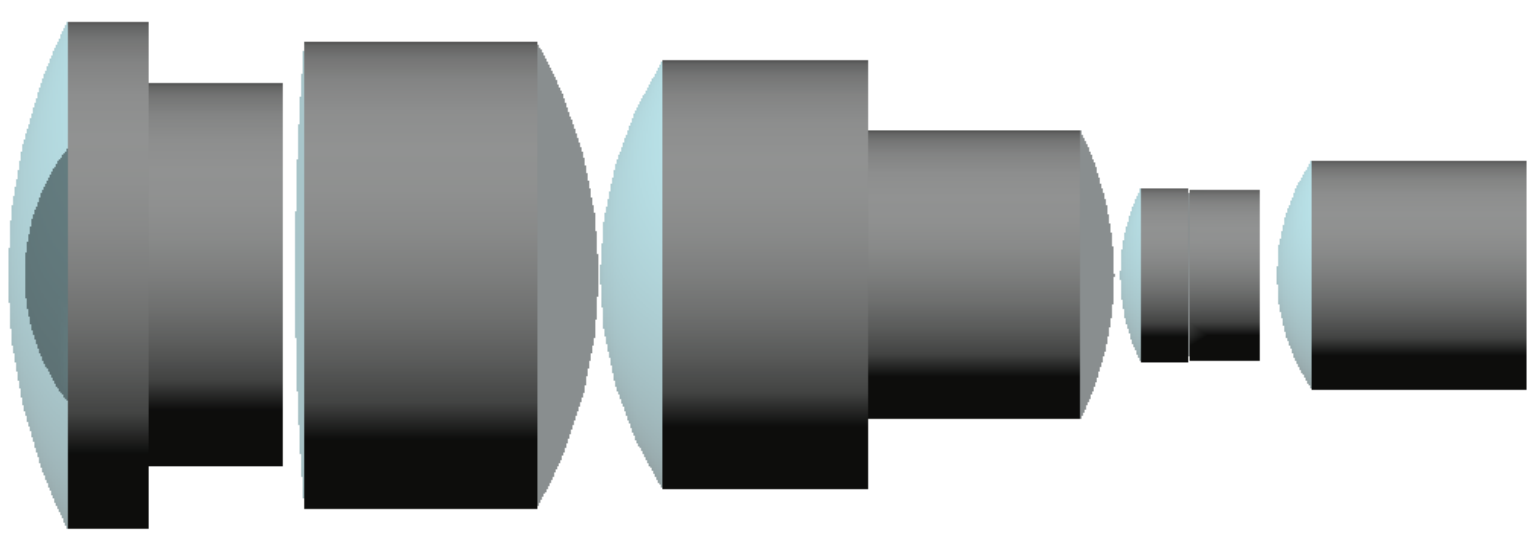

Figure B.21: Option \#2 3D Plot Side View

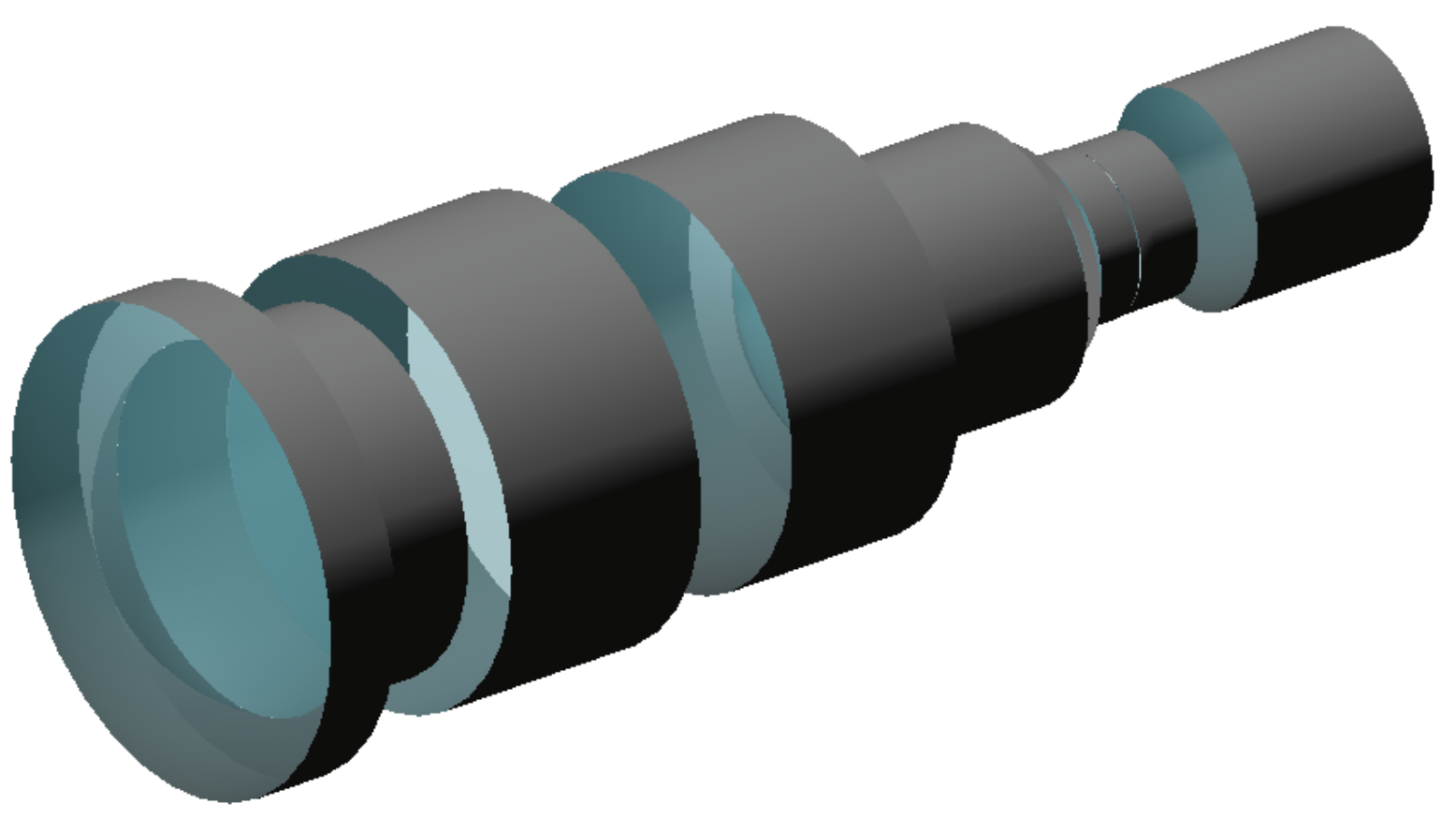

Figure B.22: Option \#2 3D Plot Angled View 
B.2 Lens Option \#2

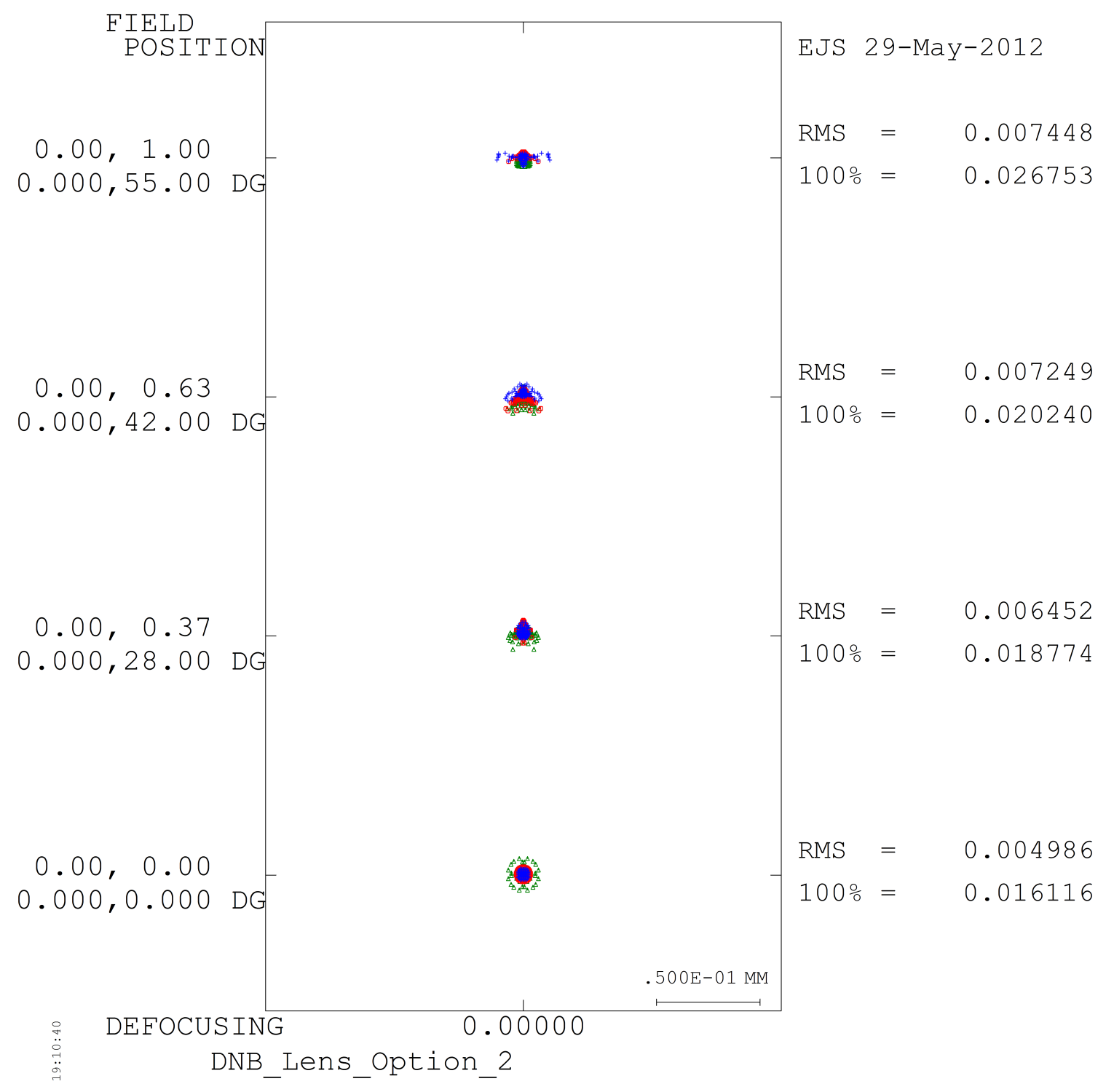

Figure B.23: Option \#2 Spot Diagram 
B.2 Lens Option \#2

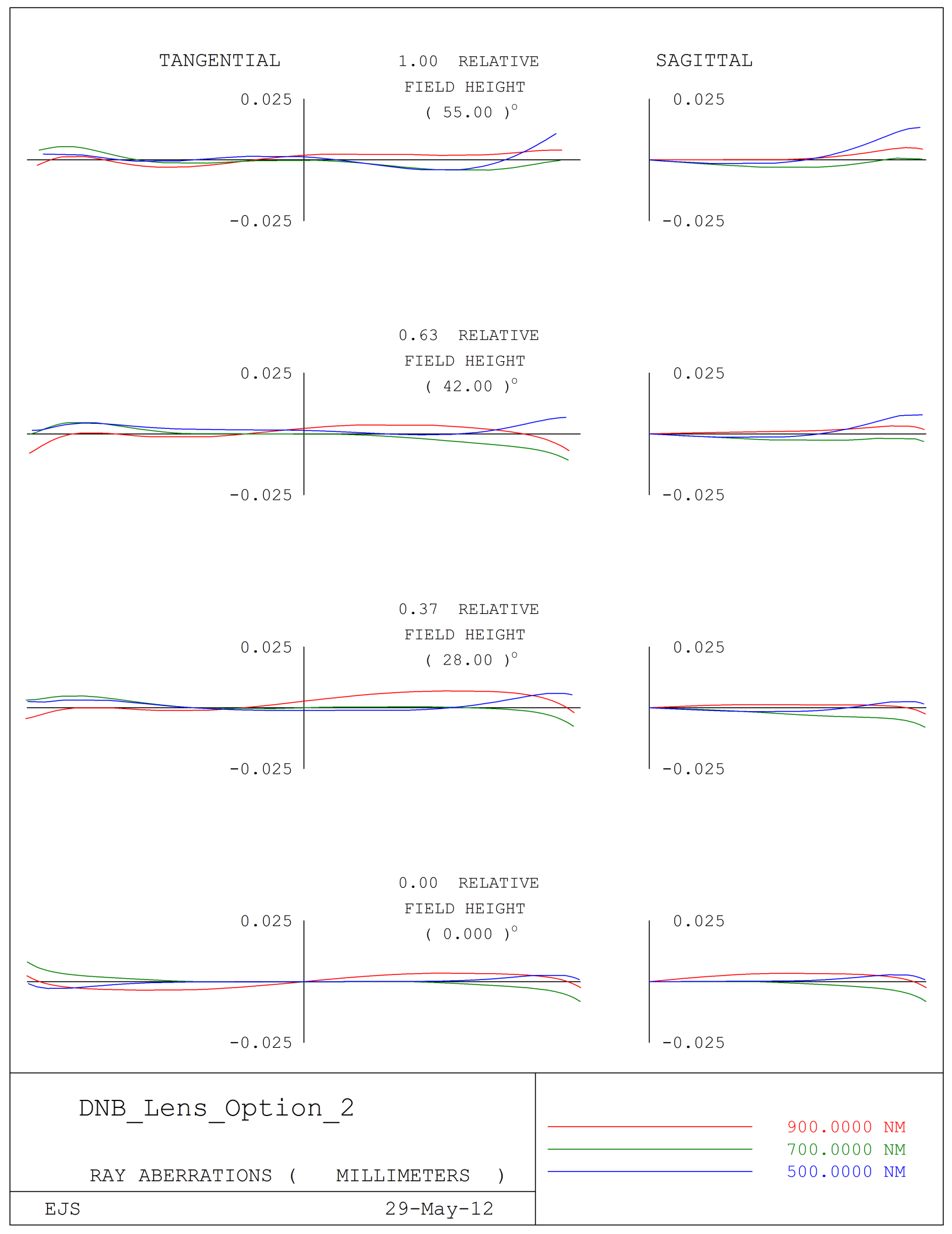

Figure B.24: Option \#2 Ray Aberration Trace 


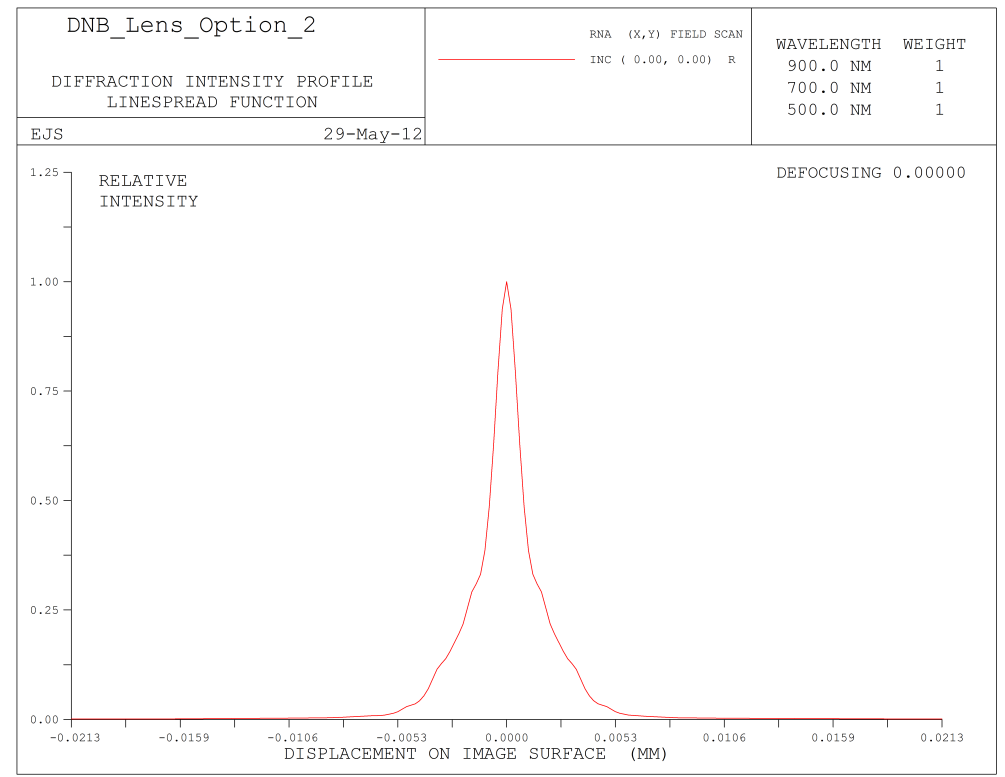

Figure B.25: Option \#2 Line Spread Function at $0^{\circ}$

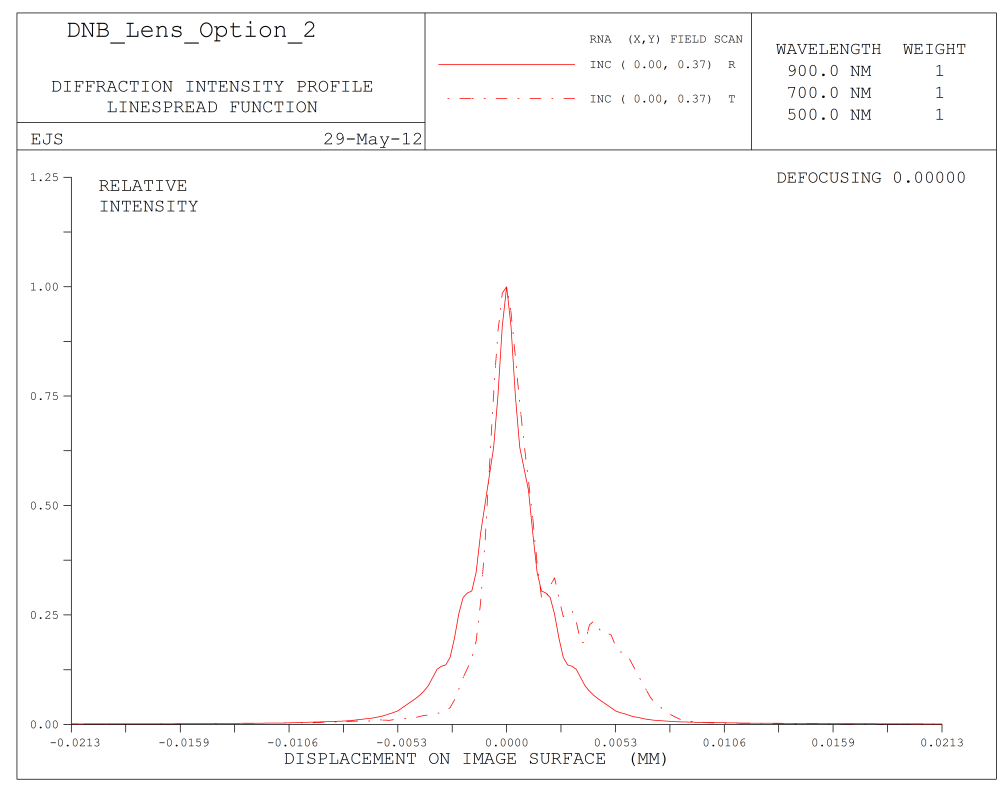

Figure B.26: Option \#2 Line Spread Function at $28^{\circ}$ 


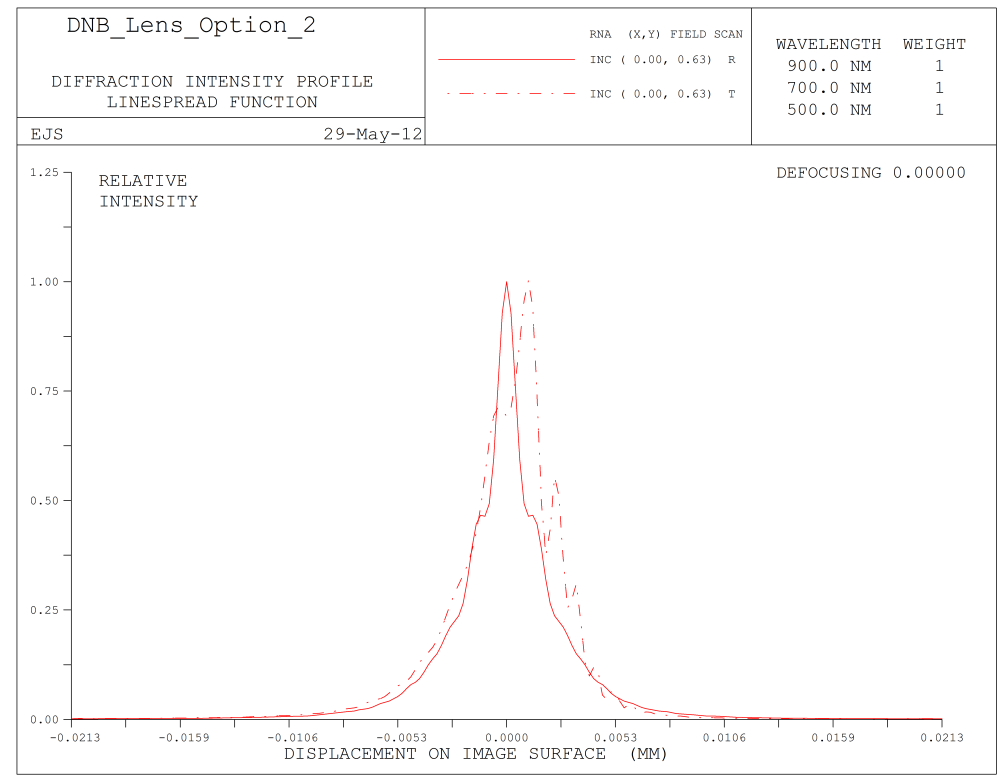

Figure B.27: Option \#2 Line Spread Function at $42^{\circ}$

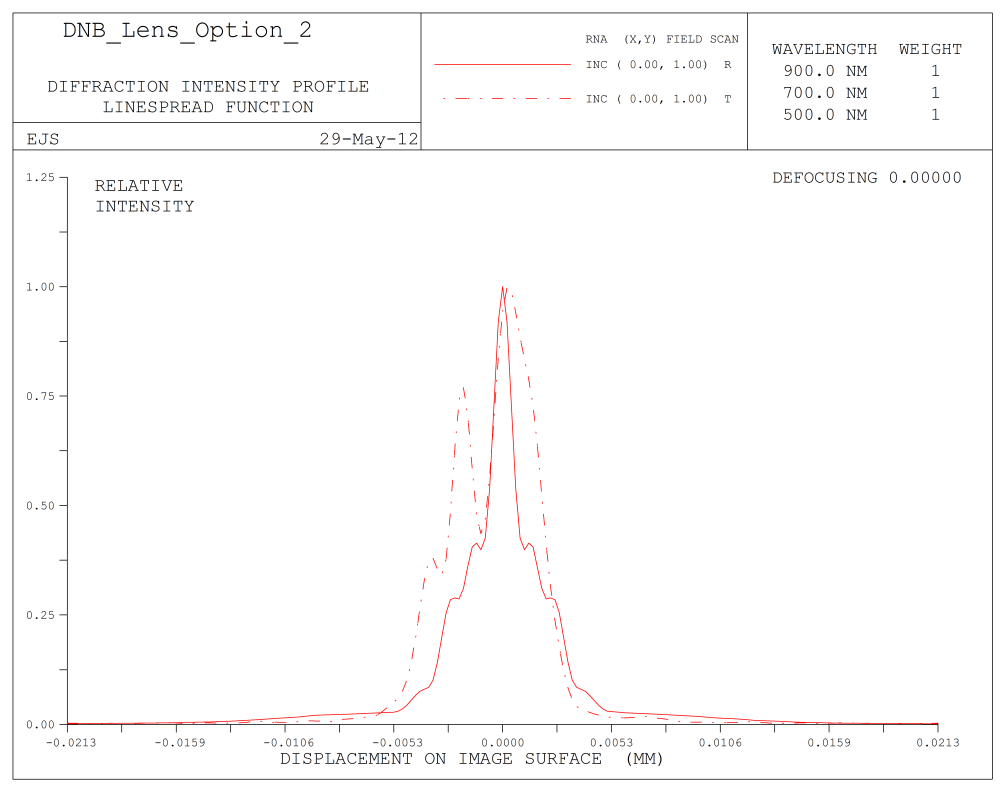

Figure B.28: Option \#2 Line Spread Function at $55^{\circ}$ 


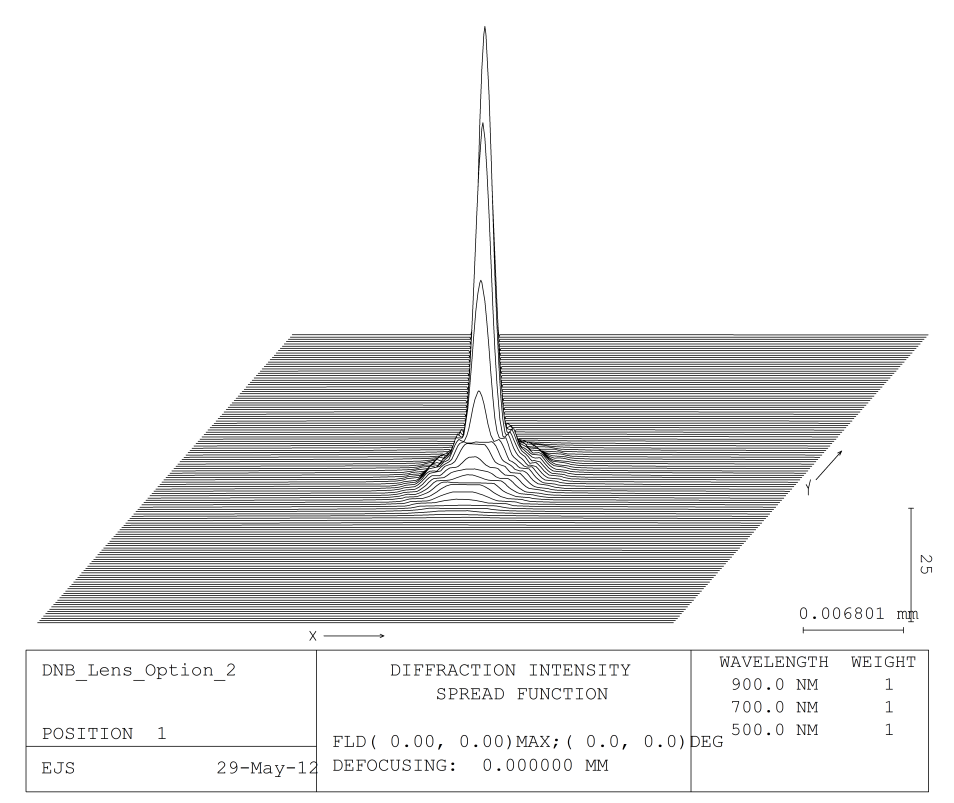

Figure B.29: Option \#2 Point Spread Function at $0^{\circ}$

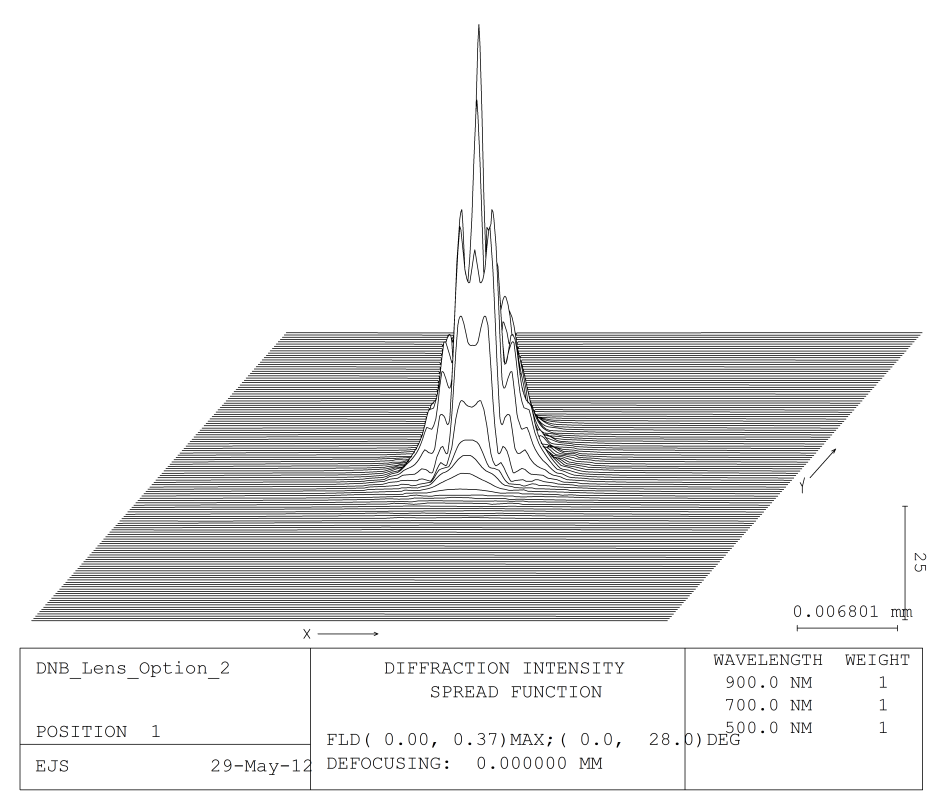

Figure B.30: Option \#2 Point Spread Function at $28^{\circ}$ 


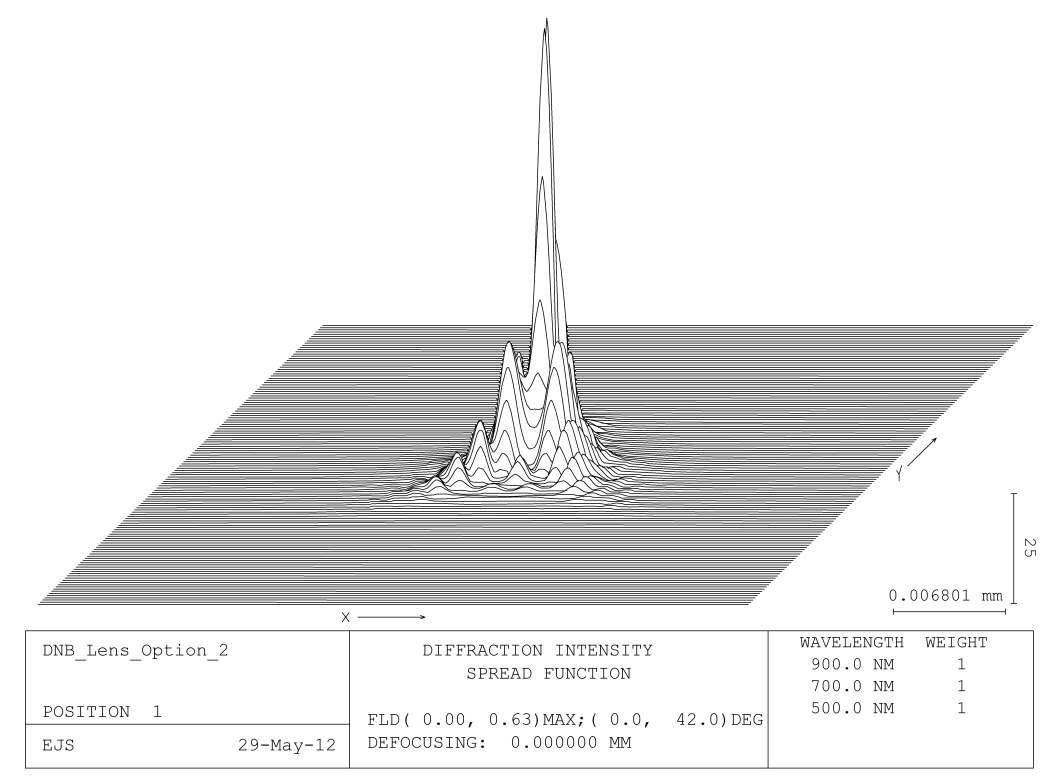

Figure B.31: Option \#2 Point Spread Function at $42^{\circ}$

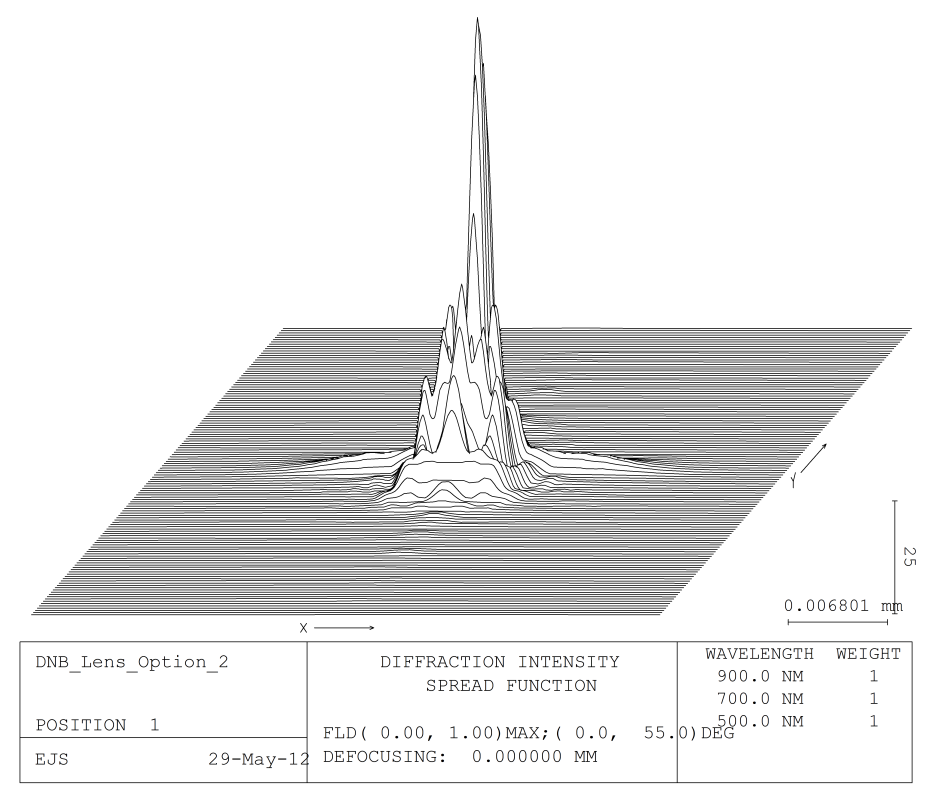

Figure B.32: Option \#2 Point Spread Function at $55^{\circ}$ 


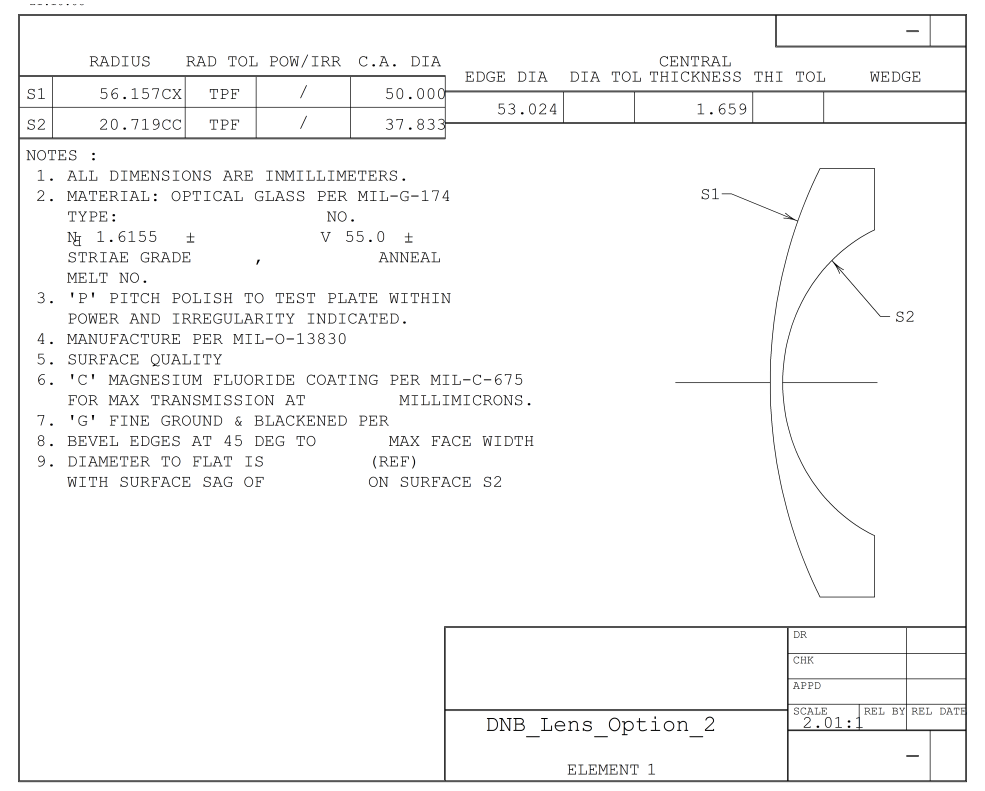

Figure B.33: Option \#2 Element \#1 Drawing

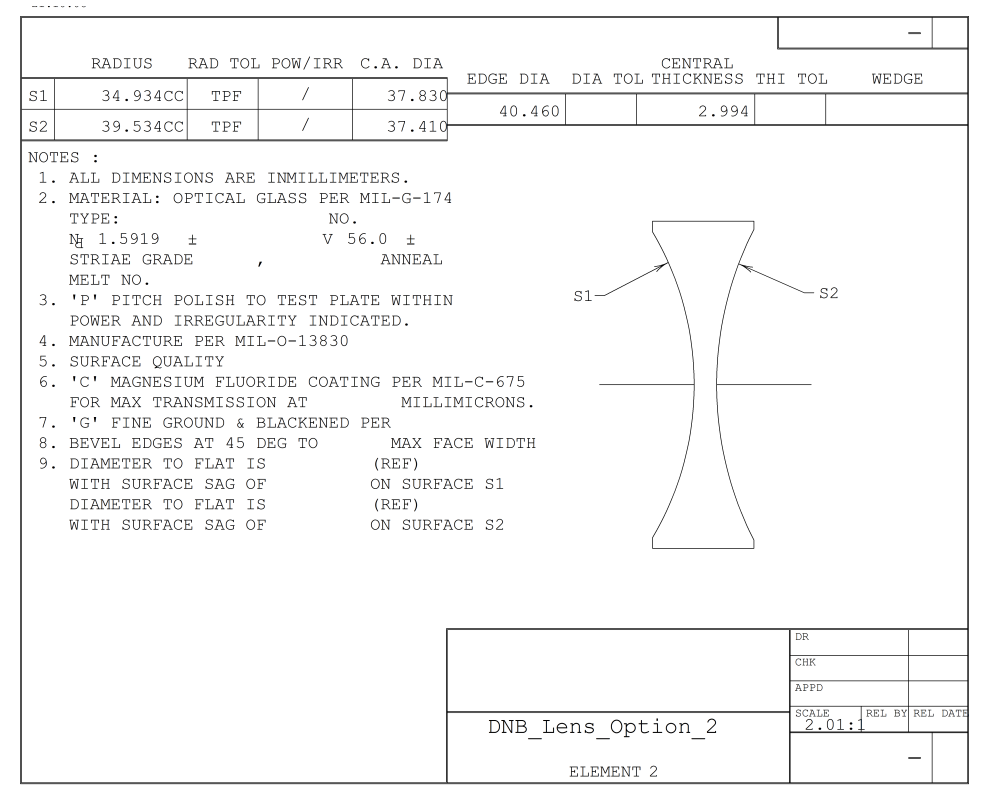

Figure B.34: Option \#2 Element \#2 Drawing 


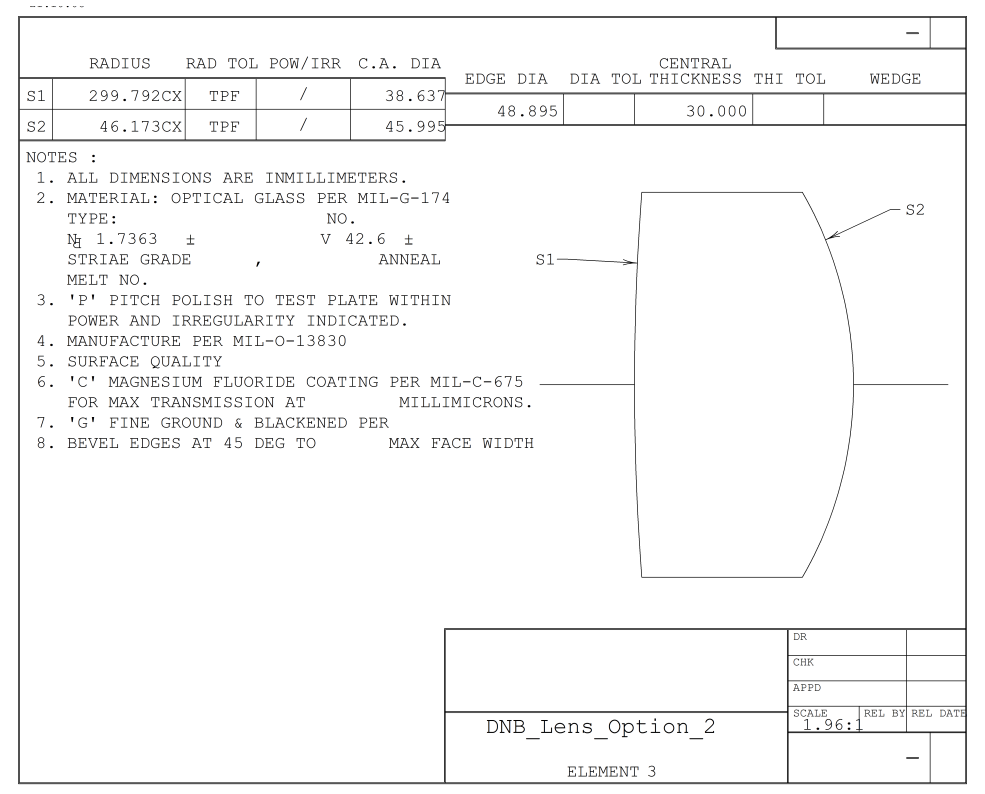

Figure B.35: Option \#2 Element \#3 Drawing

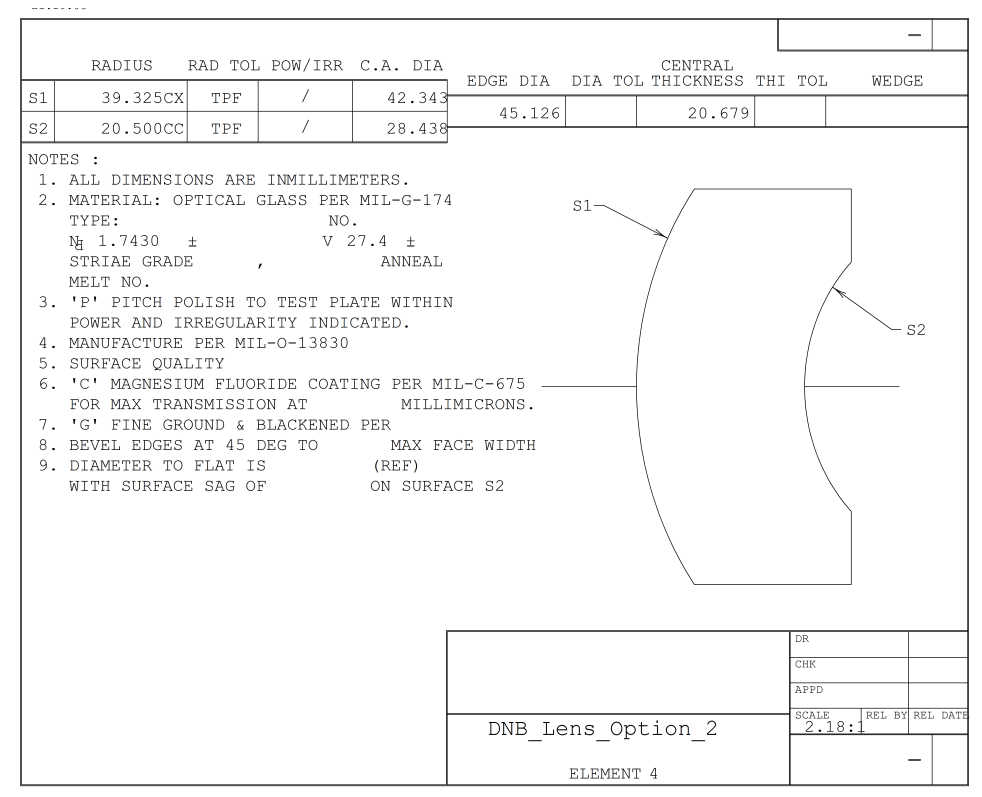

Figure B.36: Option \#2 Element \#4 Drawing 


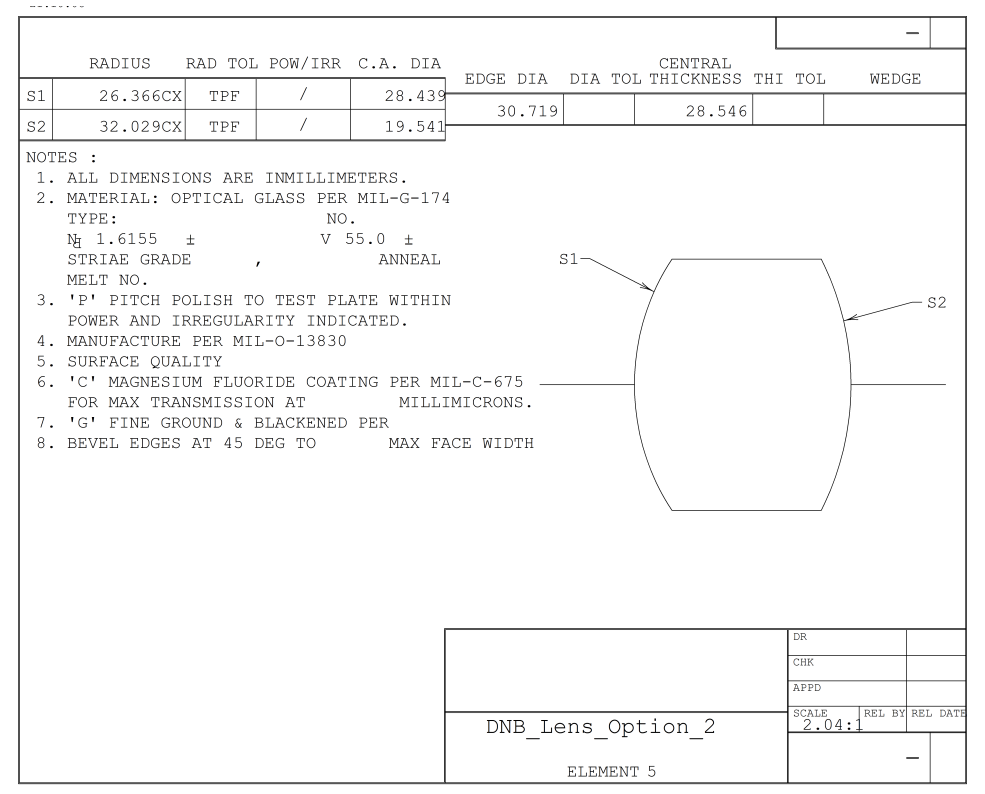

Figure B.37: Option \#2 Element \#5 Drawing

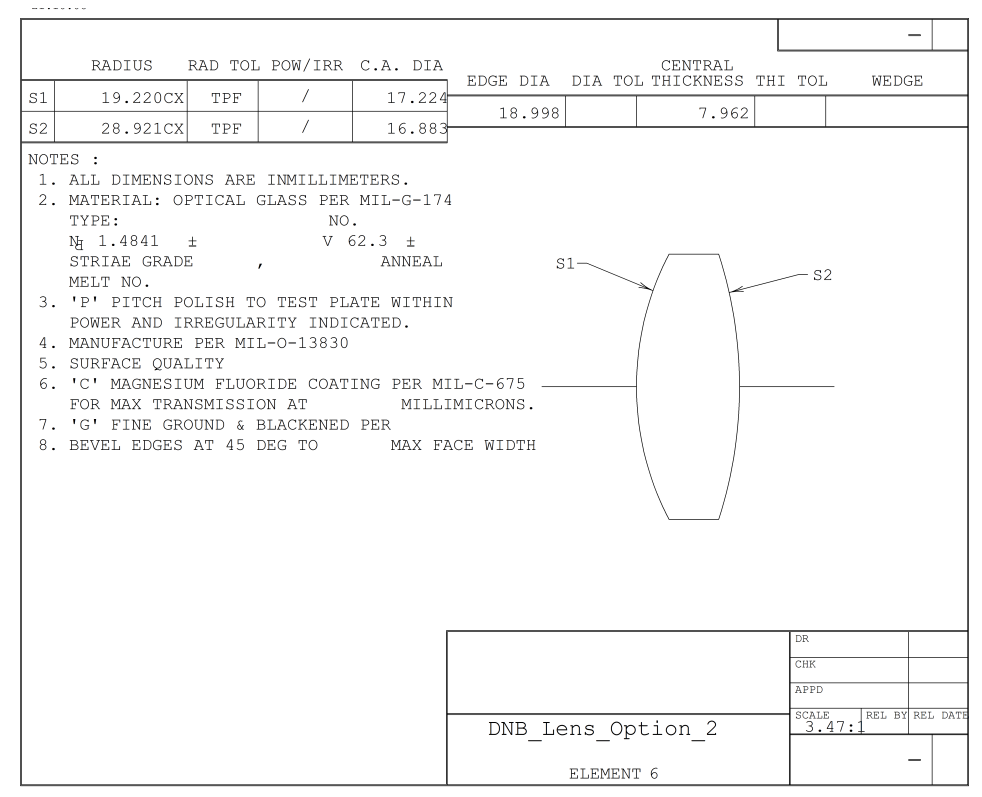

Figure B.38: Option \#2 Element \#6 Drawing 


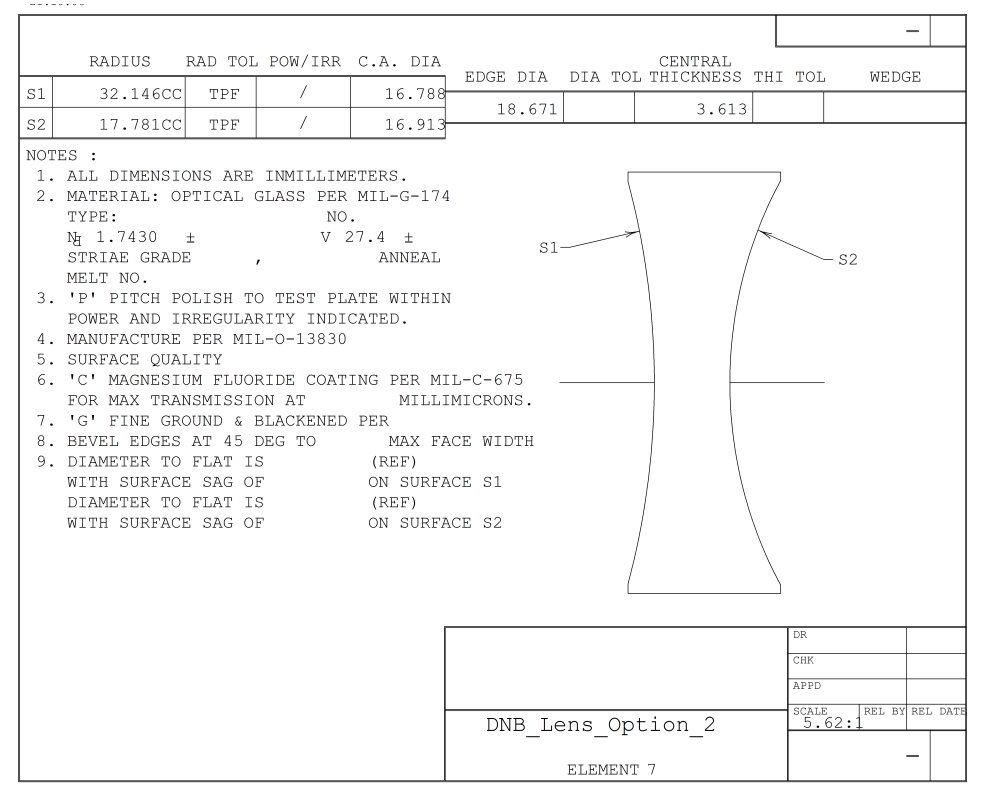

Figure B.39: Option \#2 Element \#7 Drawing

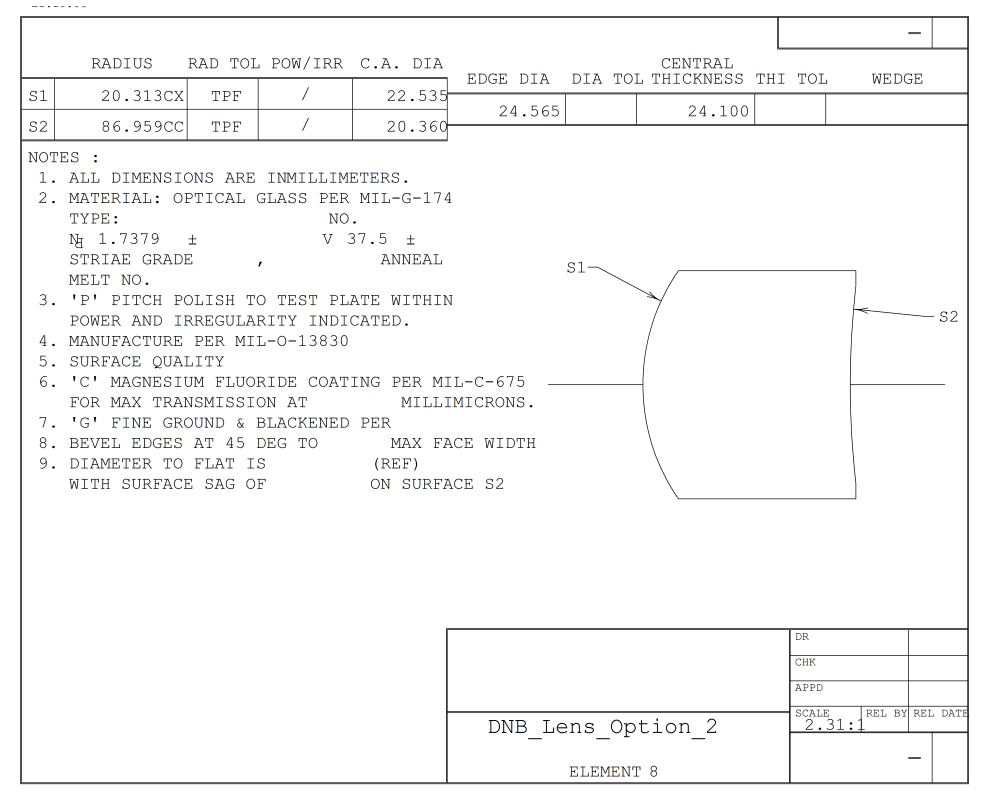

Figure B.40: Option \#2 Element \#8 Drawing 
Table B- II: Surface and aperture data for lens option \#2

\begin{tabular}{|l|r|r|r|r|}
\hline Surface & \multicolumn{1}{c|}{ Radius } & Thickness & Glass Type & Semi-Aperture \\
\hline $1:$ & 56.157 & 1.659 & 615478.550082 & 25.000 \\
\hline $2:$ & 20.719 & 17.833 & & 18.917 \\
\hline $3:$ & -34.934 & 2.994 & 591894.559683 & 18.915 \\
\hline $4:$ & 39.534 & 5.891 & & 18.705 \\
\hline $5:$ & 299.792 & 30.000 & 736271.426209 & 19.319 \\
\hline $6:$ & -46.173 & 0.100 & & 22.998 \\
\hline $7:$ & 39.325 & 20.679 & 742998.274141 & 21.172 \\
\hline $8:$ & 20.500 & 1.573 & & 14.219 \\
\hline $9:$ & 26.366 & 28.546 & 615478.550082 & 14.219 \\
\hline $10:$ & -32.029 & 0.464 & & 9.770 \\
\hline STOP: & INFINITY & 0.100 & & 8.734 \\
\hline 12: & 19.220 & 7.962 & 484099.622852 & 8.612 \\
\hline $13:$ & -28.921 & 0.100 & & 8.441 \\
\hline $14:$ & -32.146 & 3.613 & 742998.274141 & 8.394 \\
\hline $15:$ & 17.781 & 3.786 & & 8.456 \\
\hline $16:$ & 20.313 & 24.100 & 737932.374561 & 11.267 \\
\hline $17:$ & 86.959 & 1.195 & & 10.180 \\
\hline
\end{tabular}




\section{Appendix C}

\section{Parts List and Costs}

Table C- I: List of parts acquired for this project and associated costs

\begin{tabular}{|c|c|}
\hline Part & Cost \\
\hline Theia SY110 & $\$ 248.00$ \\
\hline Thorlabs LC100 & $\$ 1,250.00$ \\
\hline
\end{tabular}


Appendix D

\title{
Datasheets
}

\author{
D.1 Theia SY110
}




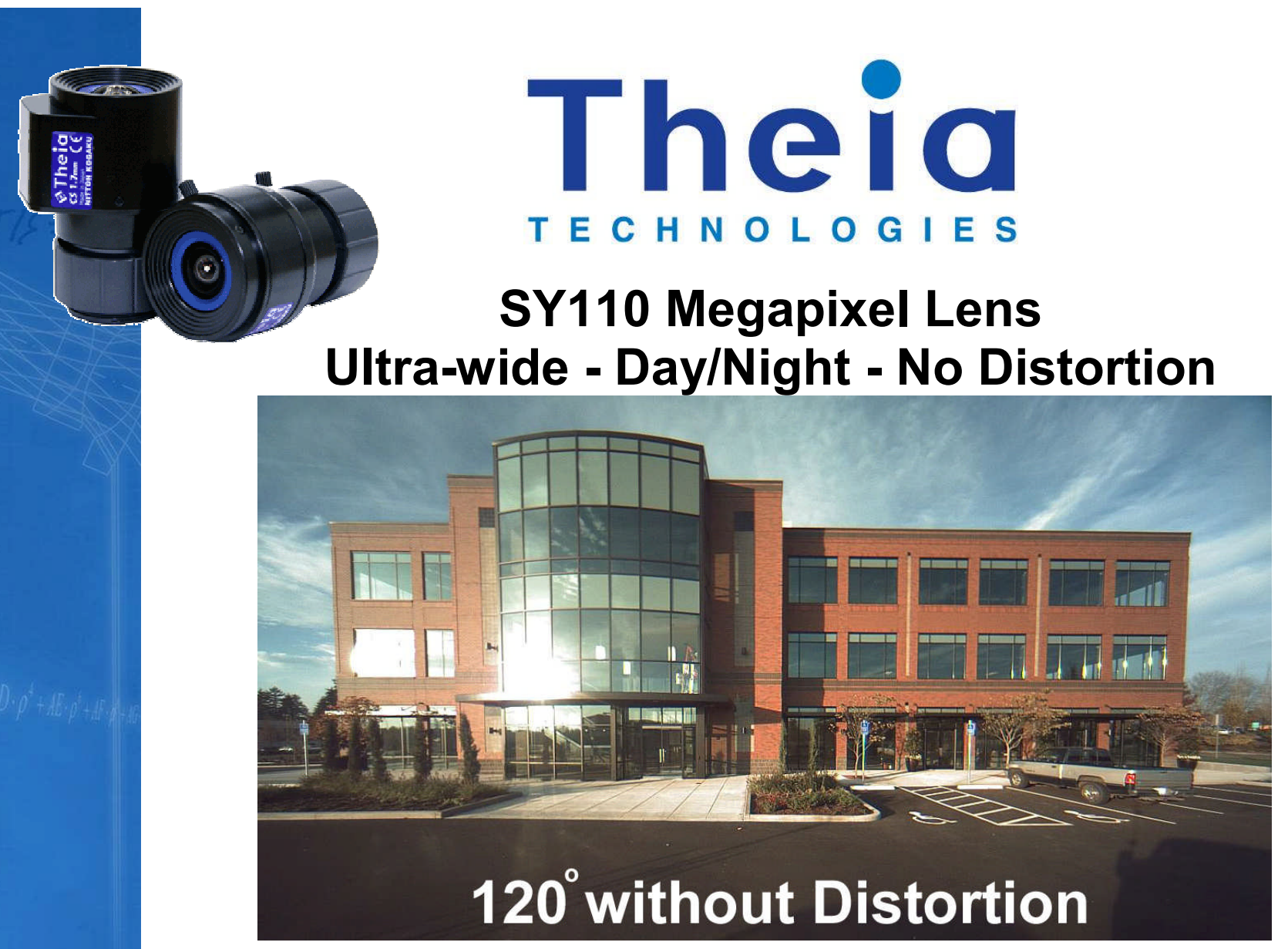

LINEAR OPTICAL TECHNOLOGY

- Ultra wide horizontal field of view up to $120^{\circ}$ provides greater security

- Patented Linear Optical Technology® enables no barrel distortion for maximum resolution

- IR corrected for Day/Night cameras

- Supports multi megapixel resolution cameras for demanding applications

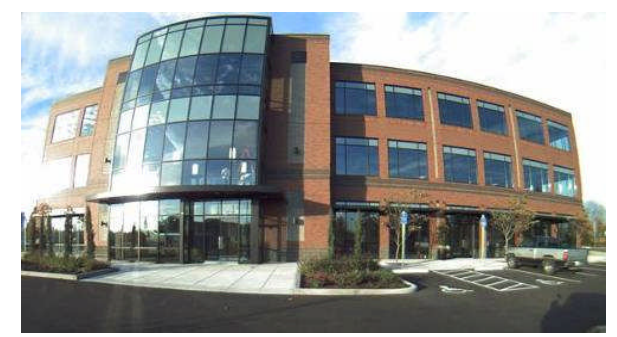

Typical wide angle lens

- Near and far objects continuously in focus without lens adjustment

- Available with CS-mount and with auto or manual iris

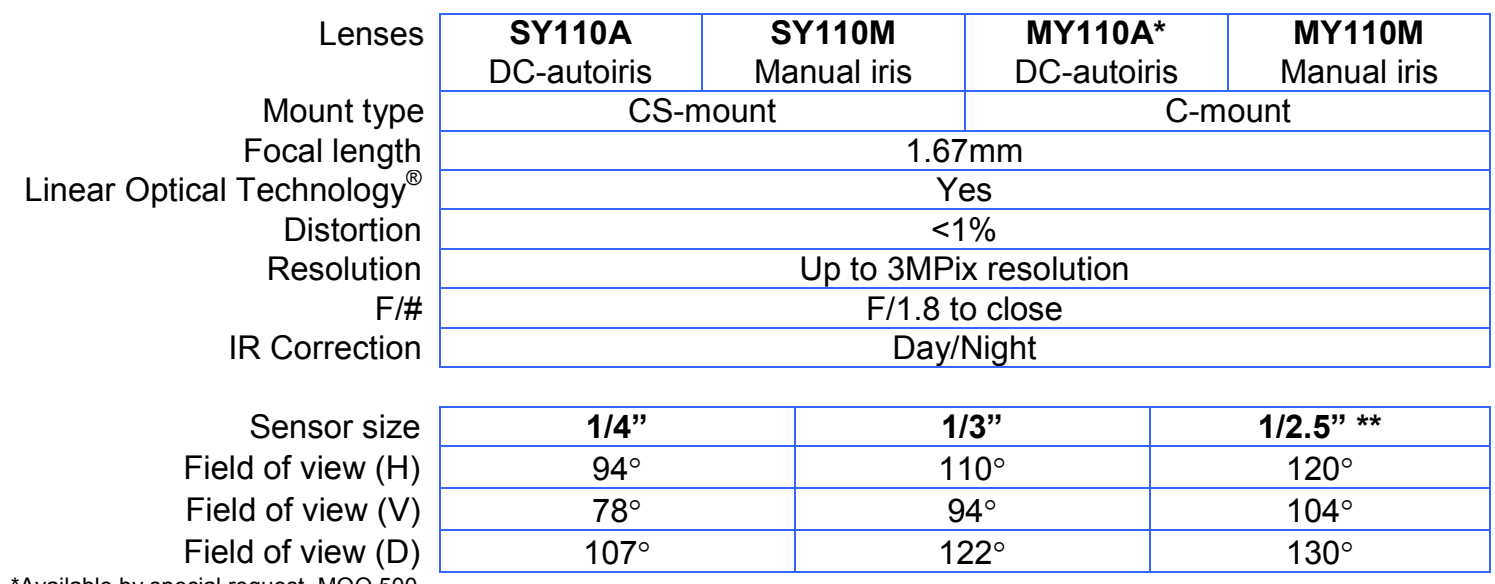

${ }^{*}$ Available by special request, MOQ 500

** Some vignetting may occur using a $1 / 2.5$ " sensor is sensor is not well aligned in the camera. 

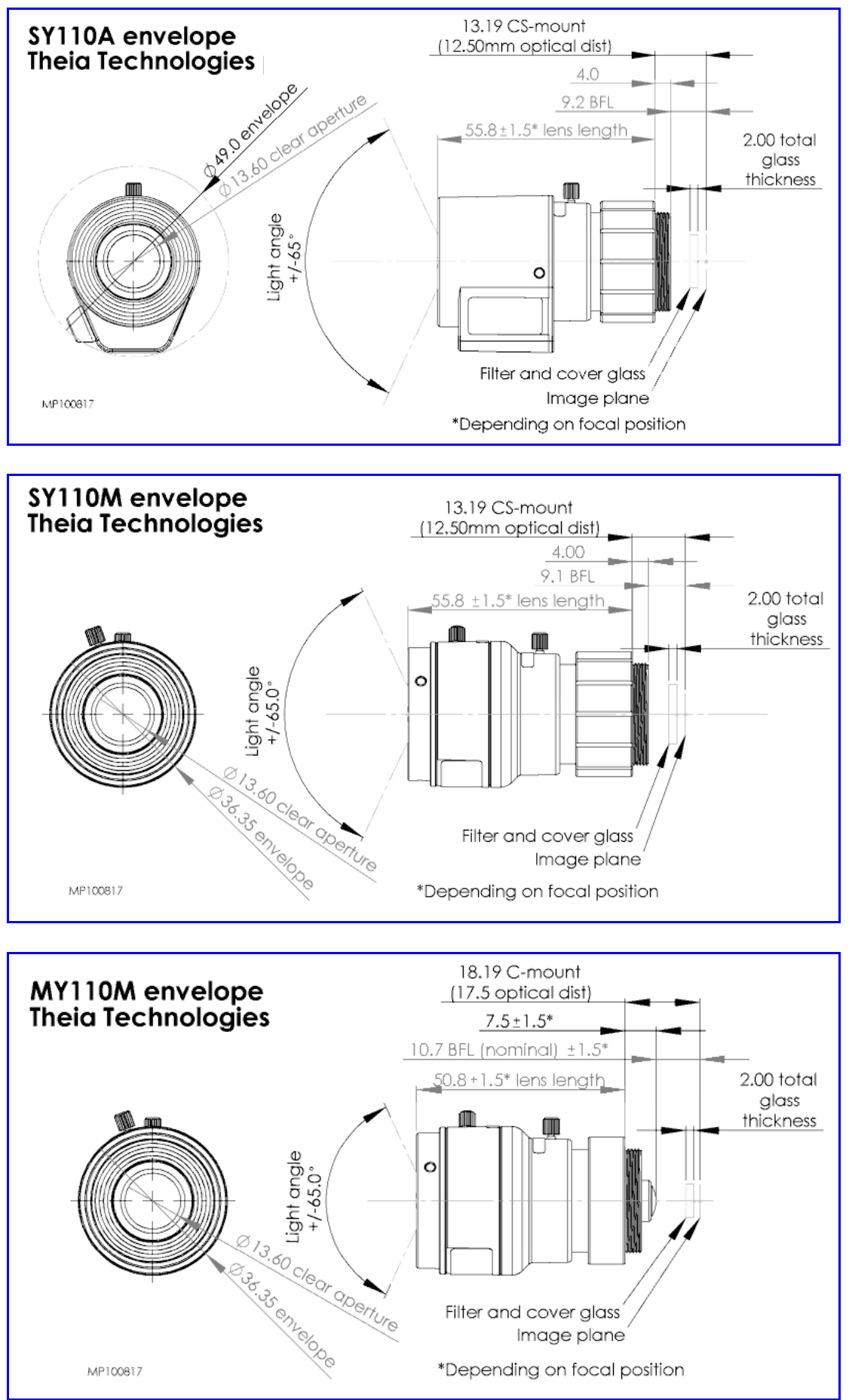

Theia Technologies, in cooperation with Nittoh Kogaku K.K., Suwa, Japan For more information contact:

Theia Technologies

info@TheiaTech.com

www. TheiaTech.com

Phone: +1-503-570-3296 
D.2 Sony ILX554B

\section{D.2 Sony ILX554B}




\section{8-pixel CCD Linear Sensor (B/W) for Single 5V Power Supply Bar-code Reader}

\section{Description}

The ILX554B is a rectangular reduction type CCD linear image sensor designed for bar code POS hand scanner and optical measuring equipment use. A built-in timing generator and clock-drivers ensure single $5 \mathrm{~V}$ power supply for easy use.

\section{Features}

- Number of effective pixels: 2048 pixels

- Pixel size: $14 \mu \mathrm{m} \times 56 \mu \mathrm{m}$ (14 $\mu \mathrm{m}$ pitch)

- Single 5V power supply

- Ultra-high sensitivity

- Built-in timing generator and clock-drivers

- Built-in sample-and-hold circuit

- Maximum clock frequency: $2 \mathrm{MHz}$

\section{Absolute Maximum Ratings}

- Supply voltage

- Operating temperature

- Storage temperature VDD

$\begin{array}{cc}6 & \mathrm{~V} \\ -10 \text { to }+60 & { }^{\circ} \mathrm{C} \\ -30 \text { to }+80 & { }^{\circ} \mathrm{C}\end{array}$

Pin Configuration (Top View)

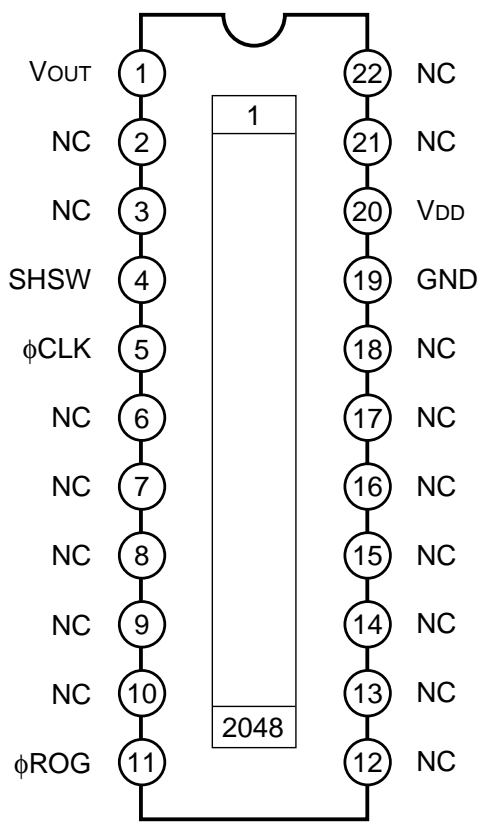

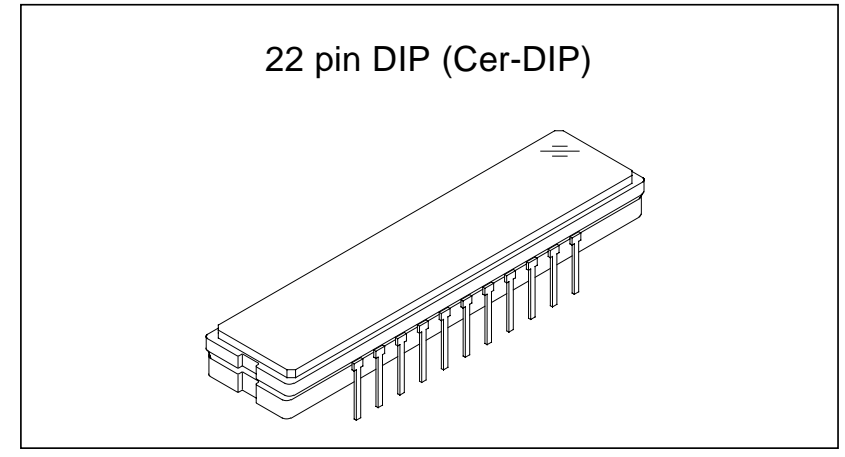

Block Diagram

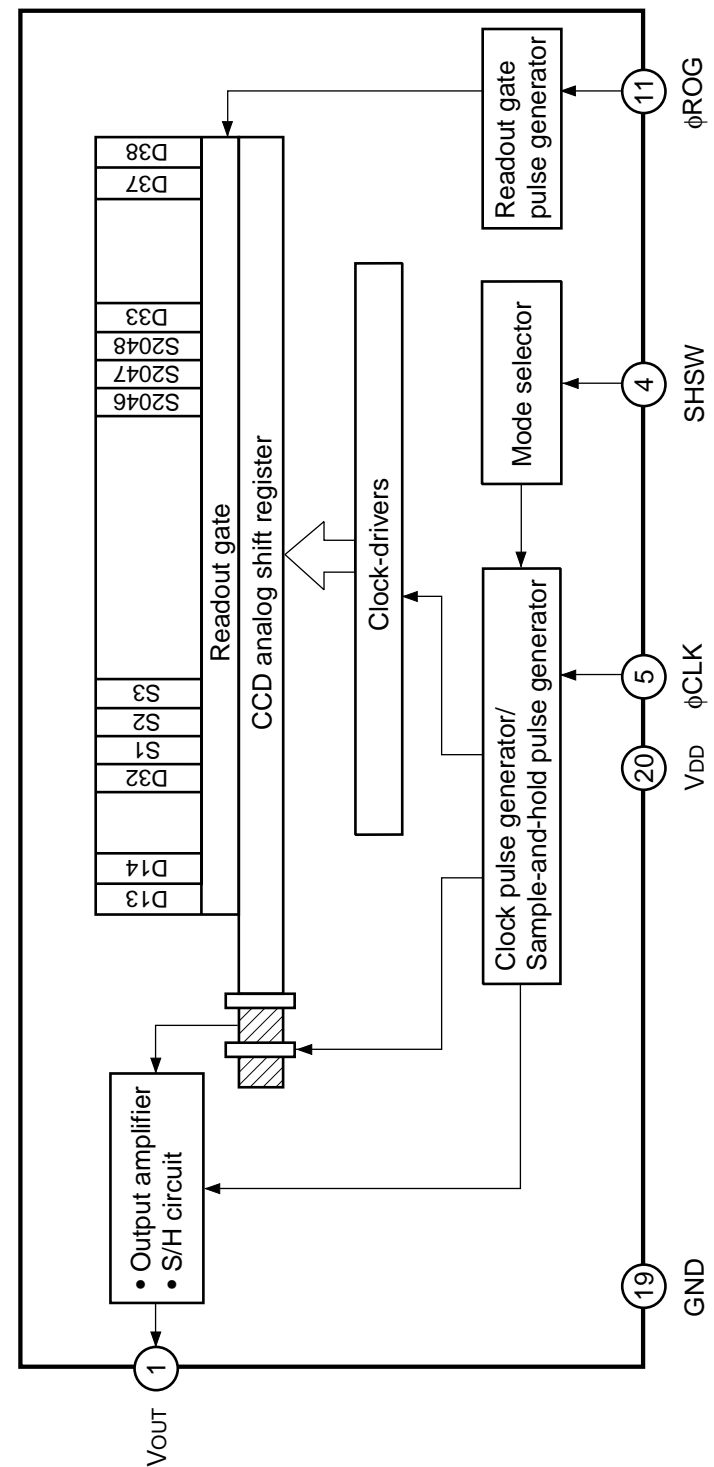

Sony reserves the right to change products and specifications without prior notice. This information does not convey any license by any implication or otherwise under any patents or other right. Application circuits shown, if any, are typical examples illustrating the operation of the devices. Sony cannot assume responsibility for any problems arising out of the use of these circuits. 
Pin Description

\begin{tabular}{|c|l|l|c|l|l|}
\hline Pin No. & Symbol & \multicolumn{1}{|c|}{ Description } & Pin No. & Symbol & Description \\
\hline 1 & Vout & Signal output & 12 & NC & NC \\
\hline 2 & NC & NC & 13 & NC & NC \\
\hline 3 & NC & NC & 14 & NC & NC \\
\hline 4 & SHSW & Switch (with S/H or without S/H) & 15 & NC & NC \\
\hline 5 & $\phi C L K$ & Clock pulse input & 16 & NC & NC \\
\hline 6 & NC & NC & 17 & NC & NC \\
\hline 7 & NC & NC & 18 & NC & NC \\
\hline 8 & NC & NC & 19 & GND & GND \\
\hline 9 & NC & NC & 20 & VDD & $5 V$ power supply \\
\hline 10 & NC & NC & 22 & NC & NC \\
\hline 11 & $\phi R O G$ & Readout gate pulse input & & & \\
\hline
\end{tabular}

\section{Mode Description}

\begin{tabular}{|c|c|}
\hline Mode in use & Pin 4 (SHSW) \\
\hline With S/H & GND \\
\hline Without S/H & VDD \\
\hline
\end{tabular}

\section{Recommended Supply voltage}

\begin{tabular}{|l|c|c|c|c|}
\hline \multicolumn{1}{|c|}{ Item } & Min. & Typ. & Max. & Unit \\
\hline VDD & 4.5 & 5.0 & 5.5 & V \\
\hline
\end{tabular}

\section{Input Clock voltage Condition*1}

\begin{tabular}{|l|c|c|c|c|}
\hline \multicolumn{1}{|c|}{ Item } & Min. & Typ. & Max. & Unit \\
\hline $\mathrm{V}_{\mathrm{IH}}$ & 4.5 & 5.0 & $\mathrm{VDD}$ & $\mathrm{V}$ \\
\hline $\mathrm{V}_{\mathrm{IL}}$ & 0 & - & 0.5 & $\mathrm{~V}$ \\
\hline
\end{tabular}

*1 This is applied to the all pulses applied externally. ( $\phi$ CLK, $\phi R O G)$

\section{Clock Characteristics}

\begin{tabular}{|c|l|c|c|c|c|}
\hline Item & Symbol & Min. & Typ. & Max. & Unit \\
\hline Input capacity of $\phi$ CLK & C $\phi$ CLK & - & 10 & - & $\mathrm{pF}$ \\
\hline Input capacity of $\phi R O G$ & C $\phi$ ROG & - & 10 & - & $\mathrm{pF}$ \\
\hline
\end{tabular}




\section{Electro-optical Characteristics}

$\left(\mathrm{Ta}=25^{\circ} \mathrm{C}, \mathrm{VDD}_{\mathrm{DD}}=5 \mathrm{~V}\right.$, Clock frequency: $1 \mathrm{MHz}$, Light source $=3200 \mathrm{~K}$,

IR cut filter: $\mathrm{CM}-500 \mathrm{~S}(\mathrm{t}=1.0 \mathrm{~mm})$, Without $\mathrm{S} / \mathrm{H}$ mode $)$

\begin{tabular}{|l|l|c|c|c|c|c|}
\hline \multicolumn{1}{|c|}{ Item } & Symbol & Min. & Typ. & Max. & Unit & Remarks \\
\hline Sensitivity 1 & R1 & 180 & 240 & 300 & $\mathrm{~V} /(\mathrm{Ix} \cdot \mathrm{s})$ & Note 1 \\
\hline Sensitivity 2 & R2 & - & 3500 & - & $\mathrm{V} /(\mathrm{Ix} \cdot \mathrm{s})$ & Note 2 \\
\hline Sensitivity nonuniformity & PRNU & - & 5.0 & 10.0 & $\%$ & Note 3 \\
\hline Saturation output voltage & VSAT & 0.8 & 1.0 & - & $\mathrm{V}$ & - \\
\hline Dark voltage average & VDRK & - & 3.0 & 6.0 & $\mathrm{mV}$ & Note 4 \\
\hline Dark signal nonuniformity & DSNU & - & 6.0 & 12.0 & $\mathrm{mV}$ & Note 4 \\
\hline Image lag & IL & - & 1 & - & $\%$ & Note 5 \\
\hline Dynamic range & DR & - & 333 & - & - & Note 6 \\
\hline Saturation exposure & SE & - & 0.004 & - & $\mathrm{Ix} \cdot \mathrm{s}$ & Note 7 \\
\hline 5V current consumption & IVDD & - & 5.0 & 10 & $\mathrm{~mA}$ & - \\
\hline Total transfer efficiency & TTE & 92 & 98.0 & - & $\%$ & - \\
\hline Output impedance & Zo & - & 250 & - & $\Omega$ & - \\
\hline Offset level & Vos & - & 2.85 & - & $\mathrm{V}$ & Note 8 \\
\hline
\end{tabular}

Note)

1. For the sensitivity test light is applied with a uniform intensity of illumination.

2. Light sourse: $\operatorname{LED} \lambda=660 \mathrm{~nm}$

3. PRNU is defined as indicated below. Ray incidence conditions are the same as for Note 1.

$$
\text { PRNU }=\frac{\left(V_{\text {MAX }}-V_{\text {MIN }}\right) / 2}{V_{\text {AVE }}} \times 100[\%] \quad \begin{aligned}
& \text { The maximum output of all the valid pixels is set to VMAX, } \\
& \text { the minimum output to VMIN and the average output to VAVE. }
\end{aligned}
$$

4. Integration time is $10 \mathrm{~ms}$.

5. Typical value is used for clock pulse and readout pulse. Vout $=500 \mathrm{mV}$.

6. $\quad \mathrm{DR}=\frac{\mathrm{V}_{\mathrm{SAT}}}{\mathrm{V}_{\mathrm{DRK}}}$

When optical integration time is shorter, the dynamic range sets wider because dark voltage is in proportion to optical integration time.

7. $\mathrm{SE}=\frac{\mathrm{VSAT}}{\mathrm{R} 1}$

8. Vos is defined as indicated below.

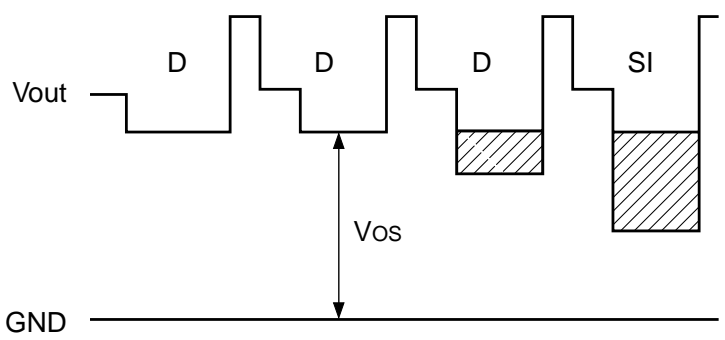




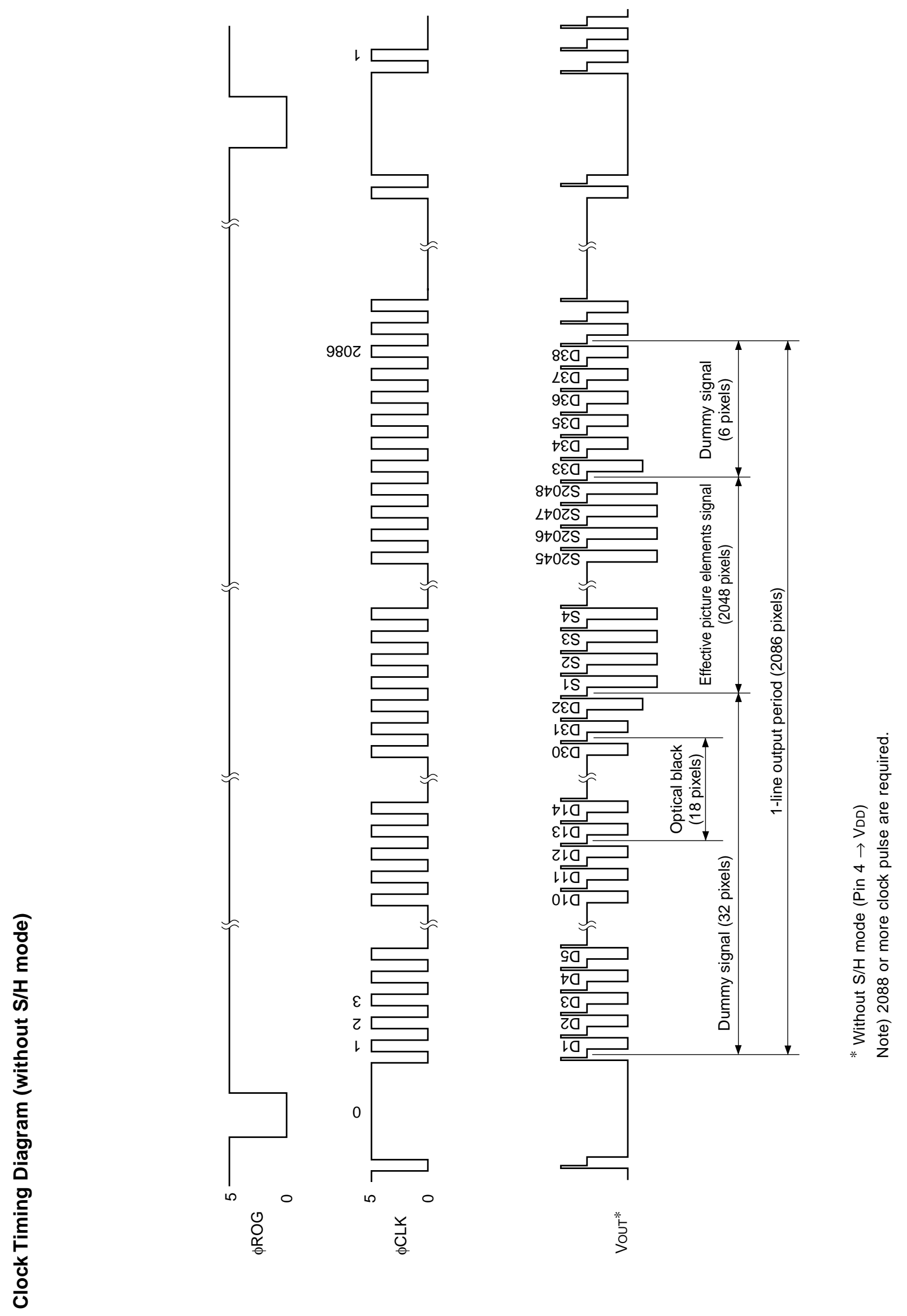




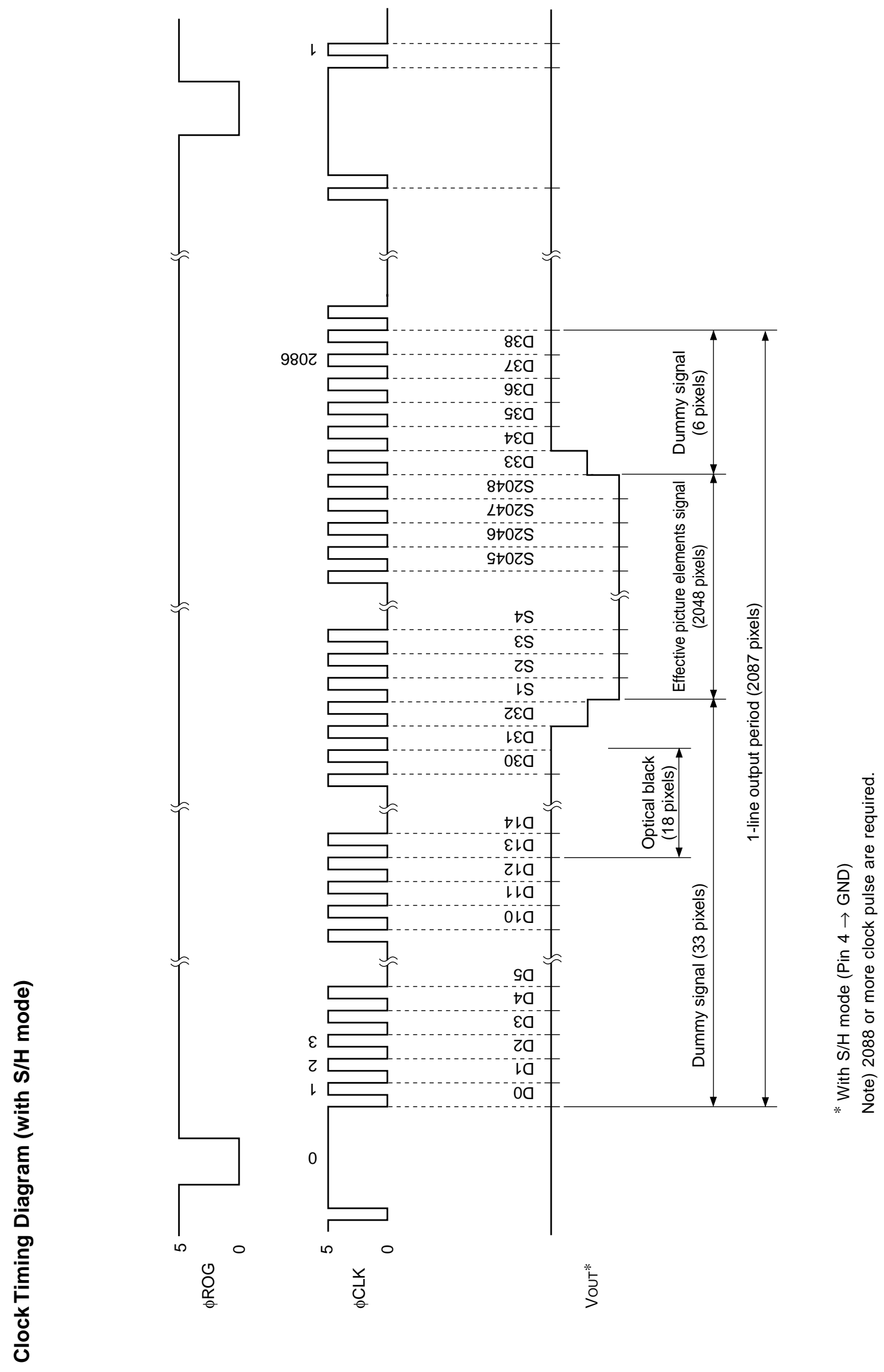


$\phi C L K$ Timing (For all modes)

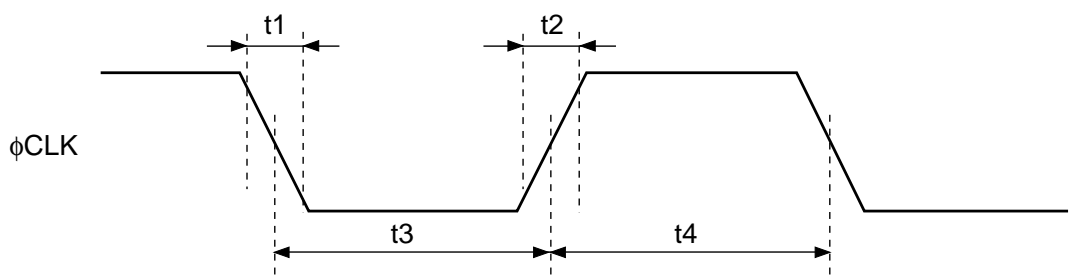

\begin{tabular}{|l|c|c|c|c|c|}
\hline \multicolumn{1}{|c|}{ Item } & Symbol & Min. & Typ. & Max. & Unit \\
\hline$\phi$ CLK pulse rise/fall time & $\mathrm{t} 1, \mathrm{t} 2$ & 0 & 10 & 100 & $\mathrm{~ns}$ \\
\hline$\phi$ CLK pulse duty*1 & - & 40 & 50 & 60 & $\%$ \\
\hline
\end{tabular}

*1 $100 \times \mathrm{t} 4 /(\mathrm{t} 3+\mathrm{t} 4)$

\section{$\phi R O G, \phi C L K$ Timing}

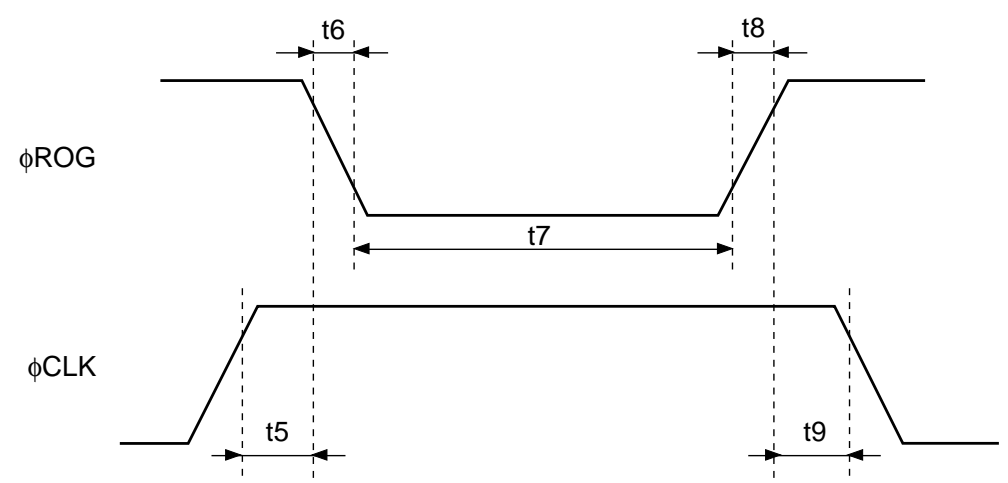

\begin{tabular}{|l|c|c|c|c|c|}
\hline \multicolumn{1}{|c|}{ Item } & Symbol & Min. & Typ. & Max. & Unit \\
\hline$\phi$ ROG, $\phi$ CLK pulse timing 1 & $\mathrm{t} 5$ & 0 & 3000 & - & $\mathrm{ns}$ \\
\hline$\phi$ ROG, $\phi$ CLK pulse timing 2 & $\mathrm{t} 9$ & 1000 & 3000 & - & $\mathrm{ns}$ \\
\hline$\phi$ ROG pulse rise/fall time & $\mathrm{t} 6, \mathrm{t} 8$ & 0 & 10 & - & $\mathrm{ns}$ \\
\hline$\phi$ ROG pulse period & $\mathrm{t} 7$ & 1000 & 5000 & - & $\mathrm{ns}$ \\
\hline
\end{tabular}




\section{$\phi C L K$, Vout Timing (Note 1)}

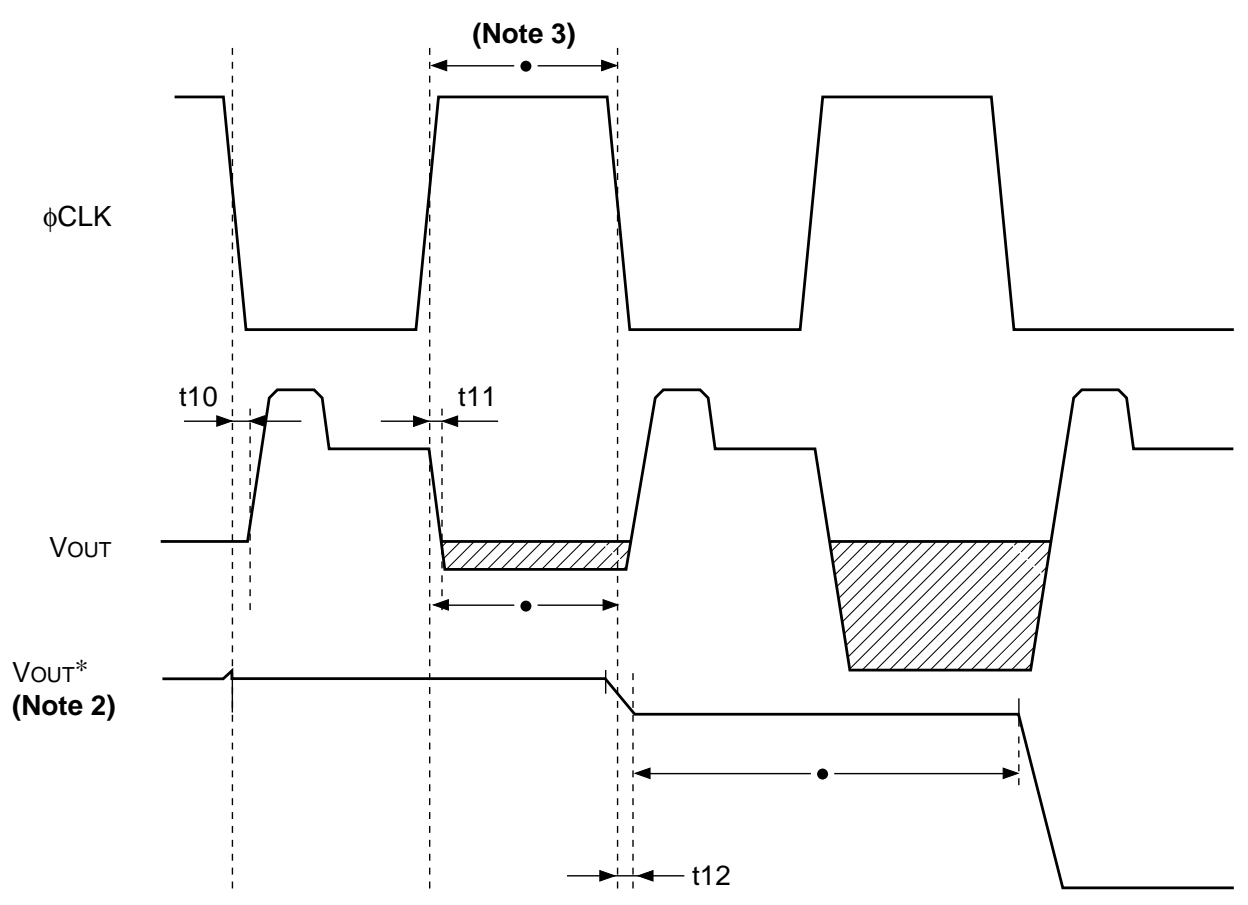

\begin{tabular}{|l|c|c|c|c|c|}
\hline \multicolumn{1}{|c|}{ Item } & Symbol & Min. & Typ. & Max. & Unit \\
\hline$\phi$ CLK-Vout 1 & $\mathrm{t} 10$ & 20 & 100 & 250 & $\mathrm{~ns}$ \\
\hline$\phi$ CLK-Vout 2 & $\mathrm{t} 11$ & 55 & 210 & 410 & $\mathrm{~ns}$ \\
\hline$\phi$ CLK-Vout* (with S/H) 3 & $\mathrm{t} 12$ & 20 & 150 & 250 & $\mathrm{~ns}$ \\
\hline
\end{tabular}

Note 1) fck $=1 \mathrm{MHz}, \phi$ CLK pulse duty $=50 \%, \phi C L K$ pulse rise/fall time $=10 \mathrm{~ns}$ Note 2) Output waveform when internal $\mathrm{S} / \mathrm{H}$ is in use.

Note 3) - indicates the correspondence of clock pulse and data period. 


\section{Example of Representative Characteristics}

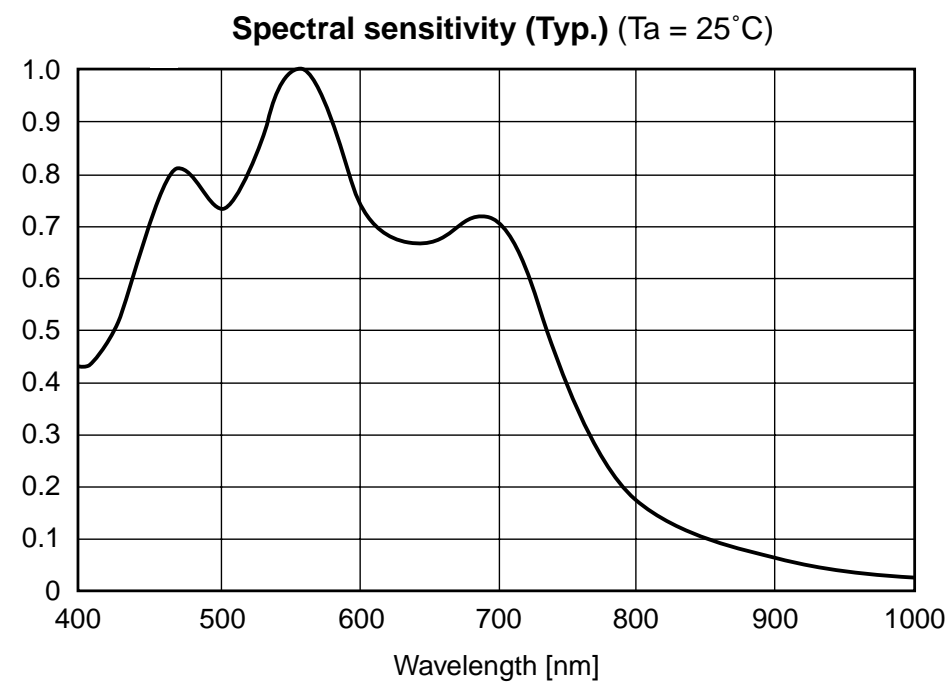

Dark voltage rate vs. Ambient temperature (Typ.)

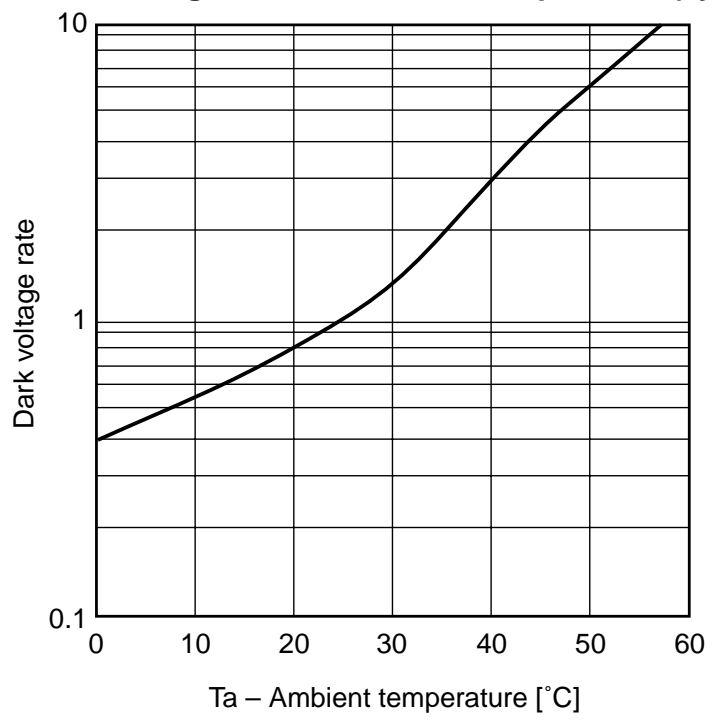


Output voltage rate vs. Integration time (Typ.)
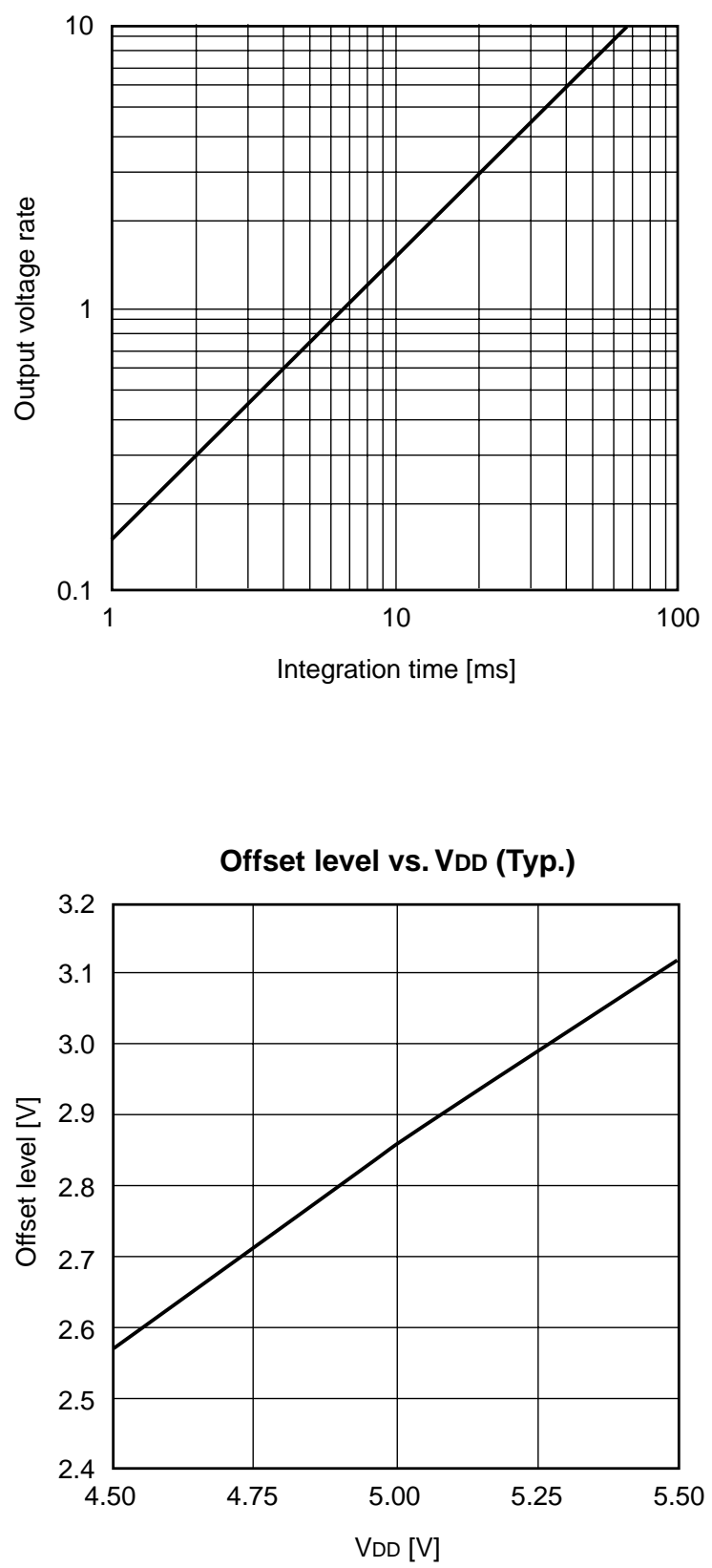

Current consumption rate vs. Clock frequency (Typ.)

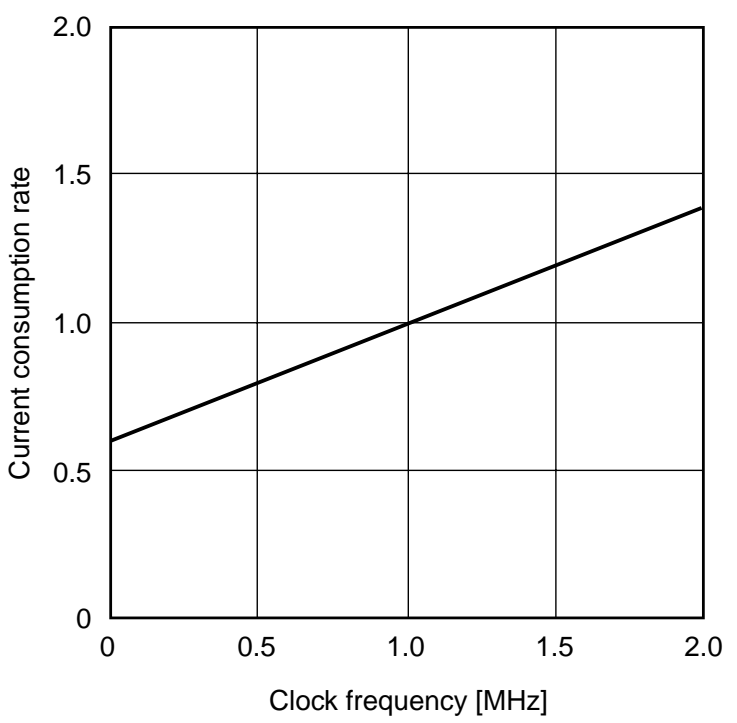

Offset level vs. Ambient temperature (Typ.)

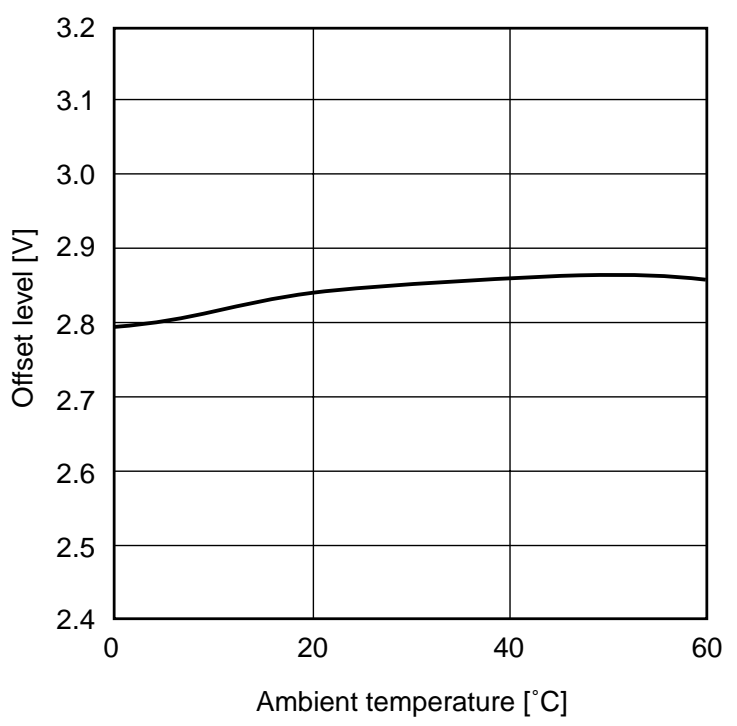




\section{Application Circuit (Without S/H mode) Note)}

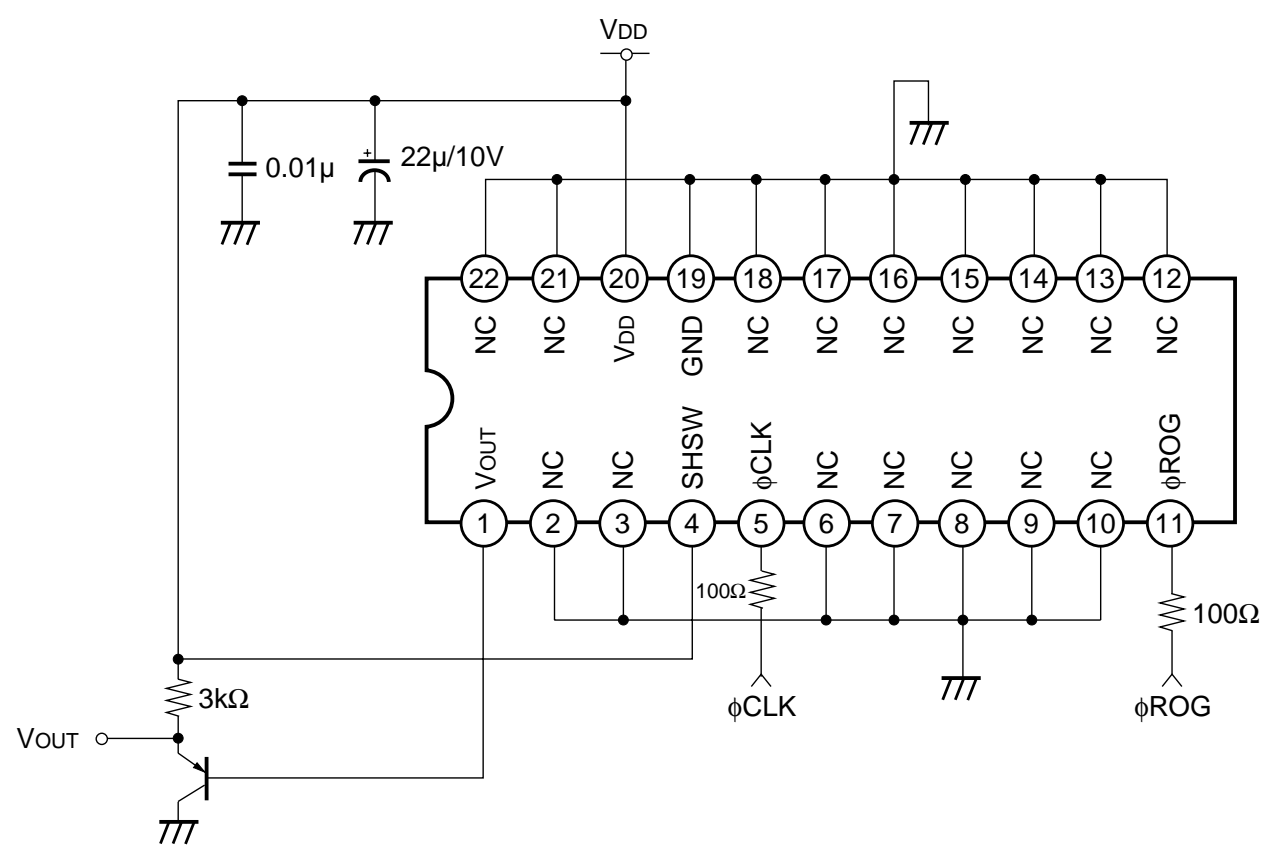

Note) This circuit diagram is the case when internal $\mathrm{S} / \mathrm{H}$ mode is not used.

Application circuits shown are typical examples illustrating the operation of the devices. Sony cannot assume responsibility for any problems arising out of the use of these circuits or for any infringement of third party patent and other right due to same. 


\section{Notes on Handling}

1) Static charge prevention

CCD image sensors are easily damaged by static discharge. Before handling, be sure to take the following protective measures.

a) Either handle bare handed or use non-chargeable gloves, clothes or material. Also use conductive shoes.

b) When handling directly use an eath band.

c) Install a conductive mat on the floor or working table to prevent the generation of static electricity.

d) lonized air is recommended for discharge when handling CCD image sensors.

e) For the shipment of mounted substrates use cartons treated for the prevention of static charges.

2) Notes on handling CCD Cer-DIP package

The following points should be observed when handling and installing this package.

a) (1) Compressive strength: $39 \mathrm{~N} /$ surface

(Do not apply any load more than $0.7 \mathrm{~mm}$ inside the outer perimeter of the glass portion.)

(2) Shearing strength: $29 \mathrm{~N} /$ surface

(3) Tensile strength: $\quad 29 \mathrm{~N} /$ surface

(4) Torsional strength: $0.9 \mathrm{Nm}$
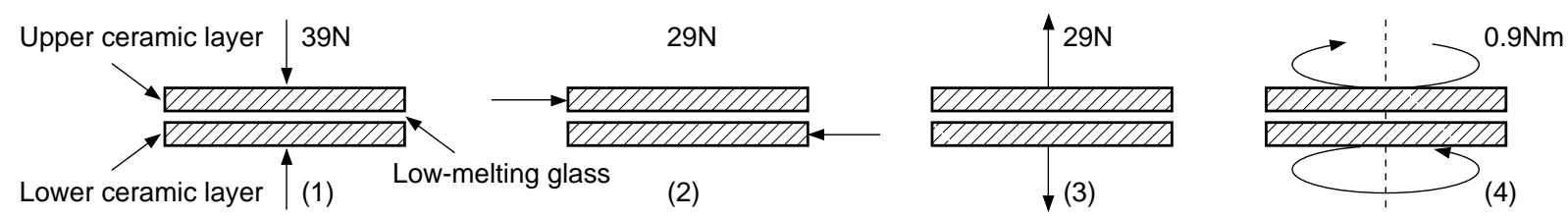

b) In addition, if a load is applied to the entire surface by a hard component, bending stress may be generated and the package may fracture, etc., depending on the flatness of the ceramic portion. Therefore, for installation, either use an elastic load, such as a spring plate, or an adhesive.

c) Be aware that any of the following can cause the glass to crack because the upper and lower ceramic layers are shielded by low-melting glass.

(1) Applying repetitive bending stress to the external leads.

(2) Applying heat to the external leads for an extended period of time with a soldering iron.

(3) Rapid cooling or heating.

(4) Applying a load or impact to a limited portion of the low-melting glass with a small-tipped tool such as tweezers.

(5) Prying the upper or lower ceramic layers away at a support point of the low-melting glass.

Note that the preceding notes should also be observed when removing a component from a board after it has already been soldered.

3) Soldering

a) Make sure the package temperature does not exceed $80^{\circ} \mathrm{C}$.

b) Solder dipping in a mounting furnace causes demage to the glass abd other defects. Use a grounded $30 \mathrm{~W}$ soldering iron and solder each pin in less than 2 seconds. For repairs and remount, cool sufficiently.

c) To dismount image sensors, do not use a solder suction equipment. When using an electric desoldering tool, ground the controller. For the control system, use a zero cross type. 
4) Dust and dirt protection

a) Operate in clean environments.

b) Do not either touch glass plates by hand or have any object come in contact with glass surfaces. Should dirt stick to a glass surface blow it off with an air blower. (For dirt stuck through static electricity, ionized air is recommended.)

c) Clean with a cotton bud and ethyl alcohol if the glass surface is grease stained. Be careful not to scratch the glass.

d) Keep in case to protect from dust and dirt. To prevent dew condensation, preheat or precool when moving to a room with great temperature differences.

5) Exposure to high temperature or humidity will affect the characteristics. Accordingly avoid storage or usage in such conditions.

6) CCD image sensors are precise optical equipment that should not be subject to mechanical shocks.

7) Normal output signal is not obtained immediately after device switch on. Use the output signal added 22500 pulses or above to $\phi$ CLK clock pulse. 

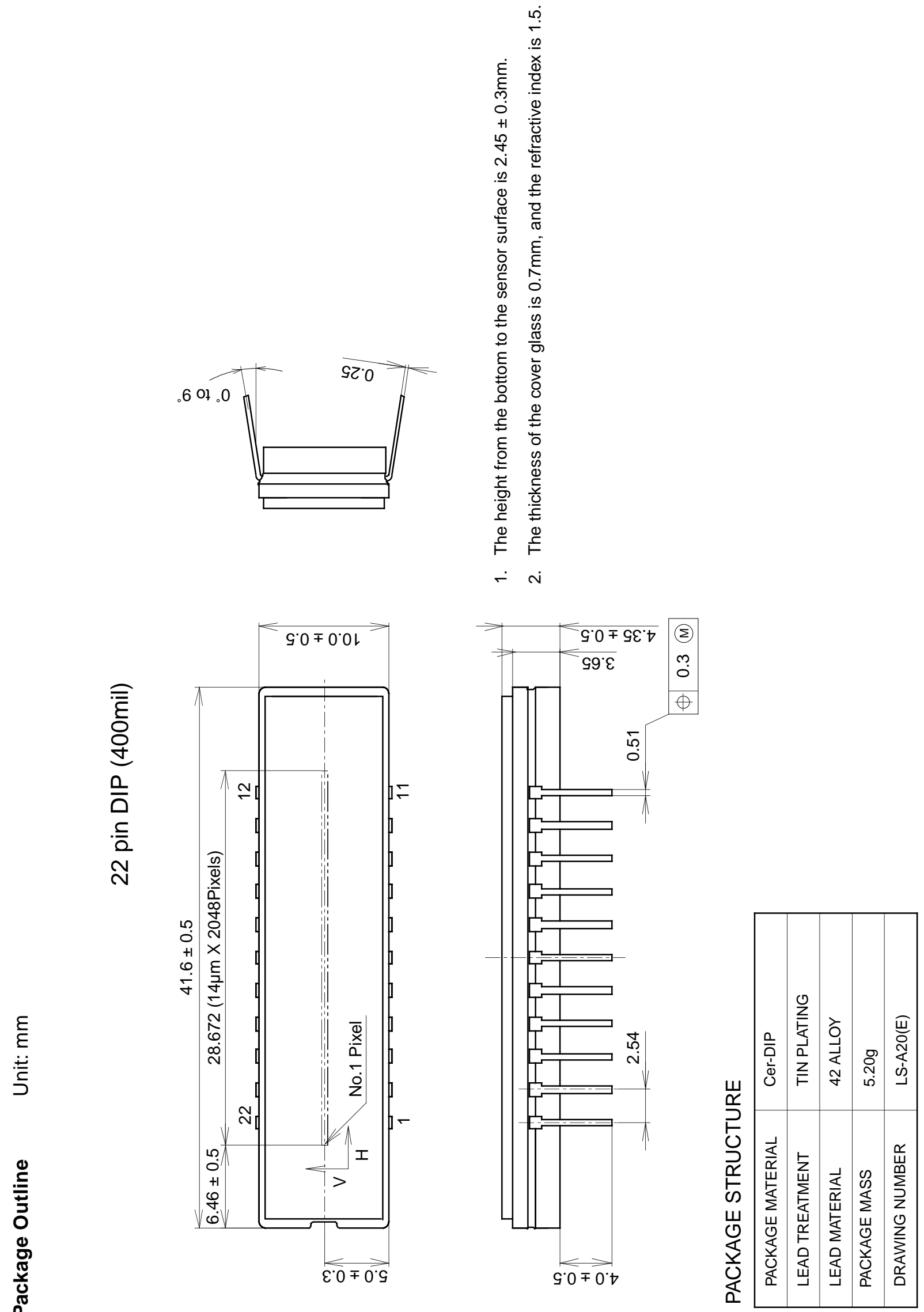


\section{Appendix E}

\section{Code Listing}

\section{E.1 Experimental MTF Generation}

The following Matlab code was used to generate the experimental MTF plots from the raw data output of the Thorlabs LC100 Linear CCD.

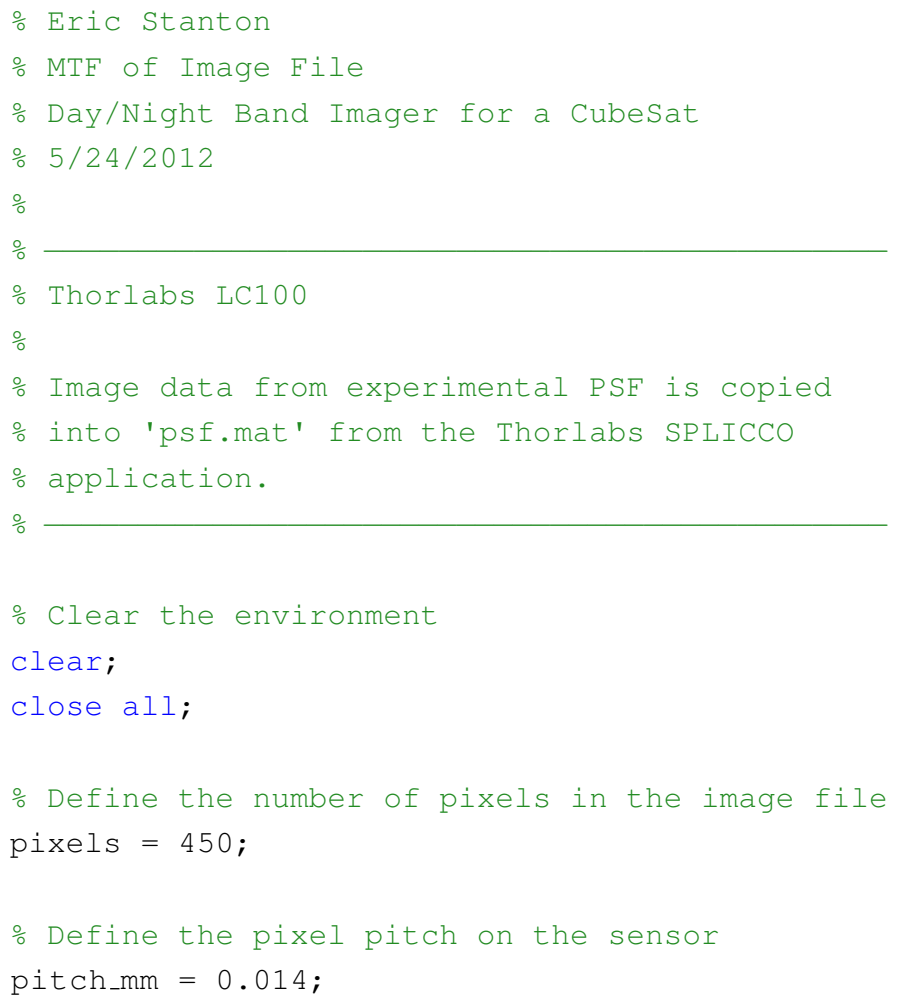




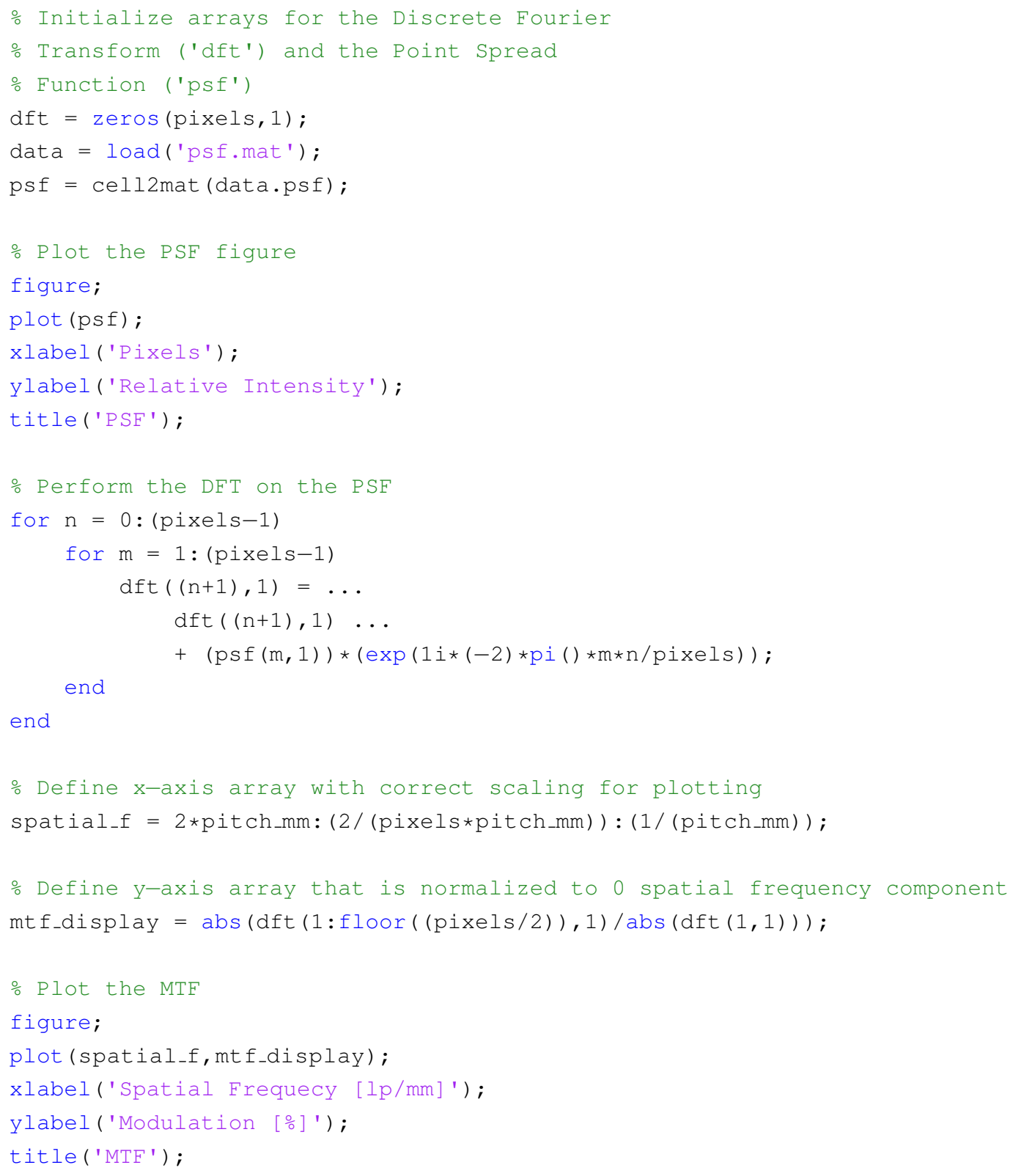




\section{Bibliography}

[1] J. Hawkins, Maj M. G. Bedard, C. E. Cote. Integrated Operational Requirements Document NPOESS, March 1996. ii, xiii

[2] LEE, SimON, et AL. CubeSat Design Specification, 2009. xi, 4, 5

[3] C. Welsch, H. Swenson, S. A. Cota, F. Deluccia, J. M. Haas, C. Schueler, R. M. Durham, J. E. Clement, P. E. Ardanuy. VIIRS (Visible Infrared Imager Radiometer Suite): A Next-Generation Operational Environmental Sensor for NPOESS, 2001. xii, 10, 11

[4] T. F. Lee, F. J. Turk, J. D. Hawkins, C. Mitrescu, S. D. Miller, and M. HAAS. Improving the Usability of Nighttime Imagery from Low Light Sensors, 2008. 2

[5] S. Mills, E. Jacobson, J. Jaron, J. McCarthy, T. Ohnuki, and M. PlonSKI. Calibration of the VIIRS Day/Night Band (DNB), November 2011. 2

[6] Goddard Space Flight Center. Joint Polar Satellite System (JPSS) VIIRS Radiometric Calibration Algorithm Theoretical Basis Document (ATBD), April 2011. 5, 6

[7] T. F. Lee, S. D. Miller, F. J. Turk, C. Schueler, R. Julian, C. Elvidge, S. Deyo, P. Dills, S. Wang. The Day/Night Visible Sensor Abroad NPOESS VIIRS, October 2011. 5, 13

[8] R. A. Schowengerdt. Remote Sensing Models and Methods for Image Processing. In Remote Sensing Models and Methods for Image Processing, 2nd ed., pages 102, 106, San Diego, CA, Chestnut Hill, MA, 1997. Academic Press. 11 
[9] J. R. Wertz, Editor, D. F. Everett, Editor, J. J. Puschell, Editor. Space Mission Engineering: The New SMAD, 2011. 13

[10] R. E. Fischer, B. Tadic-Galeb, P. R. Yoder. The Optical Design Process; Computer Performance Evaluation. In Optical System Design, 2nd ed., pages 167-176, 179-198, New York, NY, 2008. McGraw-Hill. 16, 17

[11] Optical Research Associates. Code V Introductory Users Guide 2009. 16

[12] M. Hankawa N. Aoki, T. Yamanashi. Wide Angle Lens System \#6, 03 1996. 17

[13] R. M. Ford, C. S. Coulston. Design for Electrical and Computer Engineers, October 2008. 36

[14] R. Chepesiuk. Where the Chips Fall: Environmental Health in the Semiconductor Industry. In Environmental Health Perspectives, 107, pages 452-457, 1999. 38

[15] IEEE BoArd of Directorsi. IEEE Code of Ethics 2006. 40 